Carlos Eduardo Peres Teixeira

\title{
Caracterização e Variabilidade da Hidrodinâmica da Zona Costeira adjacente ao Banco de Abrolhos
}

Dissertação apresentada ao Instituto Oceanográfico da Universidade de São Paulo, como parte dos requisitos para obtenção do título de Mestre em Ciências, área de Oceanografia Física.

Orientador:

Prof. Dr. Edmo José Dias Campos

São Paulo

2006 
Universidade de São Paulo

Instituto Oceanográfico

Caracterização e Variabilidade da Hidrodinâmica da Zona Costeira adjacente ao Banco de Abrolhos

Carlos Eduardo Peres Teixeira

Dissertação apresentada ao Instituto Oceanográfico da Universidade de São Paulo, como parte dos requisitos para obtenção do título de Mestre em Ciências, área de Oceanografia Física

Julgada em Conceito

Prof. Dr.

Prof. Dr.

Conceito

Prof. Dr.

Conceito

Prof. Dr.

Conceito

Prof. Dr.

Conceito 


\section{Sumário}

Agradecimentos $\quad$ iv

Resumo vi vi vis

Lista de Figuras $\quad$ xi

Lista de Tabelas $\quad$ xiii

Lista de Abreviações $\quad$ xiv

1 Introdução 1

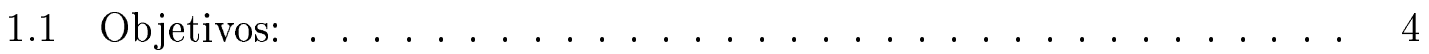

1.2 Organização do trabalho: . . . . . . . . . . . . . . 4

1.3 Descrição da área: . . . . . . . . . . . . . . 5

2 Metodologia $\quad 8$

2.1 Correntes e Marés: . . . . . . . . . . . . . . . 8

2.2 Ventos: ............................. 10

2.3 Transformada de Ondeletas: . . . . . . . . . . . . . . 12

3 Resultados e Discussão: $\quad 15$

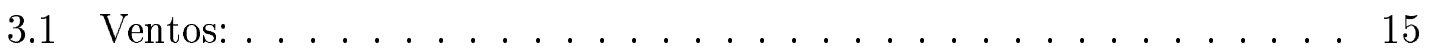

3.2 Elevação do Nível do Mar: . . . . . . . . . . . . . . . 35

3.3 Correntes: . . . . . . . . . . . . . . . . 45 
3.4 Correlação entre os dados: . . . . . . . . . . . . . . 64

3.5 Espectro de Ondeletas: . . . . . . . . . . . . . . 67

3.6 Espectro Cruzado de Ondeletas: . . . . . . . . . . . 73

3.7 Covariância de Ondeletas: . . . . . . . . . . . . . 80

4 Conclusões $\quad 86$

4.1 Sugestão para trabalhos futuros: . . . . . . . . . . . . 89

$\begin{array}{ll}\text { Referências Bibliográficas } & 90\end{array}$ 
"Não sei o que possa parecer aos olhos do mundo, mas aos meus pareço apenas ter sido como um menino brincando à beira-mar, divertindo-me com o fato de encontrar de vez em quando um seixo mais liso ou uma concha mais bonita que o normal, enquanto o grande oceano da verdade permanece completamente por descobrir à minha frente."

Isaac Newton.

"Esta dissertação é dedicada aos meus pais, Dona Maria e Sr. Teixeira, por terem acreditado em mim e sempre terem me apoiado e sem os quais seria impossível a conclusão desta obra". 


\section{Agradecimentos}

Em primeiro lugar gostaria de agradecer a Deus e aos meus anjos da guarda que me protegeram e me ajudarem na realização deste trabalho.

Em primeiro lugar gostaria de agradecer ao meu orientador e professor, Dr. Edmo Campos, por toda a paciência, pelos ensinamentos e por estar presente, me incentivando em todas a idéias e mudanças ao longo desta dissertação.

Aos "possiveis"membros da banca Prof. Dr. Miranda e Prof. Dr. Roberto Fontes (BOB), por toda a ajuda e sugestões que muito contribuíram na qualidade deste trabalho. Agradeço especialmente por terem se proposto a ajudar neste trabalho, num curto espaço de tempo e mesmo sem terem sido aprovados como banca.

Ao CNPq pela concessão da bolsa de mestrado. Agradeço ainda ao inestimável apoio do IAI através dos recursos computacionais desponiveis no LABMON e da participação em "workshops"e mini cursos promovidos pelo consórcio SACS (Projeto IAI-CNN-061).

A Aracruz Celulose e a Cepemar Meio Ambiente pela disponibilização dos dados e a Marcelo Travassos por ter ajudado a sanar as duvidas sobre os mesmos.

Agradeço a todos os professores do Instituto Oceanográfico pelos ensinamentos que tanto me ajudaram na minha formação. Em especial gostaria de agradecer ao Dr. Ilson da Silveira, pelas inúmeras conversas, pelo incentivo, profissionalismo e por ter sido responsável pela minha ida a Salvador que deu origem a este trabalho.

A todas as pessoas do LABMON: Betão, Raquel, Ana Luiza, Ana Carolina, CG, Fefito, Huaringa, Assaf e Carlão pela companhia e pelos inúmeros cafés que tornaram os meus dias de mestrado muito mais agradáveis. Obrigado Carlão por todos os ensinamentos, conversas, pelas aulas, por ter revisado esta dissertação e sobre tudo por ter me apoiado nos momentos mais difíceis. 
Obrigado aos amigos da turma de mestrado de 2004, Dri, Manu, Há, Rafael, Assaf, Fernando, Rose e Marina, pelo companheirismo e pelas noites em claro estudando Física dos Oceanos. Em especial as super amigas que ganhei aqui: Dri e Manu, vocês foram muito importantes neste lugar e espero que nossa amizade continue indefinidamente e que cresça a cada dia. Simplesmente obrigado por tudo!

Parte deste trabalho foi desenvolvido junto ao Departamento de Geociências da UFBA. Assim gostaria de agradecer o espaço e infra-estrutura cedidos e também a todas as pessoas que me ajudaram, Fabiola, Fernando, Saulo, Taoan, Maurão e Guilherme pela oportunidade. Agradeço ao Prof. Dr. Mauro Cirano pelas dicas na dissertação e especialmente sobre a vida profissional. Um agradecimento muito especial ao professor, amigo, incentivador, tio/ irmão e co-orientador extra-oficial: Dr. Guilherme Lessa (Chefia!) valeu por todo o apoio profissional e pessoal durante o período que estive na Bahia.

Por último, mas não menos importante, gostaria de agradecer a uma pessoa que muito me ajudou nestes anos de mestrado... muito obrigado Sheila!!!... por ter acreditado (mesmo quando as coisas se mostravam improváveis!), por ter me apoiado e me cobrado nas horas em que precisei, por sempre estar presente nas horas mais difíceis. Te amo muito e espero que nossa relação continue a crescer e dar frutos! 


\section{Resumo}

Os dados de correntometria, elevação do nível do mar e ventos de dois fundeios realizados dentro do Canal Sueste, na região costeira de Caravelas, foram utilizados para caracterização dos padrões de circulação atmosférica e oceânica da região, bem como para analisar a variabilidade temporal da componente sub-inercial e os mecanismos forçantes da circulação local. Para isto foi computado o espectro e a covariância entre os dados, utilizando-se da metodologia da Transformada de Ondeletas. O padrão de ventos da região caracteriza-se por uma variabilidade sazonal, no período anual, associada às migrações da Alta do Atlântico Sul. Essa variabilidade gera intensidades máximas no verão, decorrentes de ventos nordeste, e mínimas no inverno, decorrentes do vento sul. A maré local foi caracterizada como semidiurna, apresentando o maior valor de amplitude da costa leste brasileira. As marés astronômicas são as principais forçantes da variabilidade da corrente perpendicular a costa. As análises estatísticas, bem como os resultados do espectro cruzado e covariância de ondeleta demonstram que, na banda sub-inercial, a componente longitudinal do vento foi a principal responsável pela variabilidade dos campos de correntes e das oscilações do nível do mar. A componente longitudinal das correntes apresentou magnitude média de $11 \pm 0,22 \mathrm{~m} \cdot \mathrm{s}^{-1} \mathrm{e} 0,04 \pm 16 \mathrm{~m} \cdot \mathrm{s}^{-1}$, enquanto a com-

ponente transversal média foi de $2 \pm 0,10 \mathrm{~m} \cdot \mathrm{s}^{-1}$ e $0,04 \pm 11 \mathrm{~m} \cdot \mathrm{s}^{-1}$, respectivamente para a estação mais a norte e mais ao sul. Os resultados da análise de ondeletas apresentam os maiores valores energéticos nos períodos compreendidos entre 4 e 20 dias e 45 e 70 dias. 


\section{Lista de Figuras}

1.1 Localização da região de estudos, pontos de fundeio e estação meteorológica .......................... 3

3.1 Histograma de freqüência das velocidades do vento para todo o período de monitoramento. . . . . . . . . . . . 16

3.2 Distribuição da intensidade do vento por direção para todo o período de monitoramento. . . . . . . . . . . . . 17

3.3 Distribuição da intensidade do vento por direção para o ano de 2002. 18

3.4 Distribuição da intensidade do vento por direção para o ano de 2003. 19

3.5 Distribuição da intensidade do vento por direção para o ano de 2004. 19

3.6 Distribuição da intensidade do vento por direção para as estações do verão no período de monitoramento. . . . . . . . . . . . . 23

3.7 Distribuição da intensidade do vento por direção para as estações de outono no período de monitoramento. . . . . . . . . . . . 24

3.8 Distribuição da intensidade do vento por direção para as estações de inverno no período de monitoramento. . . . . . . . . . . . 24

3.9 Distribuição da intensidade do vento por direção para as estações de primavera no período de monitoramento. . . . . . . . . 25

3.10 Série temporal das velocidades da componente do vento longitudinal à linha de costa $(\mathrm{v})$ para o ano de $2002 \ldots \ldots . \ldots . . \ldots 28$ 
3.11 Série temporal das velocidades da componente do vento longitudinal à linha de costa (VT) para o ano de 2003 . . . . . . . . . 29

3.12 Série temporal das velocidades da componente do vento longitudinal à linha de costa $(\mathrm{v})$ para o ano de 2004. . . . . . . . . . 29

3.13 Diagrama mostrando a evolução das frentes frias ao longo dà costa do Brasil para o mês de Setembro de 2002. . . . . . . . . . . . 30

3.14 Diagrama mostrando a evolução das frentes frias ao longo dà costa do Brasil para o mês de Maio de 2002. . . . . . . . . . . . . . 30

3.15 Série temporal das velocidades da componente do vento transversal à linha de costa $(\mathrm{v})$ para o ano de 2002. . . . . . . . . . 31

3.16 Série temporal das velocidades da componente do vento transversal à linha de costa (v) para o ano de 2003. . . . . . . . . . 31

3.17 Série temporal das velocidades da componente do vento transversal à linha de costa (v) para o ano de 2004. . . . . . . . . . . 32

3.18 Médias e Desvios Padrões Mensais das velocidades da componente do vento longitudinal à linha de costa (v) para todo o período de estudo. 33

3.19 Médias e Desvios Padrões Mensais das velocidades da componente do vento transversal à linha de costa $(\mathrm{u})$ para todo o período de estudo. . 34

3.20 Série temporal da elevação do nível do mar para a estação \#106 para o ano de 2002. . . . . . . . . . . . . . . . 39

3.21 Série temporal da elevação do nível do mar para a estação \#106 para o ano de $2003 \ldots \ldots \ldots \ldots$. . . . . . . . . . . . . . 40

3.22 Série temporal da elevação do nível do mar para a estação \#106 para

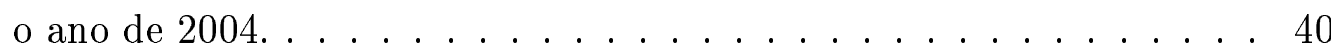

3.23 Série temporal da elevação do nível do mar para a estação \#506 para o ano de $2002 \ldots \ldots \ldots \ldots$. . . . . . . . . . . . . 41

3.24 Série temporal da elevação do nível do mar para a estação \#506 para

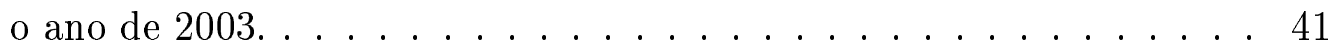


3.25 Série temporal da elevação do nível do mar para a estação \#506 para o ano de 2004. . . . . . . . . . . . . . . . 42

3.26 Médias mensais da elevação do nível do mar para a estação \#106. . 43

3.27 Médias mensais da elevação do nível do mar para a estação \#506. 44

3.28 Histograma de freqüência das direções das correntes para estação \#106. 48

3.29 Histograma de freqüência das direções das correntes para estação \#506. 48

3.30 Série Temporal da corrente paralela à costa na estação \#106 para o ano $2002 . \ldots \ldots \ldots \ldots \ldots$

3.31 Série Temporal da corrente paralela à costa na estação \#106 para o ano $2003 . \ldots \ldots \ldots \ldots \ldots$

3.32 Série Temporal da corrente paralela à costa na estação \#106 para o ano $2004 . \ldots \ldots \ldots \ldots \ldots \ldots \ldots$

3.33 Série Temporal da corrente paralela à costa na estação \#506 para o ano $2002 . \ldots \ldots \ldots \ldots \ldots \ldots \ldots$

3.34 Série Temporal da corrente paralela à costa na estação \#506 para o

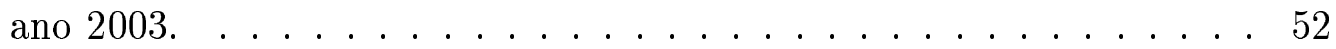

3.35 Série Temporal da corrente paralela à costa na estação \#506 para o

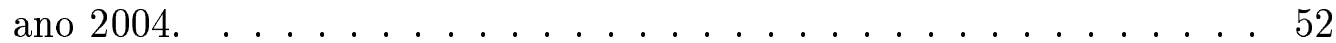

3.36 Série Temporal da corrente perpendicular à costa na estação \#106

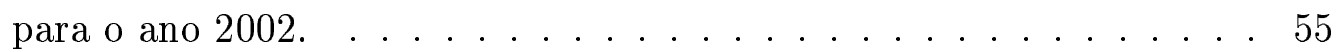

3.37 Série Temporal da corrente perpendicular à costa na estação \#106 para o ano $2003 . \ldots \ldots \ldots \ldots \ldots$

3.38 Série Temporal da corrente perpendicular à costa na estação \#106 para o ano $2004 . \ldots \ldots \ldots \ldots$

3.39 Série Temporal da corrente perpendicular à costa na estação \#506 para o ano $2002 . \ldots \ldots \ldots \ldots$

3.40 Série Temporal da corrente perpendicular à costa na estação \#506 para o ano $2003 . \ldots \ldots \ldots \ldots \ldots$ 
3.41 Série Temporal da corrente perpendicular à costa na estação \#506 para o ano 2004. . . . . . . . . . . . . . 57

3.42 Médias e Desvios Padrões mensais da corrente paralela à costa na estação \#106. . . . . . . . . . . . . . . . . . 61

3.43 Médias e Desvios Padrões mensais da corrente paralela à costa na estação \#506. . . . . . . . . . . . . . . . . . . 62

3.44 Médias e Desvios Padrões mensais da corrente perpendicular à costa na estação \#106. . . . . . . . . . . . . . . . . . 62

3.45 Médias e Desvios Padrões mensais da corrente perpendicular à costa na estação \#506. . . . . . . . . . . . . . . 63

3.46 Espectro de Potência de Ondeleta e espectro global de ondeleta da componente longitudinal do vento. . . . . . . . . . . . 69

3.47 Espectro de potência de ondeleta e espectro global de ondeleta da componente transversal do vento. . . . . . . . . . . . . . 69

3.48 Espectro de potência de ondeleta e espectro global de ondeleta da componente longitudinal da corrente na estação \#506. . . . . . . . 71

3.49 Espectro de potência de ondeleta e espectro global de ondeleta da componente transversal da corrente na estação \#506. . . . . . . . . . 71

3.50 Espectro de potência de ondeleta e espectro global de ondeleta dos dados de nível na estação \#506. . . . . . . . . . . . . . . . 72

3.51 Espectro cruzado de ondeleta entre os dados das componentes longitudinais do vento e das correntes para estação \#506. . . . . . . . . 75

3.52 Espectro cruzado de ondeleta entre os dados das componentes longitudinal do vento e transversal das correntes para estação \#506. . . 76

3.53 Espectro cruzado de ondeleta entre os dados da componente transversal do vento e elevação do nível do mar para a estação \#506. . . . . . 77

3.54 Espectro cruzado de ondeleta entre os dados das componente longitudinal do vento e da elevação do nível do mar para estação \#506. 78 
3.55 Espectro cruzado de ondeleta entre os dados das componentes transversais do vento e das correntes para estação \#506. . . . . . . . . 78

3.56 Espectro cruzado de ondeleta entre os dados da componente transversal do vento e elevação do nível do mar para a estação \#506. . . . . . 79

3.57 Covariância de ondeleta entre os dados das componentes longitudinais do vento e das correntes para estação \#506. . . . . . . . . . . . . 81

3.58 Covariância de ondeleta entre os dados da componente transversal das correntes e a elevação do nível do mar para estação \#506. . . . 82

3.59 Covariância de ondeleta entre os dados das componentes longitudinal do vento e transversal das correntes para estação \#506. . . . . . . . . 82

3.60 Covariância de ondeleta entre os dados das componente longitudinal do vento e da elevação do nível do mar para estação \#506. . . . . . . 83

3.61 Covariância de ondeleta entre os dados das componentes transversais do vento e transversal das correntes para estação \#506. . . . . . . . . 84

3.62 Covariância de ondeleta entre os dados das componente transversal do vento e da elevação do nível do mar para estação \#506. . . . . . . 85 


\section{Lista de Tabelas}

2.1 Posições e profundidades das estações . . . . . . . . . . . . 9

3.1 Direções dos ventos para cada um dos anos de monitoramento . . . . 20

3.2 Número e duração das frentes frias que chegaram à região de Caravelas durante o período de estudo. . . . . . . . . . . . 20

3.3 Número e duração dos VCAN que atuaram na região adjacente a Caravelas durante o período de estudo. . . . . . . . . . . . . 21

3.4 Intensidades e direções do vetor resultante do vento para cada um dos meses do ano. . . . . . . . . . . . . . . . 23

3.5 Estatísticas anuais da banda sub-inercial dos dados do campo de vento. 27

3.6 Resultados da análise harmônica dos dados de elevação do nível do mar na estação \#106. . . . . . . . . . . . . . . . . . 37

3.7 Resultados da análise harmônica dos dados de elevação do nível do mar na estação \#506. . . . . . . . . . . . . . . . . 37

3.8 Estatísticas anuais da banda sub-inercial dos dados de elevação do nível do mar da estação \#106. . . . . . . . . . . . . . . . . . . 42

3.9 Estatísticas anuais da banda sub-inercial dos dados de elevação do nível do mar para estação \#506. . . . . . . . . . . . . . . 42

3.10 Resultados da análise harmônica do campo de velocidade na estação

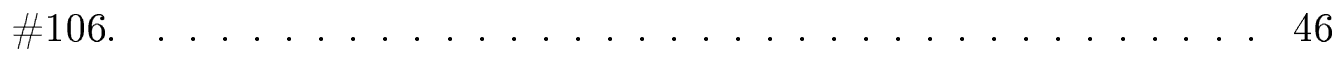


3.11 Resultados da análise harmônica do campo de velocidade na estação

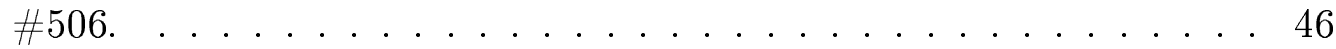

3.12 Estatísticas anuais da banda sub-inercial do campo de correntes para estação \#106. . . . . . . . . . . . . . . . . 59

3.13 Estatísticas anuais da banda sub-inercial do campo de correntes para estação \#506. . . . . . . . . . . . . . . . . . 59

3.14 Índices de determinação, coeficientes de correlação cruzada e defasagem entre os campos da estação \#106. . . . . . . . . . . 66

3.15 Índices de determinação, coeficientes de correlação cruzada e defasagem entre os campos da estação \#506. . . . . . . . . . . . 66 


\section{Lista de Abreviações}

$$
\begin{array}{ll}
\text { AAS } & - \text { Alta (anti - ciclone) do Atlântico Sul } \\
\mathrm{CA} & - \text { Complexo de Abrolhos } \\
\mathrm{CL} & - \text { Corrente Longitudinal } \\
\mathrm{CT} & - \text { Corrente Transversal } \\
\mathrm{CVO} & - \text { Covariância de Ondeletas } \\
\mathrm{E} & - \text { Leste } \\
\mathrm{ECO} & - \text { Espectro Cruzado de Ondeletas } \\
\mathrm{ENE} & - \text { Leste Nordeste } \\
\text { FF } & - \text { Frentes Frias } \\
\mathrm{N} & - \text { Norte } \\
\mathrm{NE} & - \text { Nordeste } \\
\text { NW } & - \text { Noroeste } \\
\mathrm{OMJ} & - \text { Oscilação de Madden - Julian } \\
\text { PCLB } & - \text { Plataforma Continental Leste Brasileira } \\
\mathrm{S} & - \text { Sul } \\
\text { SW } & - \text { Sudoeste } \\
\text { TF } & - \text { Transformada de Fourier } \\
\text { TO } & - \text { Transformada de Ondeletas } \\
\text { VCAN } & - \text { Vortices Ciclônicos em Altos Níveis } \\
\text { VL } & - \text { Vento Longitudinal } \\
\text { VT } & - \text { Vento Transversal } \\
\text { W } & - \text { Oeste }
\end{array}
$$




\section{Capítulo 1}

\section{Introdução}

A preferência da humanidade na ocupação da zona costeira e litorânea e a utilização dos oceanos para o desenvolvimento de atividades econômicas, como a exploração de petróleo, aqüicultura, geração de energia, transporte, turismo entre outras, gera uma série de alterações ambientais.

Modificações da circulação local, decorrentes de obras de infra-estrutura, fixação de estruturas para extração e transporte de petróleo e deságües de efluentes, por exemplo, podem gerar alterações no transporte de nutrientes, sedimentos e no ciclo bio-geoquímico. Na maioria das vezes tais alterações resultam em impactos negativos sobre a biota, como mudanças em sua composição e biomassa, floração de algas nocivas, contaminação de organismos e eventualmente até das populações costeiras. A determinação das conseqüências geradas pela pressão antrópica em um ecossistema é uma tarefa difícil, mas que deve ser aplicada na tentativa de avaliar as inter-relações entre todos os componentes do ecossistema, buscando uma maior integração e harmonia desse ambiente.

Nesse sentido, em dezembro de 2001, o Instituto Brasileiro de Meio Ambiente e dos Recursos Naturais Renováveis (IBAMA) solicitou a realização de um programa multidisciplinar para o monitoramento da obra de dragagem do delta de 
maré vazante defronte ao Canal do Tomba, situado na foz do Rio Caravelas, sul da Bahia. A obra tem como objetivo facilitar a via de acesso ao terminal de barcaças da Aracruz Celulose (Figura 1.1) e mereceu uma atenção especial pela possibilidade de alteração na circulação hidrodinâmica e no transporte de sedimentos na região adjacente ao Complexo de Abrolhos (CA). Além disso, a área de descarte do material dragado situa-se a poucos quilômetros do CA.

A parte hidrodinâmica desse programa de monitoramento, constou da coleta contínua, a cada meia hora, de informações em dois pontos fixos através do fundeio de dois correntômetros Interocean S4ADW, dispostos a 3 metros do fundo. Além dos registros de correntometria, foram coletados dados de elevação do nível do mar, turbidez e ondas nesses dois pontos. Também foram obtidos dados de direção e intensidade do vento em uma estação costeira distante $12 \mathrm{Km}$ do ponto de fundeio .

O monitoramento foi iniciado em janeiro de 2001 e estendendo-se até a presente data, totalizando mais de cinco anos de coleta contínua de dados. Este programa possui um caracter excepcional por tratar-se da coleta de dados de correntometria mais extensa já realizada no Brasil e por tais dados se referirem à dinâmica da circulação da plataforma interna, tema que possui poucos estudos na literatura da área (Lentz et al., 1999). 


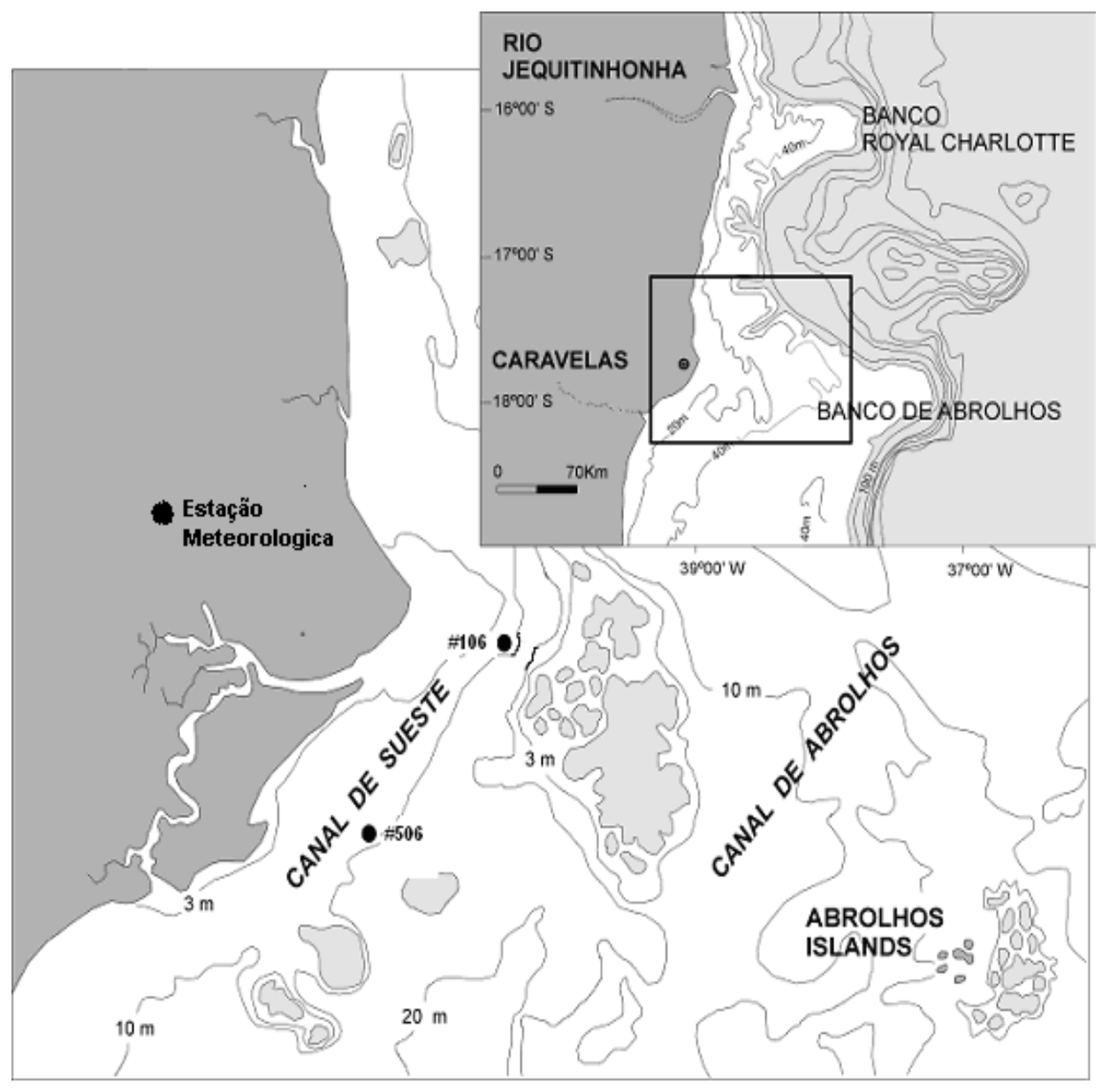

Figura 1.1: Localização da região de estudos. Os pontos destacados com um circulo correspondem aos locais de fundeio e a estação meteorológica. 


\subsection{Objetivos:}

O objetivo geral desta dissertação é a caracterização da circulação costeira adjacente ao Complexo de Abrolhos e a determinação das suas forçantes em períodos sub-inerciais.

Utilizando-se dos três primeiros anos de dados do monitoramento, os objetivos específicos do trabalho são:

- descrição da circulação costeira, do padrão de ventos e da elevação do nível do mar na região;

- uso da metodologia da Transformada de Ondeletas para determinação do espectro de variabilidade, correlação e covariância dos campos acima;

Alguns resultados sobre marés e estatísticas básicas das correntes supra-inerciais são apresentados. Porém este trabalho está focado na compreensão da componente sub-inercial dos campos.

\subsection{Organização do trabalho:}

A presente dissertação esta organizada da seguinte forma:

- Capitulo 1: é feita a introdução geral do trabalho e a determinação dos objetivos gerais e específicos;

- Capitulo 2: apresenta a descrição da área de estudo, caracterização dos dados e da metodologia empregada; 
- Capitulo 3: exibe e discute os resultados obtidos;

- Capitulo 4: apresenta as conclusões da dissertação e recomendações para trabalhos futuros.

\subsection{Descrição da área:}

Os fundeios para a coleta dos dados estão situados a cerca de dez quilômetros da desembocadura do Rio Caravelas, dentro do canal Sueste. A área de estudo é adjacente ao Complexo de Abrolhos considerado o maior e mais rico sistema de recifes de coral do Atlântico Sul (Leão and Ginsburg, 1997) e está localizada dentro da plataforma continental leste brasileira (PCLB).

O setor interno da PCLB possui uma batimetria complexa, sendo formada por uma série de recifes de corais, ilhas vulcânicas, bancos rasos e canais, que podem alterar a circulação costeira na região. A plataforma possui uma largura média de $50 \mathrm{Km}$, largura esta que pode atingir $200 \mathrm{Km}$ em frente ao Banco de Abrolhos.

O CA tem uma área aproximada de $6000 \mathrm{Km}^{2}$, e está localizado no prolongamento da PCLB entre $17^{\circ} 20^{\prime}$ e $18^{\circ} \mathrm{S} 10^{\prime}$ e foi transformado em Parque Nacional Marinho pelo decreto 88.218 de 06/04/1983. Além do valor ecológico, o complexo possui também um grande valor econômico, e vem recebendo grande atenção da comunidade científica devido às atividades turísticas que estão sendo desenvolvidas na região e da proximidade a reservas de óleo e gás presentes em profundidades inferiores a $14 \mathrm{~m}$.

Dentro da topografia do CA devem-se destacar os canais Sueste e de Abrolhos ambos com uma orientação NE-SW, uma profundidade média de $20 \mathrm{~m}$, uma largura de $20 \mathrm{Km}$ e um comprimento de $50 \mathrm{Km}$ e os Bancos de Abrolhos e Royal Charlotte, formados por uma serie de pequenas ilhas coralinas e corais de franjas. 
Existem poucos trabalhos na literatura sobre o clima da região. De forma geral, sabe-se que o CA está localizado na parte sul da área dos ventos alísios e que o clima local está condicionado à posição da Alta (ou anticiclone) do Atlântico Sul (AAS) (Chaves, 1999). De acordo com Chaves (1999), o vento resultante possui uma direção nordeste entre os meses de novembro a fevereiro e de Sudeste nos meses de março a agosto. Isso ocorre devido a migração, para norte, da célula AAS no verão, e para sul no inverno (Chaves, 1999).

O tempo na região é influenciado diretamente pela penetração de frentes frias (FF) e pela liberação de vórtices ciclônicos em altos níveis (VCAN) ou baixas frias. Um maior número de FF chega a região durante o inverno e outono, enquanto um menor número ocorre durante o verão (Andrade, 2004). De forma geral, o avanço das FF impõe maior intensidade aos ventos de sudeste, adicionando uma componente su-sudoeste na circulação atmosférica.

Os VCAN são sistemas de baixa pressão formados na alta troposfera, possuindo uma circulação direta com movimentos ascendentes de ar quente e úmido na periferia e movimentos descendentes de ar frio e seco em seu centro. A época de maior incidência de VCAN são os meses de dezembro a março e os mesmos provocam tempo seco e impedem a penetração de sistemas frontais (Gan, 1982).

É interessante notar que existe uma grande variabilidade interanual no número de FF e VCAN (Chaves, 1999; Gan, 1982), o que influência diretamente o padrão de circulação atmosférica sobre a região.

O litoral sul da Bahia apresenta uma precipitação anual média de $1600 \mathrm{~mm}$, concentrada em poucos meses ao longo do ano. As maiores precipitações ocorrem nos meses de maio a julho enquanto o período mais seco concentra-se nos meses de agosto a outubro (Chaves, 1999).

Cinco pequenos rios desembocam nas proximidades da área de estudo (Rios Burunhém, Jucuruçú, Itanhém, Peruipe e Caravelas), os quais combinados apresentam uma descarga anual de aproximadamente $120 \mathrm{~m}^{3} \cdot \mathrm{s}^{-1}$ (DNAEE, 1987). Com uma 
descarga aproximada de $113 \mathrm{~m}^{3} \cdot \mathrm{s}^{-1}$, o Rio Mucuri é o maior contribuinte de água doce da região, desaguando a aproximadamente $60 \mathrm{Km}$ da área de estudo. A influência desta descarga sobre a região continental ainda permanece desconhecida. De acordo com os trabalhos de Leipe et al. (1999) e Summerhayes et al. (1976), a circulação sobre a plataforma, incluindo a zona costeira, é dominada por águas tropicais provenientes de meandros da corrente do Brasil $\left(\mathrm{T}>22{ }^{\circ} \mathrm{C}\right.$ e S $\left.>36.9\right)$, porém estes estudos foram efetuados durante períodos curtos e isolado e que apresentavam baixa descarga continental.

Os estudos da hidrodinâmica local estão restritos aos trabalhos de Leipe et al. (1999) e Lessa and Cirano (2006). Leipe et al. (1999) utilizou dados termo-halinos, de turbidez e de correntometria de três dias de fundeios no Canal de Abrolhos e Sueste realizados no verão de 1995. O mesmo concluiu que a circulação local é dominada por vento e modulada pela maré, ressaltando ainda a importância das intrusões de águas provenientes dos meandros da Corrente do Brasil sobre a plataforma. Além disso, os autores destacaram, a grande simetria entre as correntes de superfície e de fundo.

No trabalho de Lessa and Cirano (2006), os autores utilizaram-se dos primeiros 548 dias de medições de correntometria do presente trabalho. $\mathrm{O}$ artigo sugere que o vento local e marés têm importância secundária na variabilidade das correntes. $\mathrm{O}$ vento de larga escala e fluxos sub-inerciais são os mecanismos de maior importância para a circulação. Os autores ressaltam ainda o fato de registros indicarem que a área de estudo apresenta a maior amplitude de maré de toda a costa leste Brasileira. 


\section{Capítulo 2}

\section{Metodologia}

\subsection{Correntes e Marés:}

A variação temporal da intensidade e direção médias das correntes oceânicas, bem como a variação da maré foi registrada por meio de dois correntômetros eletromagnéticos Interocean, modelo S4ADW, fundeados a $3 \mathrm{~m}$ do fundo e aproximadamente $9 \mathrm{Km}$ da costa. O equipamento possui uma precisão de $4 \mathrm{~mm}$ nas medidas de elevação, $0,2 \mathrm{~cm} \cdot \mathrm{s}^{-1}$ e $0,5^{\circ}$ nos campos de intensidade e direção das correntes, respectivamente. Os dois fundeios foram denominados de estação \#106 e \#506 e encontram-se ao norte e ao sul do domínio, respectivamente (Figura 1.1), separados por uma distância de 14,3 km. Nestas mesmas estações foram colocados sensores de pressão para se medir as variações do nível do mar. As posições e as profundidades (em relação ao nível médio) nas quais estão situados os correntômetros e o sensores de pressão estão listadas na Tabela 2.1 . 
Tabela 2.1: Posições e profundidades das estações

\begin{tabular}{|c|c|c|c|}
\hline Estação & Latitude & Longitude & Profundidade \\
\hline 106 & $17^{\circ} 48^{\prime} \mathrm{S}$ & $39^{\circ} 7^{\prime} \mathrm{W}$ & $7.7 \mathrm{~m}$ \\
\hline 506 & $17^{\circ} 53^{\prime} \mathrm{S}$ & $39^{\circ} 13^{\prime} \mathrm{W}$ & $8.7 \mathrm{~m}$ \\
\hline
\end{tabular}

Os sensores de pressão e os correntógrafos foram configurados para registrar, a cada 30 minutos uma a média de 240 leituras medidas por 2 minutos (freqüência amostral de $2 \mathrm{~Hz}$ ). Algumas lacunas foram geradas devido a problemas no funcionamento dos equipamentos ou a paradas para manutenção dos mesmos.

Dados espúrios foram identificados e removidos após o estabelecimento de um envelope, ao longo das séries, definido pela média mais ou menos dois desvios padrões (Emery and Thomson, 1997), estabelecendo assim um critério de confiança em 95\% para a qualidade dos dados. A média e o desvio foram calculados para uma janela móvel de 10,5 horas centrada no dado de interesse. Quando o valor central encontrava-se fora desse envelope o mesmo foi descartado e identificado como lacuna.

O coleta das medições do nível do mar apresentou alguns problemas, devido ao tombamento da estrutura de fixação dos sensores e o posterior posicionamento em locais com profundidades ligeiramente diferentes. Quando possível, estes problemas foram identificados visualmente e corrigidos.

Todas as lacunas iguais ou inferiores a 8 horas foram preenchidas por interpolação polinomial. Ao total foram interpolados 33 lacunas na estação \# 506 e 32 na estação \#106. As lacunas interpoladas possuem um comprimento médio de 2,5 horas em ambas as estações. Por possuírem uma duração maior que 8 horas, algumas lacunas não foram interpoladas, porém por representarem menos que $6 \%$ dos dados, estas lacunas não interferiram nos resultados estatísticos.

As metodologias de análise espectral e de ondeletas são suscetíveis a lacunas e para que as análises fossem possíveis um ruido branco foi adicionado aos campos que apresentavam lacunas (Emery and Thomson, 1997). 
Os dados de corrente foram rotacionados no sentido horário em $35^{\circ}$ e assim alinhados conforme a orientação da linha de costa e também do canal. Após o alinhamento, as velocidades foram decompostas nas componentes paralela (v) e perpendicular (u) a linha de costa.

As rotinas do pacote $T_{\text {_tide }}$ (Pawlowicz et al., 2002) foram utilizadas para a análise das correntes de maré e cálculo de seus principais constituintes. Para tanto foram utilizados os campos de velocidade alinhados com a costa.

Depois de reduzidos ao nível médio, os dados de elevação do nível do mar de cada estação foram analisados através da metodologia da análise harmônica para o cálculo das principais constituintes de maré, usando as rotinas do pacote T_tide (Pawlowicz et al., 2002). O procedimento de redução ao de nível médio de cada estação permitiu a comparação entre as duas séries temporais.

As componentes da corrente e os dados de elevação do nível do mar foram divididos nas bandas supra-inercial e sub-inercial através de um filtro passa baixa do tipo Lanczos-Cosseno. O filtro Lanczos-Cosseno atua no domínio do tempo removendo $50 \%$ da energia na freqüência de corte. Foi utilizado um período de corte de 39 horas, correspondente ao período inercial para latitude de $17^{\circ}$.

\subsection{Ventos:}

A velocidade e direção média dos ventos foi registrada em intervalos de meia hora, durante todo o período de monitoramento, por uma estação meteorologica Campbell, de propriedade da Aracruz Celulose, posicionada a $12 \mathrm{~km}$ da costa (Figura 1.1). A metodologia para a localização dos valores espúrios foi a mesma exposta acima. As lacunas inferiores a 6 horas existentes na série temporal foram interpoladas o que permitiu a construção de uma série de dados de ventos quase continua. Novamente, quando necessário, as lacunas resultantes foram preenchidas através da adição de 
um ruído branco aos campos de vento.

Para a decomposição das componentes paralela (v) e perpendicular à costa $(\mathrm{u})$, os dados de vento foram rotacionados em $35^{\circ}$ e assim alinhados conforme a orientação da linha de costa e também do canal, além disso os dados também foram rotacionados em $180^{\circ}$ para mudar o padrão da direção "de onde vem", usado em meteorologia, para o padrão "para onde vai", usado em oceanografia.

Os Boletins Climanálise do INPE-CPTEC (CLIMANALISE, 2002-2004), do período de Janeiro de 2002 a Dezembro de 2004, foram usados para obtenção dos dados mensais da quantidade de frentes e VCAN que chegam a região de Caravelas. 


\subsection{Transformada de Ondeletas:}

A metodologia de Transformada de Ondeleta (TO) foi desenvolvida na década de 1980 por pesquisadores como Morlet, Grossmann, Meyer e Daubechies (Torrence and Compo, 1998) e apresenta vantagens em relação a outras metodologias normalmente utilizadas em geociências para decomposição de sinal como, por exemplo, a transformada de Fourier (TF). Nos últimos anos tem havido crescente interesse na TO dentro da área de geociências, devido à possibilidade de se obter novas perspectivas e discernimentos que não são factíveis com outras ferramentas tradicionais (Torrence and Compo, 1998; Ghil et al., 2002).

Enquanto a TF foi desenvolvida para a análise de sinais estacionários, a TO foi formulada para o estudo de sinais não-estacionários. A TF, nos fornece a amplitude

e fase média de cada harmônico sobre todo o período (análise global), enquanto a TO nos dá a resposta local da amplitude e fase de cada harmônico. Assim, a TO é particularmente útil para detectar sinais não estacionários, ou flutuações de caráter episódico. Adicionalmente, a TF só permite a reconstrução total do sinal, enquanto que a TO possibilita a reconstrução global e também de partes deste sinal (Torrence and Compo, 1998))

A TO utiliza uma janela adaptativa (dilatação) no domínio tempo-freqüência que automaticamente estreita-se quando enfoca oscilações de alta freqüência e alarga-se para baixas freqüências. Estas características são adequadas na análise de sinais geofísicos que possuem componentes de múltipla escala.

O termo ondeleta refere-se a um conjunto de ondas formadas por dilatação 
$\psi(t) \rightarrow \psi(2 t)$ e translação $\psi(t) \rightarrow \psi(t+1)$ de uma única função $\psi(t)$,que é quadraticamente integrável sobre o campo dos reais ou espaço [L2 (R)] e possui energia finita. A função $\psi(t)$ pode ser chamada de "ondeleta mãe", "ondeleta básica"ou "ondeleta analisadora", enquanto que as funções dilatadas e transladadas derivadas da ondeleta mãe são chamadas simplesmente de "ondeletas"(Torrence and Compo, 1998).

A ondeleta mãe utilizada foi a ondeleta complexa de Morlet (Torrence and Compo, 1998). A mesma foi escolhida devido a trabalhos anteriores destacarem a sua capacidade para capturar variações nas periodicidades dos sinais geofísicos, tais como simetria ou assimetria, e variação temporal brusca ou suave. A ondeleta complexa de Morlet é definida como uma onda plana modulada por um envelope Gaussiano de largura unitária (Torrence and Compo, 1998). Esta ondeleta é expressa através da fórmula:

$$
\psi(t)=\pi^{-1 / 4} e^{-t^{2} / 2} e^{i \omega_{0} t}
$$

onde: t é o tempo, s é a escala das ondeletas, $\omega_{0}$ é uma freqüência não dimensional.

No presente trabalho foi utilizado o conjunto de rotinas desenvolvido por Grinsted et al. (2004) para o cálculo do espectro de ondeletas. Este pacote foi desenvolvido para o ambiente Matlabß e, além do espectro, calcula também a covariância e o espectro cruzado entre duas séries, com as respectivas fases. No programa é feito um teste de significância entre os valores do espectro de ondeleta encontrados e um ruído vermelho, e os resultados com significância maior do que $95 \%$ são delimitados nos gráficos.

A covariância e o espectro cruzado de ondeleta foram utilizados para o entendimento do grau de relação entre dois campos e suas escalas de tempo. Os cálculos para a obtenção do espectro cruzado, da coerência e das respectivas fases seguiram a metodologia descrita em Torrence and Webster (1999) e Grinsted et al. (2004).

O espectro cruzado (ECO) nos fornece as regiões, no domínio da freqüência e 
do tempo, onde ambas as séries possuem alta energia nos informando ainda sobre a fase entre os sinais. Caso os dois sinais sejam fisicamente relacionados, a fase entre os sinais deve ser consistente ou variar pouco (Moore et al., 2005).

A covariância de ondeleta (CVO) fornece uma medida de correlação, para um defasagem zero, entre duas series temporais em função da freqüência e do tempo. Os resultados são dados no intervalo entre 0 e 1 e são independentes da diferença de fase entre os sinais (Moore et al., 2005).

Os resultados da CVO devem ser interpretados com cuidado, pois eles apenas informam se dois sinais variam numa mesma freqüência. A importância da freqüência é informado pelo ECO. Em suma a CVO nos fornece a relação entre os períodos de variabilidade enquanto o ECO informa a importância destes períodos para os dois sinais em conjunto. 


\section{Capítulo 3}

\section{Resultados e Discussão:}

\subsection{Ventos:}

Nesta seção serão utilizados as medições do campo de vento do período de janeiro de 2002 à janeiro de 2005, adquiridos numa estação automática situada a $12 \mathrm{Km}$ da costa 1.1. Inicialmente será feita uma descrição dos padrões sazonais da circulação atmosferica e seus forçantes e serão analisadas variações inter-anuais dos dados. Numa segunda etapa os dados serão decompostos nas componentes longitudinal e transversal e seus resultados apresentados e discutidos, bem como os resultados da banda sub-inercial destes campos.

A intensidade média da velocidade dos ventos para o período de estudo foi de $4,25 \pm 1,96 \mathrm{~m} \cdot \mathrm{s}^{-1}$, sendo a maior velocidade observada igual a $13,40 \mathrm{~m} \cdot \mathrm{s}^{-1}$ no mês de fevereiro de 2002 .

A distribuição de freqüência das velocidades foi relativamente simétrica, de modo que a velocidade média situou-se dentro da classe modal identificada na figura 3.1 entre 3,6 e $5,7 \mathrm{~m} \cdot \mathrm{s}^{-1}$, tal classe modal perfaz um total de $39.4 \%$ das observações.

A figura 3.2 apresenta o gráfico de distribuição da intensidade do vento por direção. Nota-se que a direção predominante foi de nordeste (NE) com 13,5\% de 
ocorrência ao longo do período de observação, seguido pelas direções sul (S)(9,7\%), leste-nordeste (ENE) $(9,0 \%)$ e leste (E)(9\%).

As maiores velocidade estiveram associadas aos ventos NE e nor-nordeste (NNE), acima de $8,8 \mathrm{~m} \cdot \mathrm{s}^{-1}$ com uma contribuição de aproximadamente $1,2 \%$. De forma geral quando agrupamos os ventos por quadrantes a direção norte (N) representa 11,8\% das medições, NE $25,2 \%$, E 16,4\%, sudeste (SE) 12,8\%, S 16,3\%, sudoeste (SW) $8 \%$, oeste (W) $3,6 \%$ e noroeste (NW) $4,3 \%$.

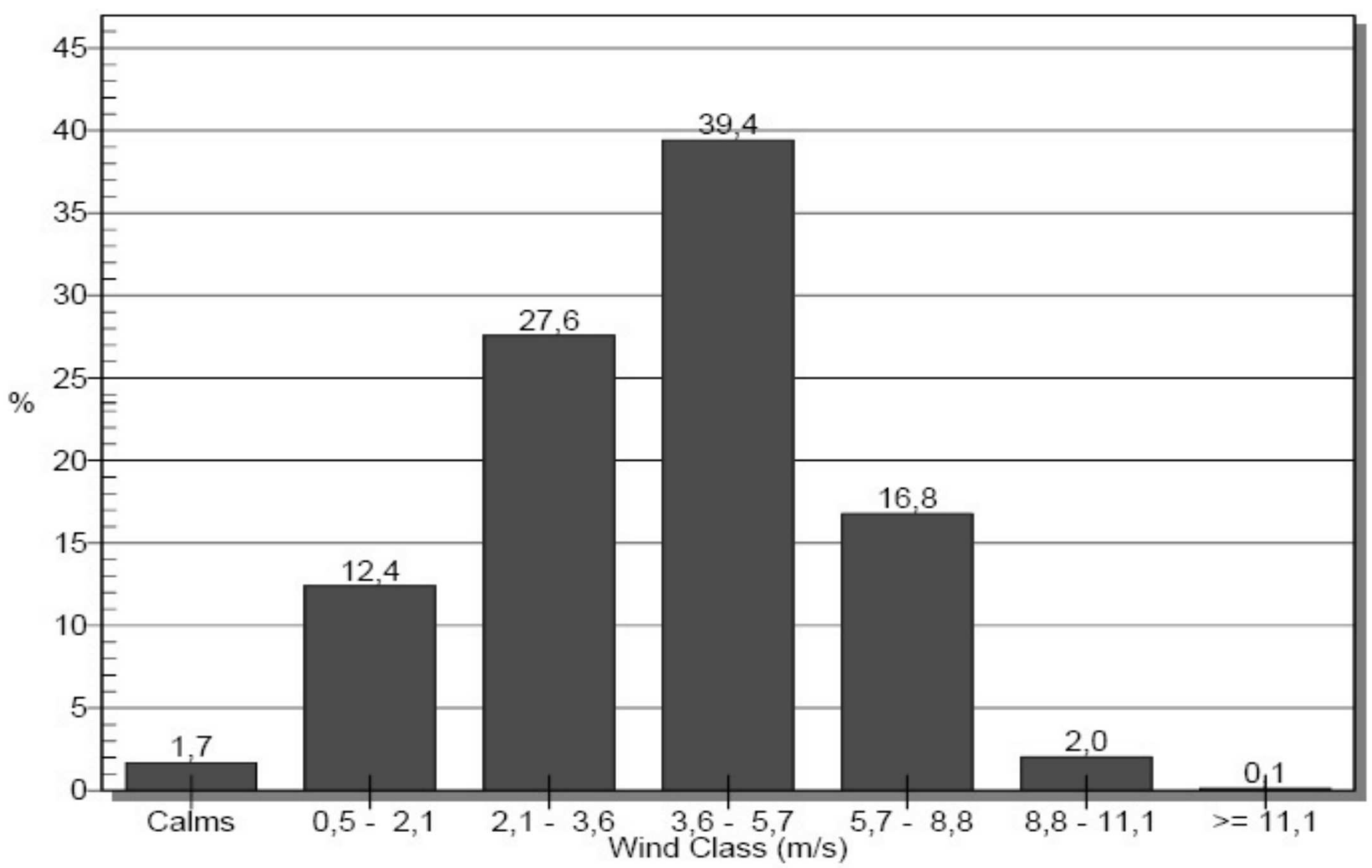

Figura 3.1: Histograma de frequêencia das velocidades do vento para todo o período de monitoramento. 


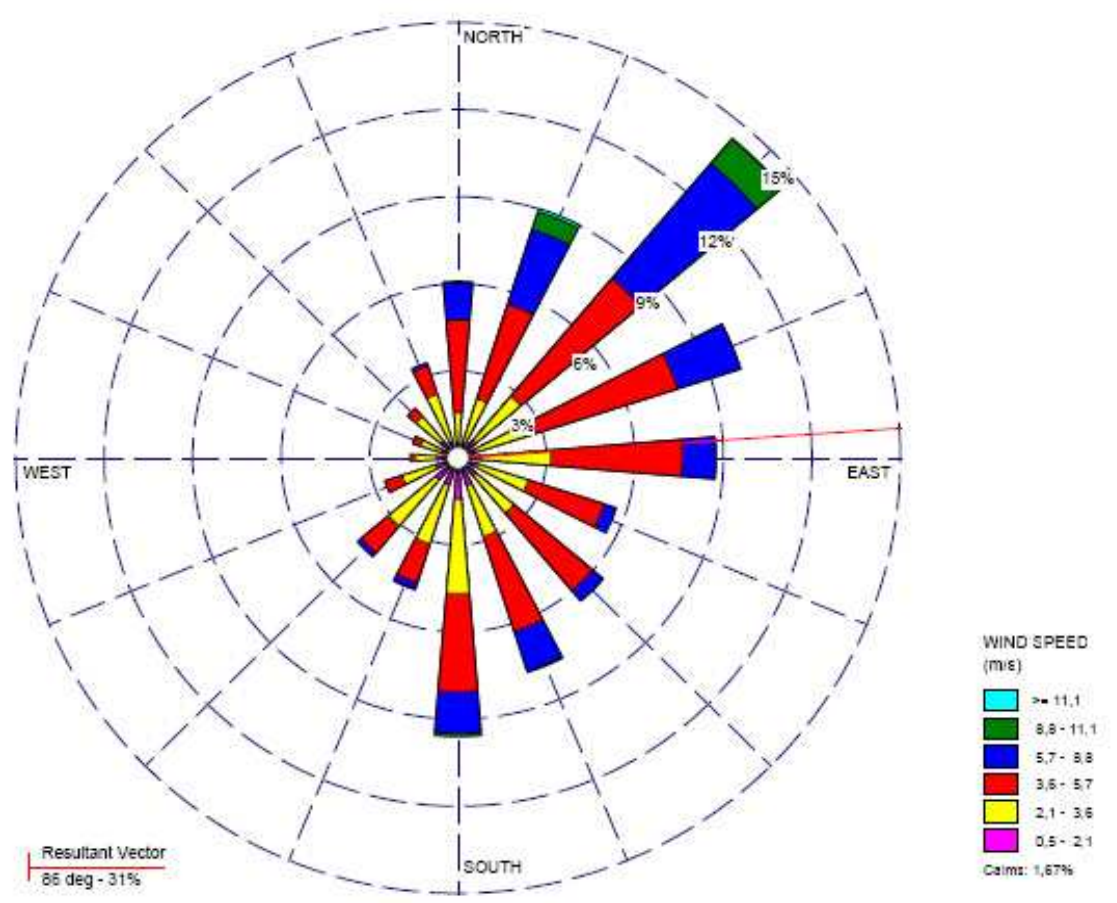

Figura 3.2: Distribuição da intensidade do vento por direção para todo o período de monitoramento.

Quando se comparam as figuras de distribuição de intensidade por direção para cada ano de análise (Figuras 3.3 à 3.5), percebemos que existe uma variabilidade inter-anual nas direções e intensidades dos ventos. O vetor resultante (vetor em vermelho nos gráficos) foi alterado de uma direção de $76^{\circ}$ e velocidade de $4,42 \pm$ $2,01 \mathrm{~m} \cdot \mathrm{s}^{-1}$ no ano de 2002 , para $91^{\circ}$ e $4.25 \pm 1,95 \mathrm{~m} \cdot \mathrm{s}^{-1}$ em 2003 e $95^{\circ}$ e $3,84 \pm$ $1,89 \mathrm{~m} \cdot \mathrm{s}^{-1} \mathrm{em} 2004$, mostrando um deslocamento na direção sul e uma diminuição na intensidade dos ventos. De acordo com a tabela 3.1 percebe-se uma diminuição na porcentagem de ventos do quadrante N-NE e um aumento nos ventos de S-SE. Esta alteração se deve, em parte, ao aumento do número e na duração das frentes que chegaram à região entre os anos de 2002 e 2004, como pode ser observado na tabela 3.3.

Apesar do aumento no número e na duração das frentes que chegaram a Caravelas ter sido relativamente pequeno comparado, por exemplo, ao que ocorre na região sudeste do país, onde este incremento foi muito maior. Como a influência de 
uma frente fria age em larga escala (Gan, 1982), estes fenômenos podem ter sido os responsáveis pela diminuição da intensidade dos ventos no período. Além disto, o número de VCAN presentes na região durante o período de estudo, também apresentou uma diminuição (tabela 3.2). De acordo com Gan (1982) a presença de um VCAN, gera uma um sistema de alta pressão sobre a região, o qual bloqueia a penetração de frentes frias e ameniza sua influência local. Assim, na presença de VCAN, a velocidade local do vento tende a diminuir.

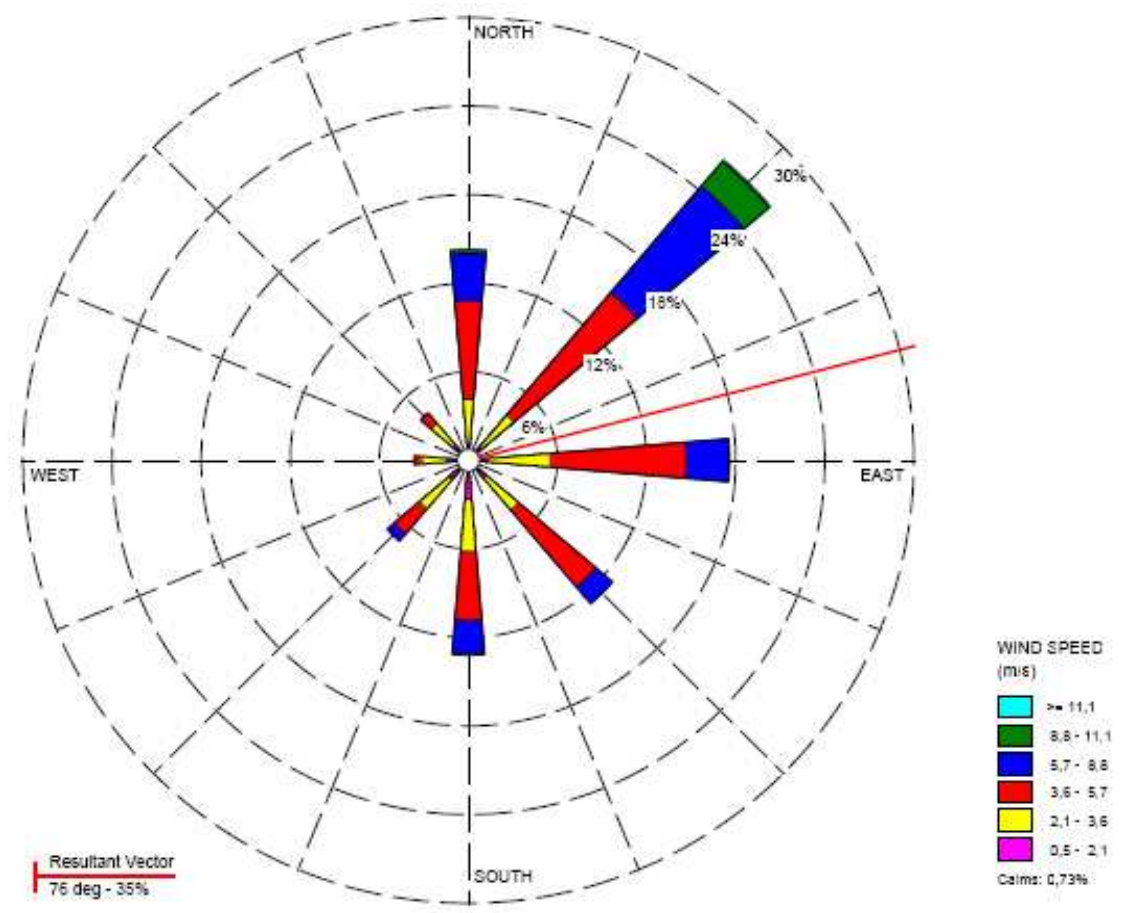

Figura 3.3: Distribuição da intensidade do vento por direção para o ano de 2002. 


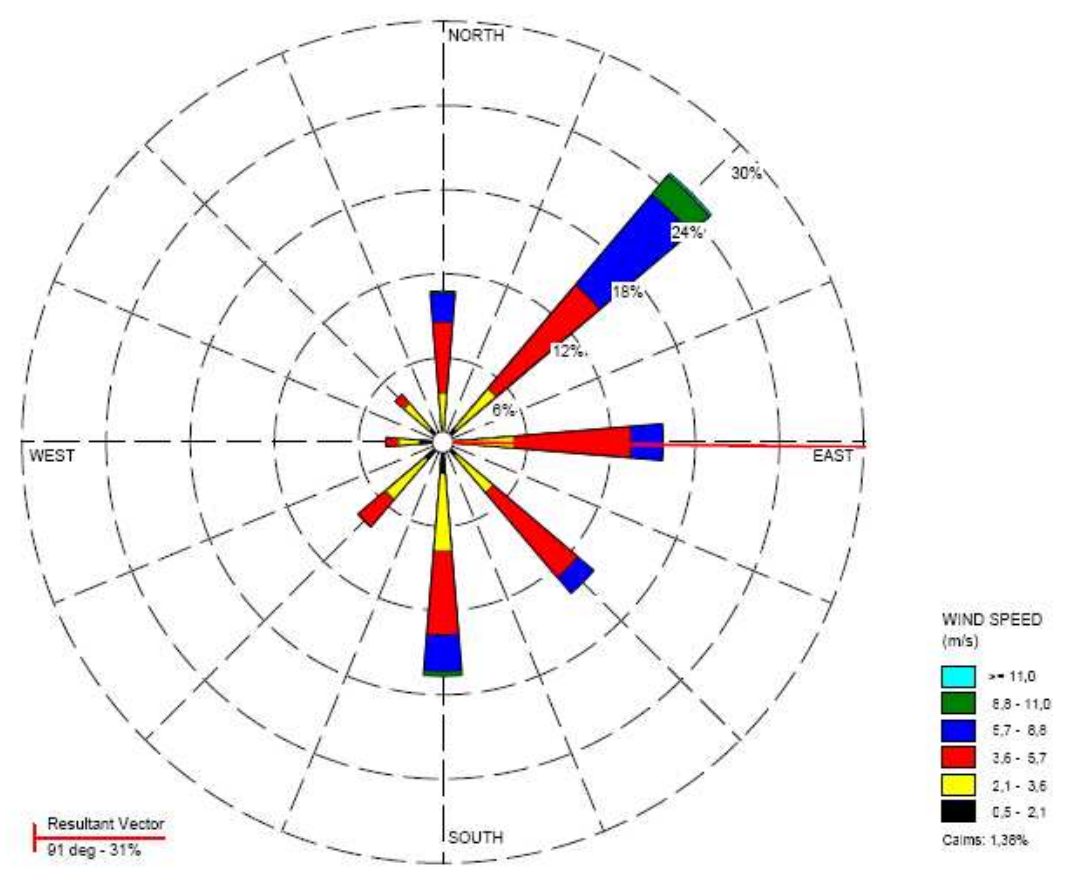

Figura 3.4: Distribuição da intensidade do vento por direção para o ano de 2003.

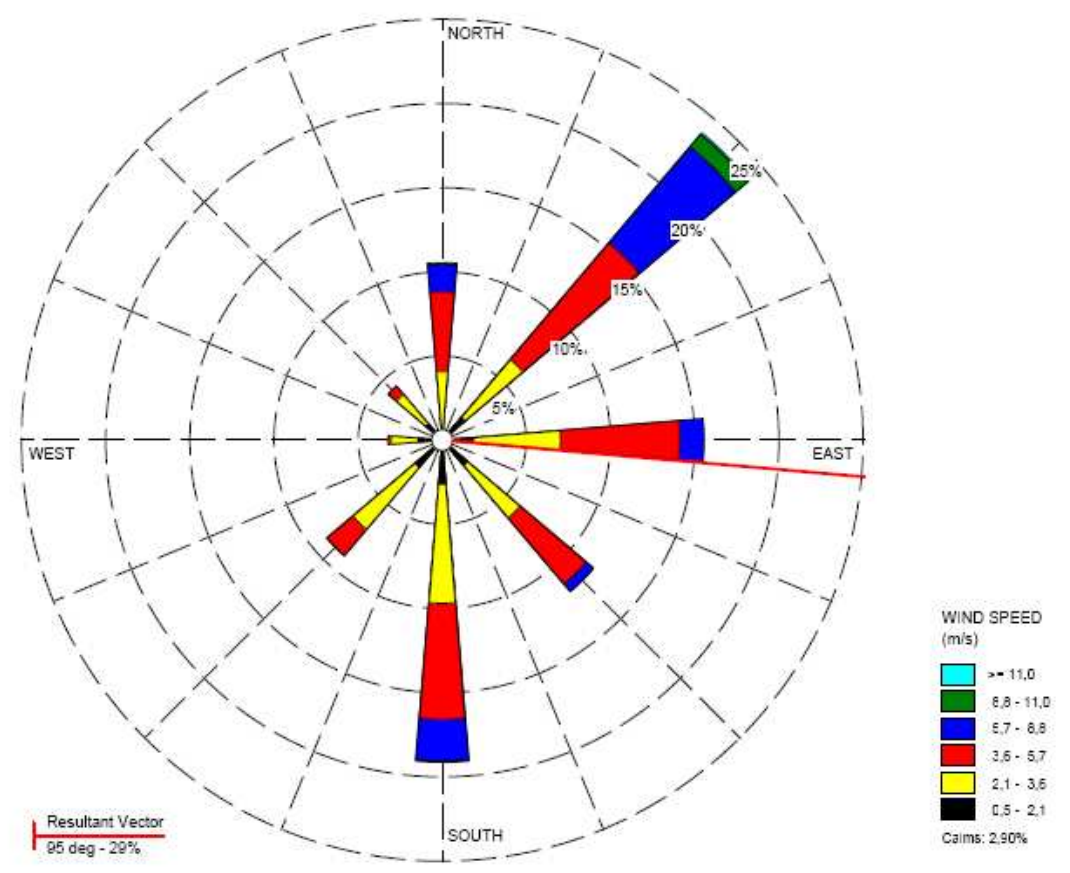

Figura 3.5: Distribuição da intensidade do vento por direção para o ano de 2004. 
Tabela 3.1: Direções dos ventos para cada um dos anos de monitoramento

\begin{tabular}{|l|c|c|c|}
\hline & $\mathbf{2 0 0 2}$ & $\mathbf{2 0 0 3}$ & $\mathbf{2 0 0 4}$ \\
\hline $\mathbf{N}$ & $14,23 \%$ & $10,75 \%$ & $10,45 \%$ \\
\hline $\mathbf{N E}$ & $26,57 \%$ & $25,02 \%$ & $23,95 \%$ \\
\hline $\mathbf{E}$ & $17,55 \%$ & $15,67 \%$ & $15,88 \%$ \\
\hline SE & $12,72 \%$ & $14,11 \%$ & $11,63 \%$ \\
\hline S & $13,17 \%$ & $16,64 \%$ & $18,91 \%$ \\
\hline SW & $7,17 \%$ & $7,91 \%$ & $8,92 \%$ \\
\hline $\mathbf{W}$ & $3,65 \%$ & $4,04 \%$ & $3,19 \%$ \\
\hline NW & $4,21 \%$ & $4,47 \%$ & $4,19 \%$ \\
\hline
\end{tabular}

Tabela 3.2: Número e duração das frentes frias (em dias) que chegaram a região de Caravelas durante o período de estudo. Fonte: Boletins Climanálise do INPECPTEC, do período de Janeiro de 2002 a Dezembro de 2004.

\begin{tabular}{|l|c|c|c|c|c|c|}
\hline & \multicolumn{2}{|c|}{ 2002 } & \multicolumn{2}{c|}{ 2003 } & \multicolumn{2}{c|}{ 2004 } \\
\hline & Frentes & Duração & Frentes & Duração & Frentes & Duração \\
\hline Jan. & 0 & 0 & 2 & 2 & 2 & 5 \\
\hline Fev. & 1 & 1 & 0 & 0 & 1 & 4 \\
\hline Mar. & 1 & 1 & 1 & 1 & 1 & 1 \\
\hline Abr. & 0 & 0 & 2 & 3 & 1 & 1 \\
\hline Mai. & 1 & 1 & 2 & 2 & 2 & 2 \\
\hline Jun. & 0 & 0 & 2 & 2 & 2 & 3 \\
\hline Jul. & 3 & 3 & 1 & 1 & 2 & 2 \\
\hline Ago. & 0 & 0 & 3 & 3 & 2 & 2 \\
\hline Set. & 4 & 7 & 2 & 2 & 1 & 1 \\
\hline Out. & 2 & 2 & 1 & 1 & 3 & 3 \\
\hline Nov. & 2 & 2 & 2 & 2 & 2 & 3 \\
\hline Dez. & 3 & 3 & 0 & 0 & 0 & 0 \\
\hline Total & 17 & 20 & 18 & 19 & 19 & 27 \\
\hline
\end{tabular}


Tabela 3.3: Número e duração dos VCAN que atuaram na região adjacente a Caravelas durante o período de estudo, Duração em dias. Fonte: Boletins Climanálise do INPE-CPTEC, do período de Janeiro de 2002 a Dezembro de 2004.

\begin{tabular}{|l|c|c|c|c|c|c|}
\hline & \multicolumn{2}{|c|}{2002} & \multicolumn{2}{c|}{ 2003 } & \multicolumn{2}{c|}{ 2004 } \\
\hline & VCAN & Duração & VCAN & Duração & VCAN & Duração \\
\hline Jan. & 2 & 10 & 3 & 17 & 2 & 13 \\
\hline Fev. & 1 & 9 & 5 & 15 & 1 & 6 \\
\hline Mar. & 3 & 7 & 2 & 9 & 3 & 6 \\
\hline Abr. & 1 & 2 & 1 & 3 & 1 & 3 \\
\hline Mai. & 1 & 3 & 0 & 0 & 0 & 0 \\
\hline Jun. & 1 & 1 & 0 & 0 & 0 & 0 \\
\hline Jul. & 1 & 1 & 0 & 0 & 0 & 0 \\
\hline Ago. & 1 & 1 & 0 & 0 & 0 & 0 \\
\hline Set. & 1 & 2 & 1 & 2 & 1 & 5 \\
\hline Out. & 1 & 3 & 1 & 3 & 2 & 6 \\
\hline Nov. & 3 & 7 & 1 & 2 & 2 & 5 \\
\hline Dez. & 4 & 15 & 1 & 2 & 3 & 8 \\
\hline Total & 20 & 61 & 15 & 53 & 15 & 52 \\
\hline
\end{tabular}

As distribuições de freqüência das velocidades e direção dos ventos para cada estação do ano estão expostas nas figuras 3.6 à 3.9. Deve-se notar que as grades de distribuição dos ventos das figuras (linhas tracejadas, indicando porcentagem) possuem valores diferentes para cada estação do ano.

Observa-se que nos meses de verão, a direção do vento preferencial foi NE, com $38,9 \%$ das ocorrências e o vetor residual (médio) apresentou uma direção de $55^{\circ}$ e uma velocidade média de $4,34 \mathrm{~m} . \mathrm{s}^{-1}$. Nesta situação os ventos de sul contribuíram com apenas 11,4\% (Figura 3.6).

Percebe-se uma grande alteração entre o padrão de ventos de verão e outono (Figura 3.7), demonstrando a característica transicional desta estação. No outono, houve um grande aumento na ocorrência dos ventos do quadrante SE e SW que associados perfazem $35 \%$ do total de ocorrências. Como conseqüência, nota-se diminuição da ocorrência dos ventos de N e NE que possuem um total de ocorrência de $5.5 \%$. Os ventos do quadrante sul, nesta região, estão associados as menores 
intensidades, fato que fez com que esta estação do ano possuísse a menor intensidade média entre as estações $\left(3,58 \mathrm{~m} \cdot \mathrm{s}^{-1}\right)$. O vetor resultante para esta estação teve direção de $143^{\circ}$, o maior valor das estações do ano, atingindo o limite sul de migração.

A figura 3.8 apresenta os resultados da estação de inverno. Percebe-se que existe uma similaridade entre o padrão de ventos de outono e inverno; com um pequeno aumento na ocorrência dos ventos de $\mathrm{E}$ e NE e diminuição dos ventos de S e SSW. O vetor resultante, desta estação possuiu direção de $130^{\circ}$ e intensidade média de 3,76 $\mathrm{m} . \mathrm{s}^{-1}$, caracterizando o retorno dos ventos para em direção para a direção Norte.

Nas estações de primavera (Figura 3.9), novamente existe um grande alteração no padrão de ventos quando comparado as estações de inverno e outono. Nesta estação, a quase totalidade de ocorrências se concentra nas direções NE e NNE o que ocasiona um aumento da intensidade dos mesmos. A direção mais ao norte e maior intensidade do vetor resultante da circulação eólica ocorrem nos meses de primavera, com valores de respectivamente $52^{\circ}$ e $5,03 \mathrm{~m} \cdot \mathrm{s}^{-1}$. A estação marca o limite norte do deslocamento do vetor vento.

A tabela 3.4 apresenta um resumo das direções e intensidades do vetor resultante para cada um dos meses do ano. Nota-se uma migração para o sul do vetor resultante, a partir do mês de Dezembro, quando o mesmo encontra-se no seu limite norte $\left(42^{\circ}\right)$ e apresenta as maiores intensidades $\left(5,22 \mathrm{~m} \cdot \mathrm{s}^{-1}\right)$. No mês de Junho o vetor resultante se apresenta no limite sul $\left(155^{\circ}\right)$ e apresenta a menor intensidade $\left(3,09 \mathrm{~m} \cdot \mathrm{s}^{-1}\right)$. A partir deste mês o vento resultante volta a migrar para norte. Esta migração sazonal dos ventos esta associada a posição da célula AAS que no verão encontra-se no seu limite para norte e no inverno no limite sul (Chaves, 1999).

De forma geral os resultados aqui apresentados corroboram aos encontrados por (Chaves, 1999) no seu estudo sobre o regime climatológico do litoral sul da região Nordeste do Brasil. 
Tabela 3.4: Intensidades e direções do vetor resultante do vento para cada um dos meses do ano. Direção em graus e intensidade em $\mathrm{m}_{\text {. }}{ }^{-1}$

\begin{tabular}{|l|c|c|c|c|c|c|}
\hline & JAN & FEV & MAR & ABR & MAI & JUN \\
\hline Direção & 54 & 49 & 84 & 131 & 155 & 155 \\
\hline Intensidade & 4,91 & 4,06 & 3,73 & 3,57 & 3,85 & 3,09 \\
\hline \hline & JUL & AGO & SET & OUT & NOV & DEZ \\
\hline Direção & 154 & 114 & 96 & 58 & 49 & 41 \\
\hline Intensidade & 3,69 & 3,78 & 4,30 & 5,14 & 5,12 & 5,22 \\
\hline
\end{tabular}

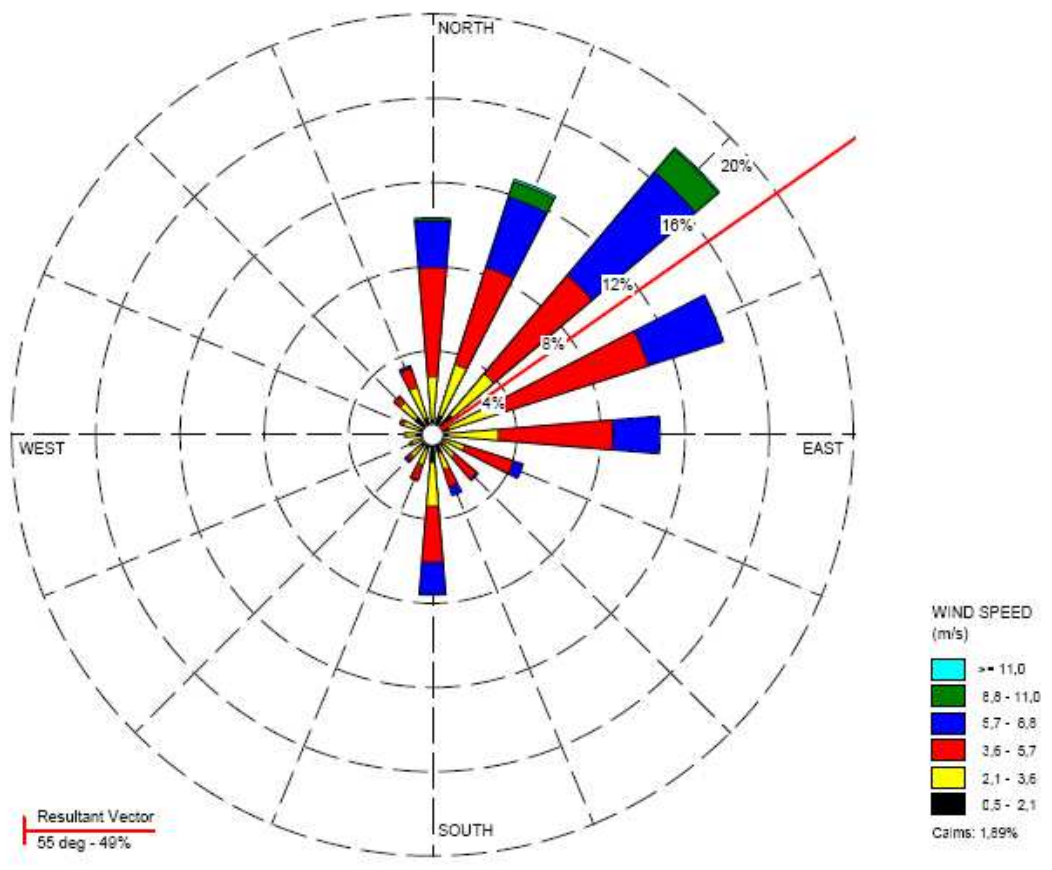

Figura 3.6: Distribuição da intensidade do vento por direção para as estações de verão no período de monitoramento. 


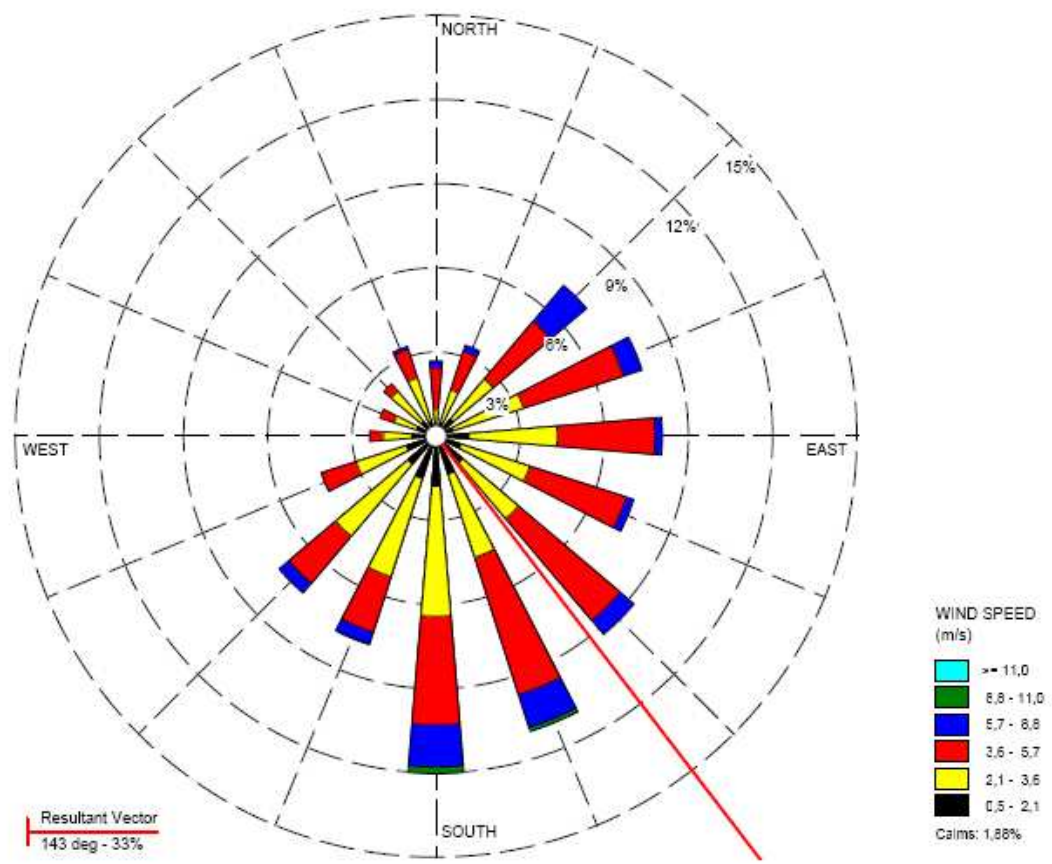

Figura 3.7: Similar a figura anterior, porém para as estações de outono.

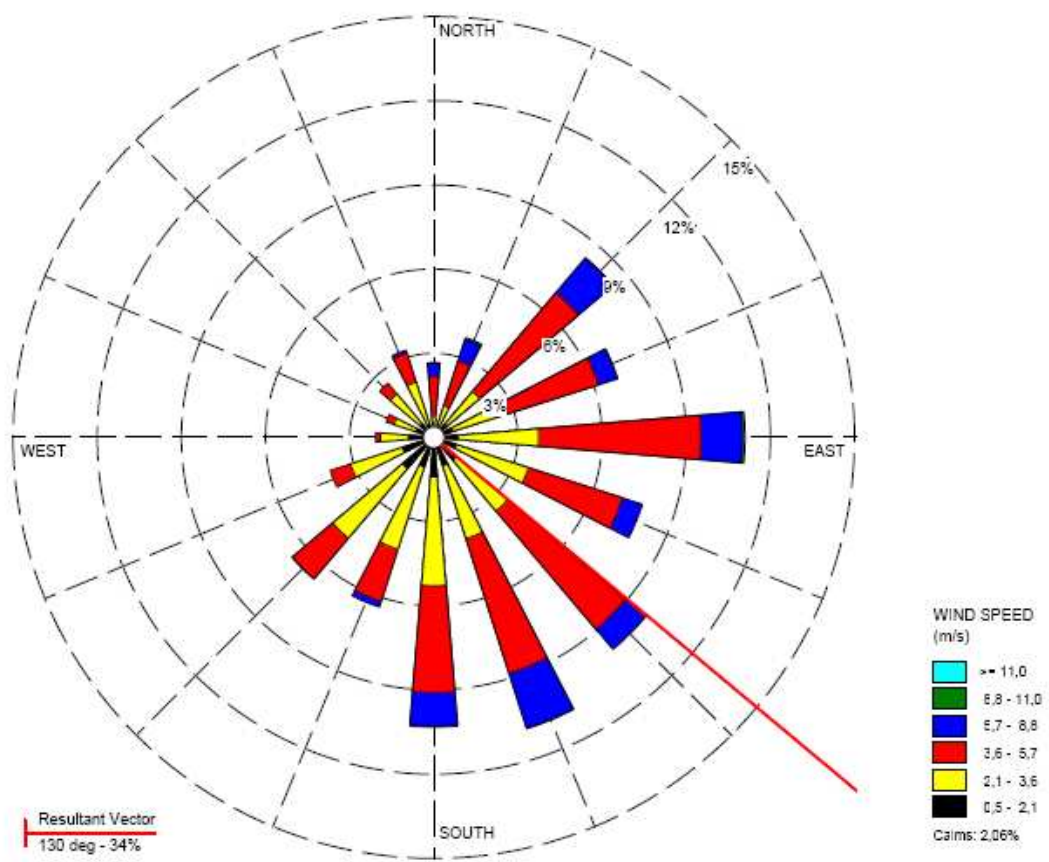

Figura 3.8: Similar a figura anterior, porém para as estações de inverno. 


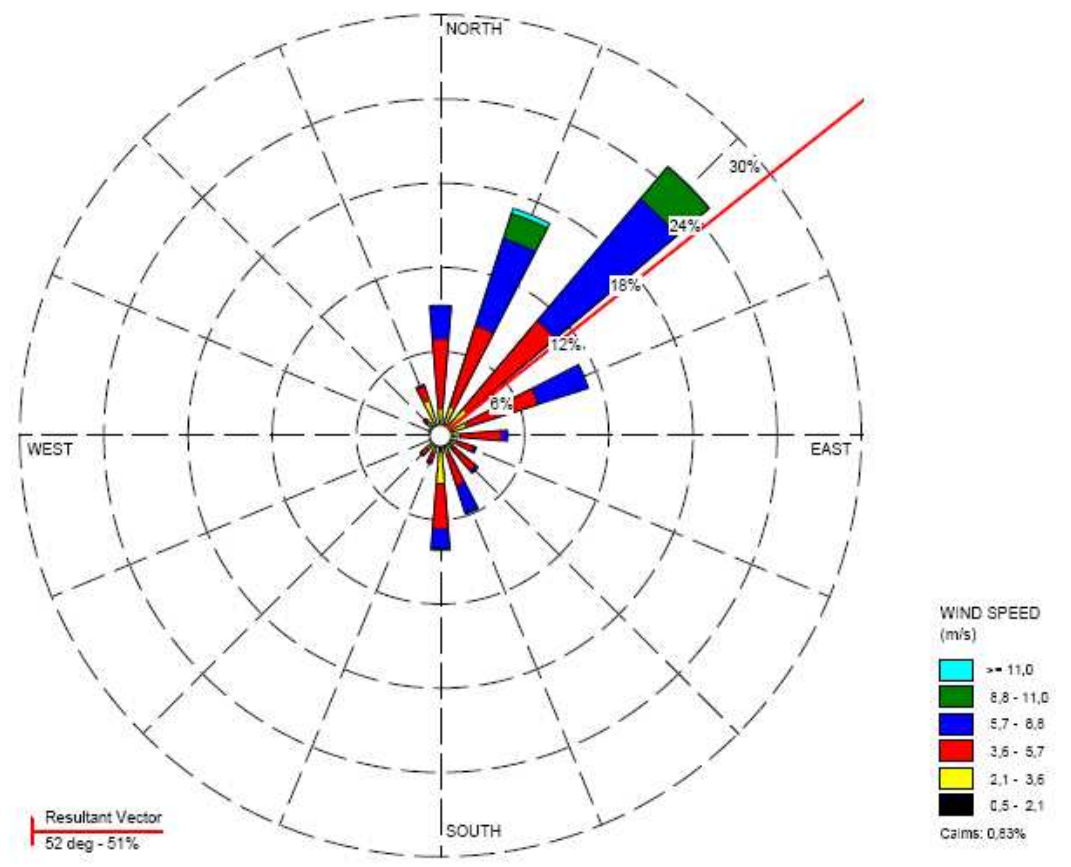

Figura 3.9: Similar a figura anterior, porém para as estações de primavera.

Após a inversão no sentido dos ventos e alinhamento com a costa, os dados foram filtrados, através de um fltro passa baixa, na freqüência inercial e decompostos nas componentes longitudinal e transversal. Na tabela 3.5 estão tabulados as médias, os desvios padrões e os valores máximos para as componentes longitudinal (VL) e transversal (VT) do vento para cada um dos três anos de estudo. As séries temporais das componentes para cada um dos anos de monitoramento são apresentadas nas figuras 3.10 à 3.17 . Na linha tracejada, estão plotados os valores destas componentes filtrados no período inercial local através de um filtro Lanczos-Cosseno.

De forma geral a componente longitudinal do vento apresentou maiores intensidades do que a componente transversal em todo o período observado.

A componente longitudinal filtrada possuiu valores negativos em $68 \%$ das medições, devido a predominância dos ventos de nordeste, porém nota-se que os valores tornamse positivos de forma muito rápida em várias ocasiões, como no período compreendido entre os dias 03/09/2002 e 02/10/2002. Esta mudança no sentido dos ventos esta associada com a passagem de frentes na região. 
A figura 3.13, possui um diagrama que mostra a passagens de frentes ao longo da costa brasileira para o mês de Setembro de 2002. Através do mesmo percebemos que quatro frentes frias chegaram ao litoral do sudeste brasileiro no mês de Setembro o que gerou quatro mudanças no sentido dos ventos longitudinais (Figura 3.10). Deve-se notar que muitas vezes uma frente fria permanece vários dias sobre a região (Figura 3.14) o que gera uma longa reversão no sentido do vento, como observado entre os dias 22/05/2002 e 30/05/2002 (Figura 3.10).

Observando os primeiros dias do mês de maio de 2002 nas figuras de distribuição de frentes e na série temporal do vento longitudinal, notamos que, como dito anteriormente, não é necessário uma frente chegar à região para que haja uma inversão no sentido do vento. Nestes dias a frente fria se deslocou apenas até a região de Cabo Frio (Figura 3.14), mas mesmo assim houve uma alteração no sentido do vento (Figura 3.10).

A componente transversal do vento filtrado, possui velocidades negativas em $71 \%$ das ocorrências, demonstrando a importância secundaria dos ventos provenientes do continente. Através das séries temporais da componente transversal nota-se uma oscilação em maior freqüência que a componente longitudinal do vento.

Na tabela 3.5 estão tabulados as médias, os desvios padrões, os valores máximos positivos e negativos e a freqüência de ocorrência média de eventos positivos e negativos para as componentes longitudinal e transversal do vento. Para o cálculo destas estatísticas foram usados os dados na banda sub-inercial, para cada um dos três anos de estudo.

Através da tabela percebemos que a média anual da componente longitudinal do vento possui valores negativos em todos os anos, porém esta média vai adquirindo valores mais positivos (menores intensidades absolutas) ao longo do período de estudo, fato este associado ao aumento da freqüência dos ventos positivos (de SW) no mesmo período. Este mesmo fator explica a redução dos valores máximos positivos e aumento dos valores máximos negativos ao longo do período. O desvio padrão se 
manteve relativamente constante ao longo do estudo, sendo em média duas vezes maior do que a média.

A intensidade da componente transversal do vento se manteve relativamente constante durante o período de monitoramento, apresentando um pequeno aumento no ano de 2003. O mesmo aconteceu com os valores máximos positivos e negativos. O desvio padrão diminui entre o ano de 2002 e 2004, demonstrando uma menor variabilidade desta componente do vento ao longo do período de estudo. Houve uma diminuição na freqüência dos ventos transversais positivos (de Oeste), fato este associado a maior porcentagem de ocorrência de ventos N (tabela 3.1).

Tabela 3.5: Estatísticas anuais da banda sub-inercial dos dados de campo vento. Média $=$ Média anual $\left(\mathrm{m} . \mathrm{s}^{-1}\right)$, Desvio $=$ Desvio padrão $\left(\mathrm{m} . \mathrm{s}^{-1}\right)$, Max. $\mathrm{P}=$ Máximo valor positivo observado $\left(\mathrm{m} . \mathrm{s}^{-1}\right)$, Max. $\mathrm{N}=$ Máximo valor negativo observado $\left(\mathrm{m} . \mathrm{s}^{-1}\right)$, Freq. $\mathrm{P}=$ Porcentagem total de eventos positivos(\%), Freq. $\mathrm{N}=$ Porcentagem total de eventos negativos $(\%)$.

\begin{tabular}{|l|c|c|c|c|c|c|}
\hline \multicolumn{7}{|c|}{ Componente Longitudinal do Vento } \\
\hline Ano & Média & Desvio & Max. P & Max. N & Freq. P. & Freq N. \\
\hline $\mathbf{2 0 0 2}$ & $-1,95$ & 2,98 & 6,58 & $-7,72$ & 25,78 & 74,22 \\
\hline $\mathbf{2 0 0 3}$ & $-1,41$ & 2,99 & 6,46 & $-8,19$ & 33,77 & 66,23 \\
\hline $\mathbf{2 0 0 4}$ & $-1,17$ & 2,88 & 5,67 & $-8,25$ & 36,13 & 63,87 \\
\hline \hline \multicolumn{7}{|c|}{ Componente Transversal do Vento } \\
\hline Ano & Média & Desvio & Max. P & Max. N & Freq. P. & Freq N. \\
\hline $\mathbf{2 0 0 2}$ & $-0,90$ & 1,91 & 3,83 & $-5,34$ & 33,15 & 66,84 \\
\hline $\mathbf{2 0 0 3}$ & $-1,07$ & 1,69 & 3,00 & $-5,85$ & 27,30 & 72,70 \\
\hline $\mathbf{2 0 0 4}$ & $-0,93$ & 1,52 & 3,70 & $-5,28$ & 26,11 & 73,89 \\
\hline
\end{tabular}



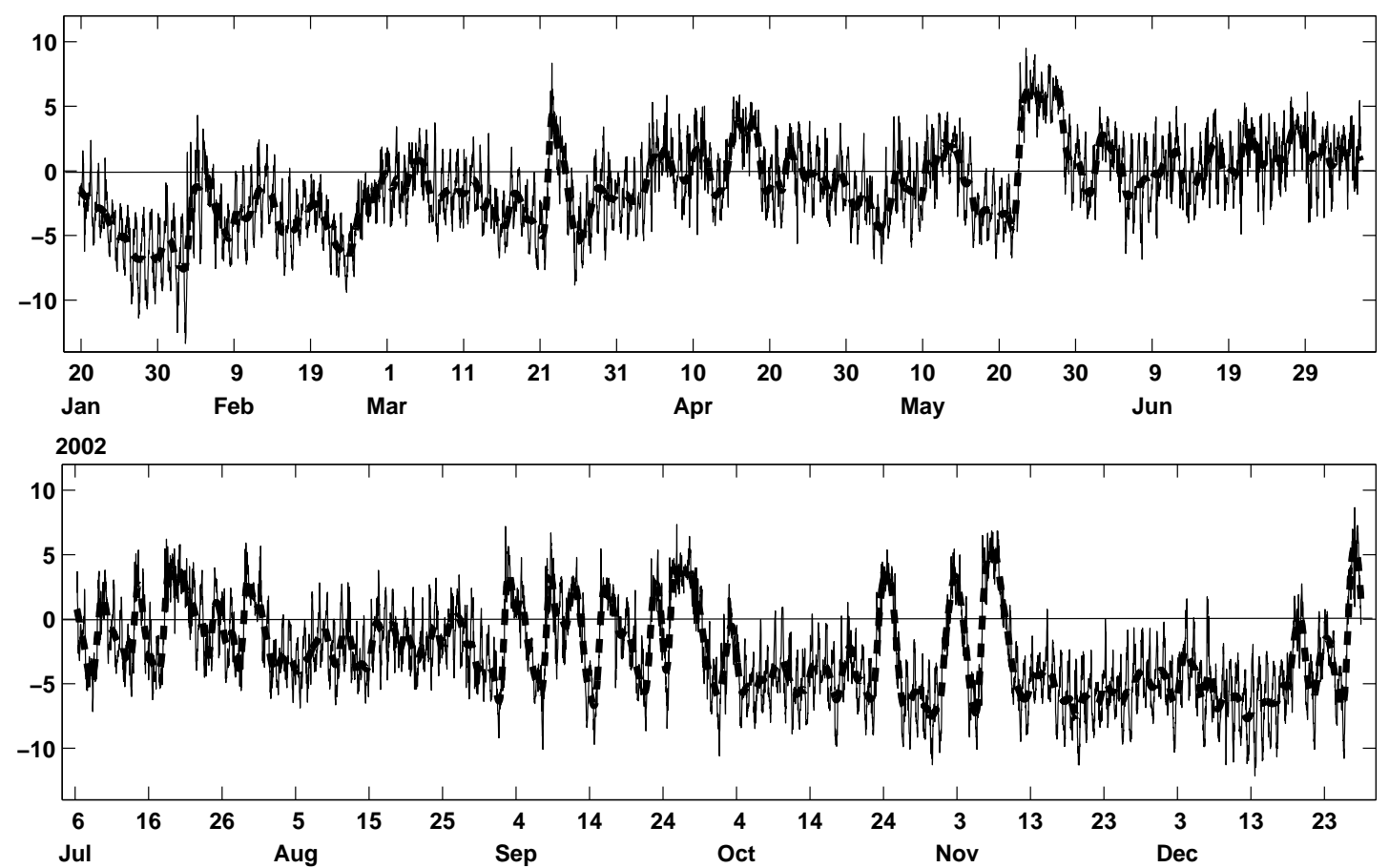

Figura 3.10: Série temporal das velocidades da componente do vento longitudinal à linha de costa (VL) para o ano de 2002 . A linha tracejada mostra a série filtrada no período inercial ( $\mathrm{T}=39 \mathrm{hs}$ ). Intensidades em $\left(\mathrm{m} \cdot \mathrm{s}^{-1}\right.$ ) 

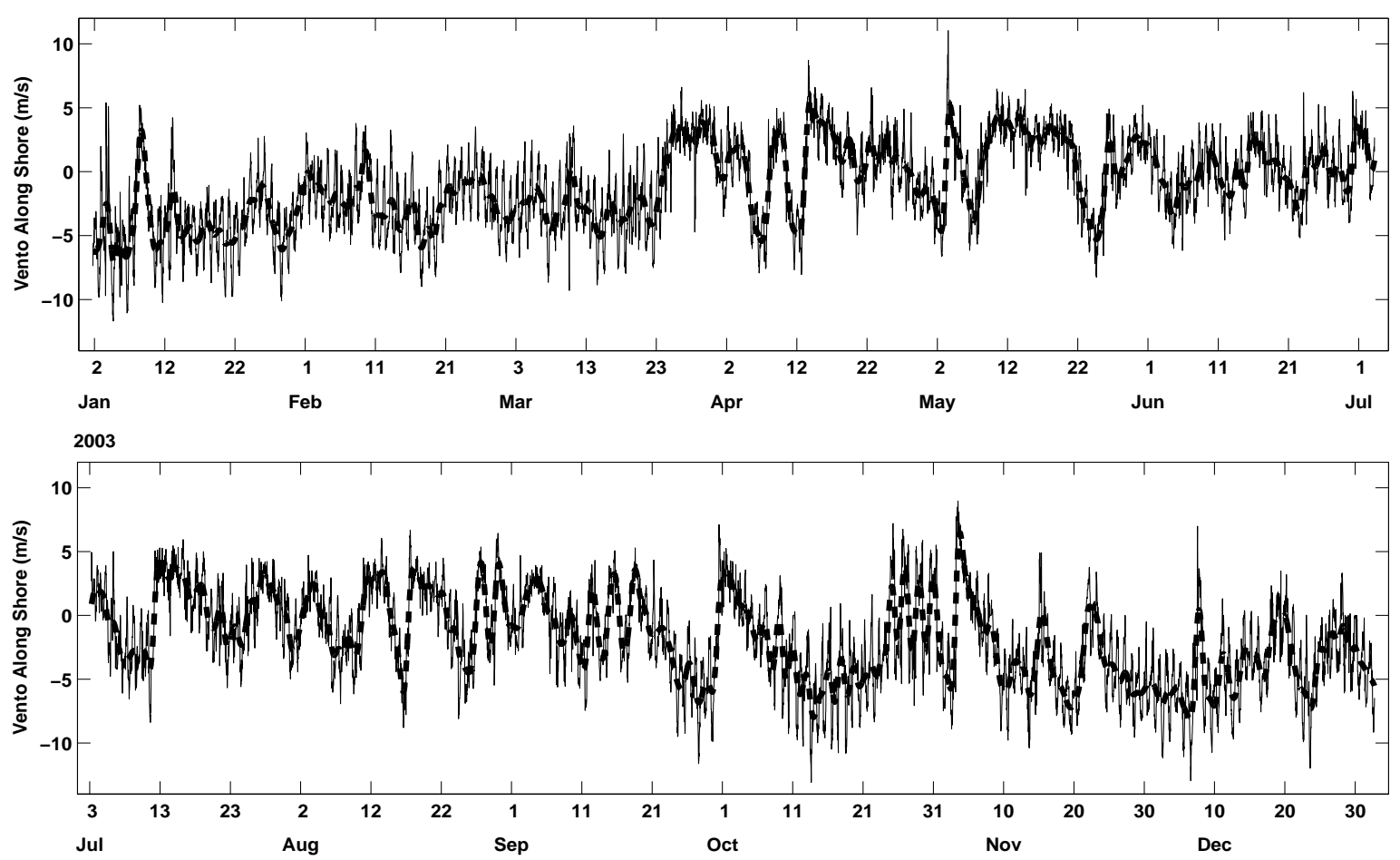

Figura 3.11: Similar a figura anterior, porém para o ano de 2003. Intensidades em $\left(\mathrm{m} \cdot \mathrm{s}^{-1}\right)$.
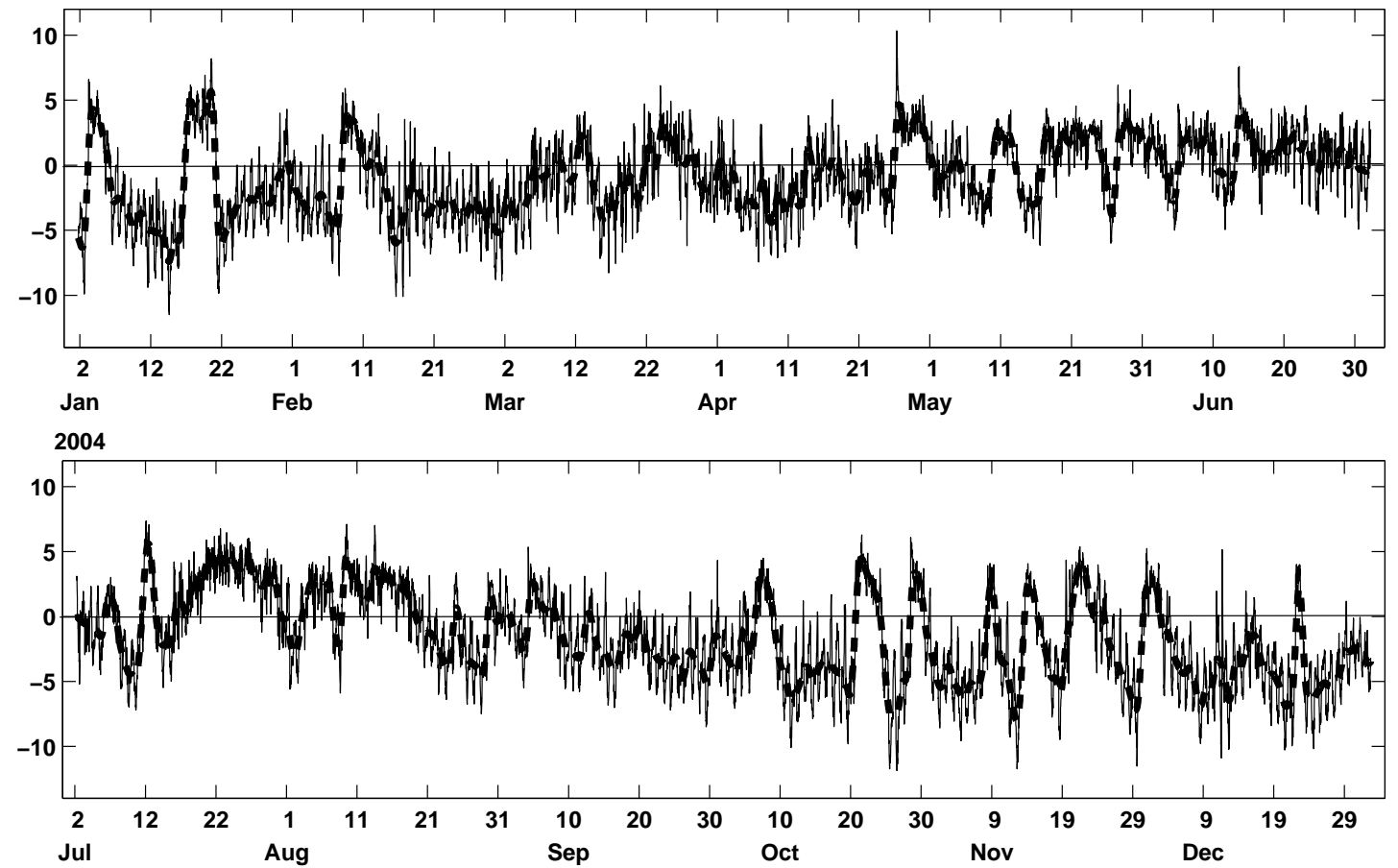

Figura 3.12: Similar a figura anterior, porém para o ano de 2004 .Intensidades em $\left(\mathrm{m} . \mathrm{s}^{-1}\right)$. 


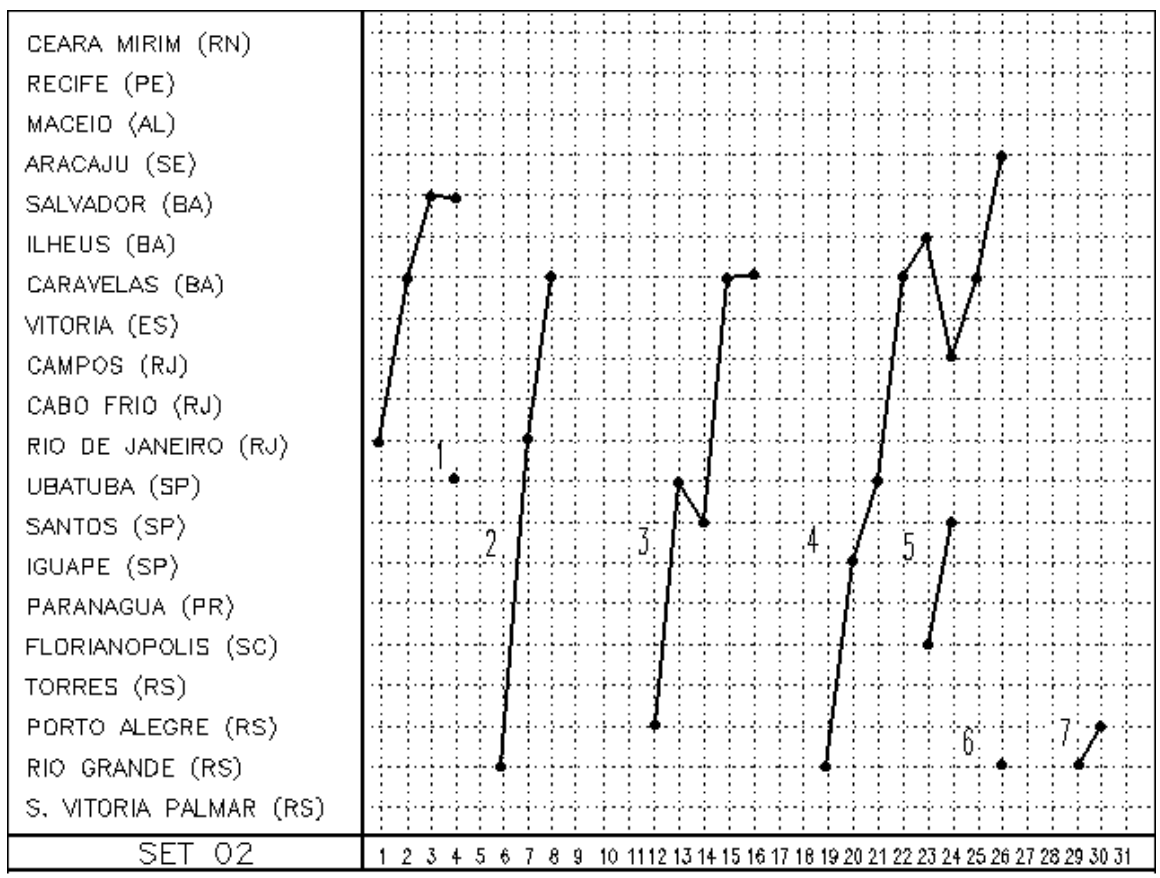

Figura 3.13: Diagrama mostrando a evolução das frentes frias ao longo dà costa do Brasil para o mês de Setembro de 2002. Fonte: Boletins Climanálise do INPE-CPTEC, do período de Setembro de 2002.

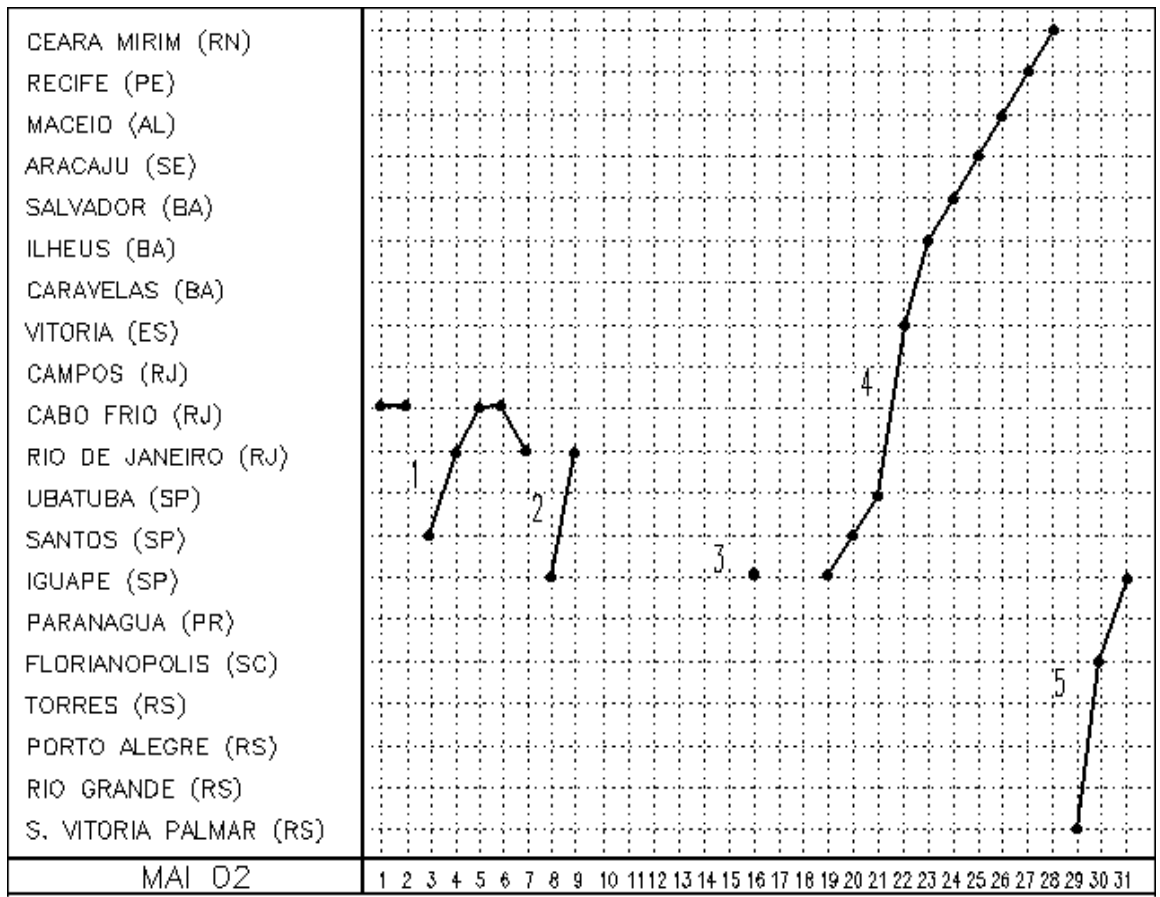

Figura 3.14: Similar a figura anterior, porém para o mês de Maio de 2002. 

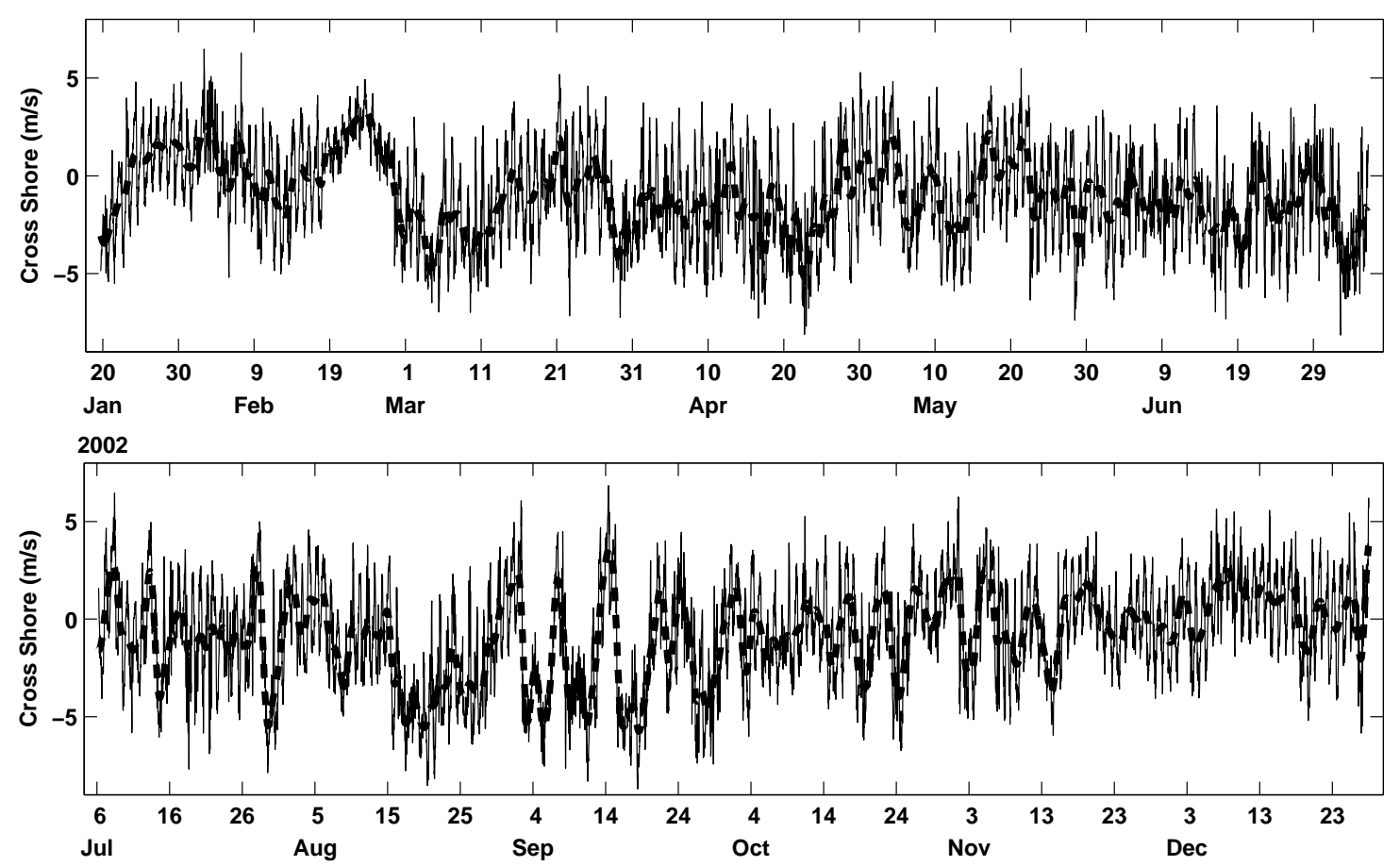

Figura 3.15: Série temporal das velocidades da componente do vento transversal à linha de costa (v) para o ano de 2002. Intensidades em $\left(\mathrm{m} . \mathrm{s}^{-1}\right)$. A linha tracejada demonstra a série filtrada no período inercial ( $\mathrm{T}=39 \mathrm{hs}$ ).

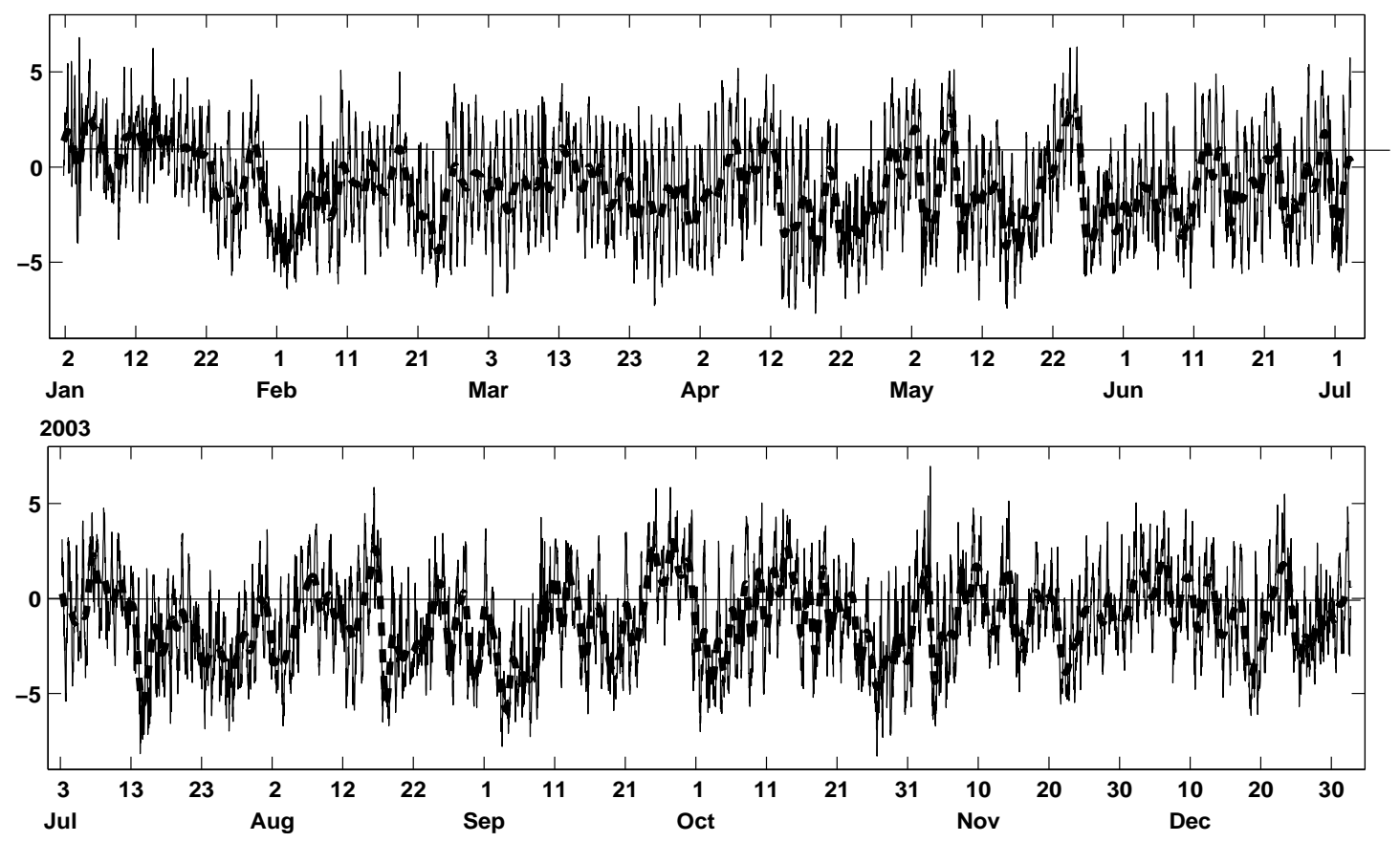

Figura 3.16: Similar a figura anterior, porém para o ano de $2003\left(\mathrm{~m} . \mathrm{s}^{-1}\right)$. 

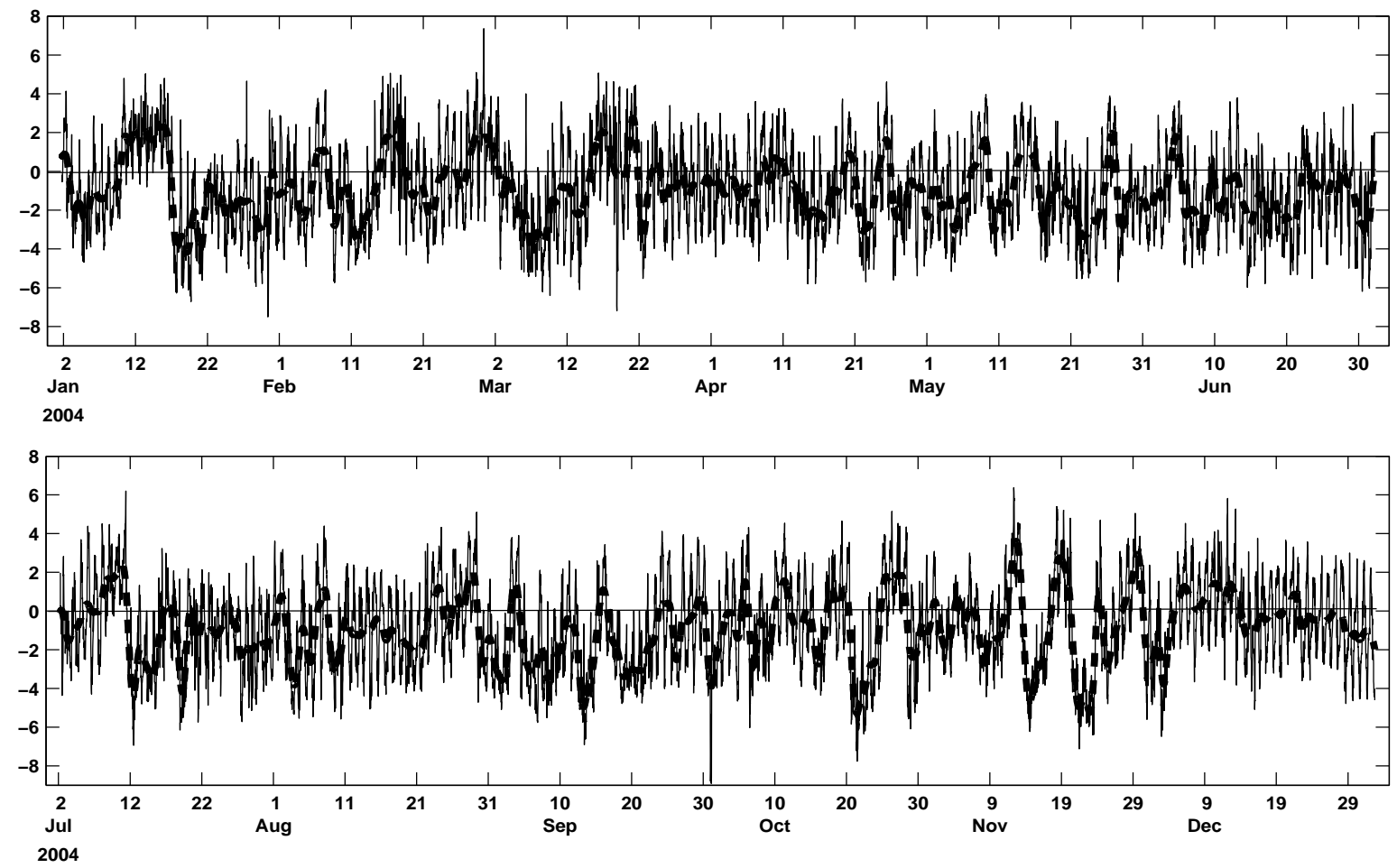

Figura 3.17: Similar a figura anterior, porém para o ano de $2004\left(\mathrm{~m}_{\mathrm{s}} \mathrm{s}^{-1}\right)$. 
As séries temporais com as médias mensais da componente longitudinal à costa, e seus respectivos desvios padrões, ao longo do período de monitoramento, estão expostas na figura 3.18. Observa-se que existe um ciclo anual demarcado com uma amplitude média de 4,0 m.s ${ }^{-1}$. As maiores velocidades médias ocorrem durante os meses de dezembro, com valores em torno de $-4,0 \mathrm{~m} . \mathrm{s}^{-1}$ enquanto as menores velocidades médias estão presentes nos meses de julho, com valores em torno de 0,5 $\mathrm{m} \cdot \mathrm{s}^{-1}$.

A componente transversal à costa (Figura 3.19), não possui um padrão anual demarcado. As intensidades médias desta componente apresentaram valores entre $-2,0 \mathrm{~m} . \mathrm{s}^{-1}$ e $-0,5 \mathrm{~m} . \mathrm{s}^{-1}$, com exceção dos meses de fevereiro e dezembro de 2002 , quando os valores médios chegaram a $0,8 \mathrm{~m} \cdot \mathrm{s}^{-1}$ e $0,5 \mathrm{~m} \cdot \mathrm{s}^{-1}$, respectivamente.

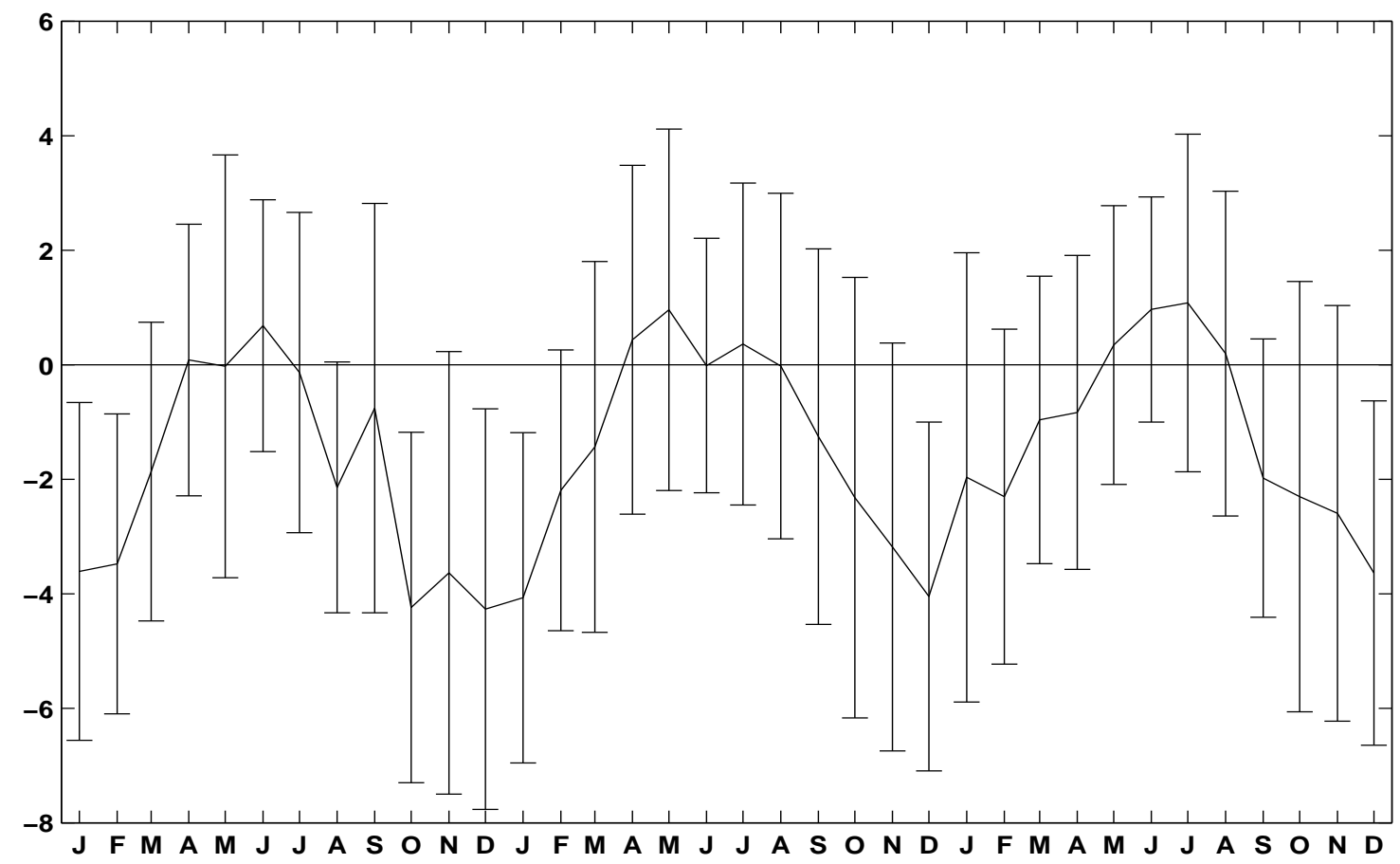

Figura 3.18: Médias Mensais e Desvios Padrões das velocidades da componente do vento longitudinal à linha de costa (v) para todo o período de estudo $\left(\mathrm{m} . \mathrm{s}^{-1}\right)$. 


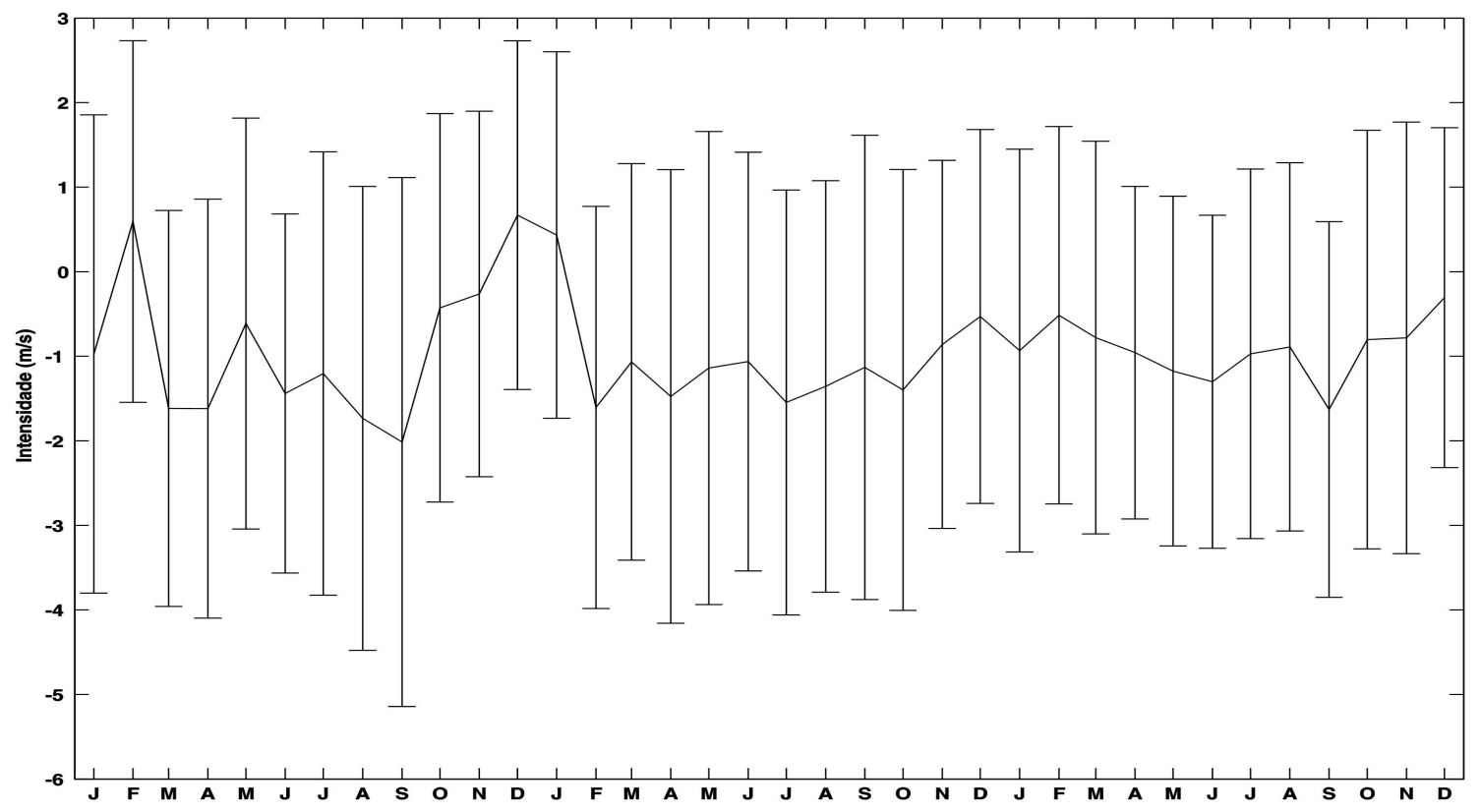

Figura 3.19: Médias e Desvios Padrões Mensais das velocidades da componente do vento transversal à linha de costa $(\mathrm{u})$ para todo o período de estudo $\left(\mathrm{m} . \mathrm{s}^{-1}\right)$.

Através dos resultados apresentados nesta seção, conclui-se que a circulação atmosférica local possui um padrão anual demarcado, o qual esta associado a posição da AAS. Este padrão anual atua principalmente sobre a componente longitudinal do vento, gerando uma alternância entre valores absolutos máximos no verão e mínimos no inverno. A direção predominante foi de nordeste com 13,5\% de ocorrência ao longo do período de observação, seguido pela direções sul com 9,7\%. As maiores velocidades ocorreram no mês de dezembro associadas a ventos de nordeste. As menores intensidades do vento ocorreram durante os meses de junho, sob a predominância de ventos de sul. Os ventos locais são afetados pela penetração de frentes frias e pelos VCAN, os quais inferem uma variabilidade anual ao sinal. Percebe-se que devido a um aumento na ocorrência dos ventos do quadrante sul, houve uma diminuição na intensidade dos ventos entre o período de 2002 e 2004. 


\subsection{Elevação do Nível do Mar:}

Nesta seção serão apresentados e discutidos os resultados da análise da variabilidade do nível do mar na região costeira de Caravelas. Para tanto, foram utilizadas séries temporais entre o período de janeiro de 2002 à janeiro de 2005, adquiridas pelos sensores de pressão instalados junto a cada um dos fundeios. Num primeiro momento serão determinados os principais constituintes de maré e o cálculo da sua importância na variação no nível do mar. A seguir será analisada a variabilidade sub-inercial do nível do mar e seus principais forçantes serão apresentados.

Um total de 45.135 dados de nível d'água foram gerados, representando uma taxa de recuperação de dados de $94 \%$. Nas tabelas 3.6 e 3.7 estão apresentados os resultados dos dez constituintes de maré mais significantes para a estação \#106 e \#506, respectivamente. As alturas de maré variaram entre um mínimo de 0,47 m e um máximo de 3,39 m. As marés registradas no canal de Sueste representam as maiores amplitudes da costa leste brasileira (Lessa and Cirano, 2006). Pereira et al. (2005) utilizaram-se de um modelo numérico para o estudo das marés barotrópicas e baroclínicas da região e também observaram uma amplificação local das constituintes M2 e S2. Esta amplificação pode estar sendo produzida pelas feições geomorfológicas locais (ilhas, canais, etc) que poderiam estar gerando alterações na onda de maré incidente na região. Este fato é observado em alguns locais do sul da Australia onde a Grande Barreira de Corais altera o onda de maré gerando amplificações locais (Griffin et al., 1987).

As amplitudes das duas maiores componentes de maré semi-diurna, M2 and S2, 
foram de aproximadamente 0,90 $\mathrm{m}$ e 0,70 $\mathrm{m}$ em ambas as estações, enquanto as componentes diurnas $\mathrm{O} 1 \mathrm{e} \mathrm{S1}$ apresentaram valores de 0,09 m e 0,05 m, respectivamente. Estes resultados estão bem próximos aos obtidos por Pereira et al. (2005).

As marés astronômicas previstas explicaram aproximadamente $96 \%$ da variabilidade do nível do mar na estação \#106 e 98\% na estação \#506. Este coeficiente de explicação foi calculado dividindo-se a variabilidade do sinal observado pela variabilidade do sinal previsto.

Como esperado, devido a proximidade das estações (aproximadamente 14,3 Km), não existem grandes diferenças entre os resultados encontrados para as constituintes de maré nas duas estações. A única ressalva esta relacionada ao décimo constituinte em importância.

Uma forma de se classificar o regime de marés em uma determinada região é através do número de forma (Nf), o qual nos permite calcular a importância relativa entre as componentes de maré semi-diurna e diurna. O mesmo pode ser obtida através da razão:

$$
N f=\frac{K 1+O 1}{M 2+S 2}
$$

Onde $\mathrm{K} 1$, $\mathrm{O} 1$ e M2, S2 representam as amplitudes dos principais componentes semi-diurnos e diurnos, respectivamente.

De acordo com o intervalo de variação do número adimensional Nf, a maré classifica-se em (Miranda et al., 2002):

- $0<\mathrm{Nf}<0,25$ - semi-diurna;

- $0,25<\mathrm{Nf}<1,5$ - mista com predominância semi-diurna;

- $1,25<\mathrm{Nf}<3,0$ - mista com predominância diurna;

- $\mathrm{Nf}>3,0$ - diurna; 
Os resultados obtidos para Nf, foram 0,12 e 0,11 para as estações \#106 e \#506, respectivamente. Através destes resultados a maré da região pode ser classificada como semi-diurna.

Tabela 3.6: Resultados da análise harmônica dos dados de elevação do nível do mar na estação \#106. Período em horas, Amplitudes e Erros de Amplitude em metros, Fase e Erro da fase em graus. Resultados de fase expressos em relação ao meridiano de Greenwich.

\begin{tabular}{|l|c|c|c|c|c|c|}
\hline Componente & Período & Sign. & Amp. & Erro Amp. & Fase & Erro Fase \\
\hline M2 & 12,42 & 431,27 & 0,893 & 0,0038 & 101,58 & 0,24 \\
\hline S2 & 12,00 & 213,02 & 0,368 & 0,0038 & 116,57 & 0,55 \\
\hline O1 & 25,84 & 82,24 & 0,091 & 0,0020 & 111,12 & 1,35 \\
\hline K1 & 23,92 & 78,67 & 0,055 & 0,0025 & 177,65 & 2,26 \\
\hline M4 & 6,21 & 74,62 & 0,034 & 0,0016 & 252,76 & 3,39 \\
\hline N2 & 12,66 & 62,51 & 0,147 & 0,0039 & 102,16 & 1,63 \\
\hline K2 & 11,96 & 61,47 & 0,111 & 0,0037 & 108,90 & 1,77 \\
\hline MN4 & 6,27 & 42,75 & 0,022 & 0,0019 & 216,45 & 5,06 \\
\hline 2MS6 & 4,09 & 34,21 & 0,012 & 0,0016 & 234,20 & 6,85 \\
\hline SK3 & 7,99 & 32,45 & 0,018 & 0,0029 & 230,31 & 7,10 \\
\hline
\end{tabular}

Tabela 3.7: Similar a tabela anterior, porém para os dados da estação \#506.

\begin{tabular}{|l|c|c|c|c|c|c|}
\hline Componente & Período & Sign. & Amp. & Erro Amp. & Fase & Erro Fase \\
\hline M2 & 12,42 & 401,45 & 0,900 & 0,0043 & 99,66 & 0,25 \\
\hline S2 & 12,00 & 192,41 & 0,380 & 0,0040 & 113,84 & 0,59 \\
\hline O1 & 25,84 & 82,84 & 0,091 & 0,0017 & 110,42 & 1,33 \\
\hline K1 & 23,92 & 80,67 & 0,054 & 0,0022 & 176,71 & 2,19 \\
\hline M4 & 6,21 & 73,45 & 0,044 & 0,0026 & 252,73 & 3,44 \\
\hline N2 & 12,66 & 68,90 & 0,147 & 0,0045 & 101,52 & 1,47 \\
\hline K2 & 11,96 & 58,57 & 0,115 & 0,0037 & 106,57 & 1,82 \\
\hline MN4 & 6,27 & 43,97 & 0,028 & 0,0024 & 216,29 & 4,92 \\
\hline 2MS6 & 4,09 & 37,55 & 0,011 & 0,0013 & 242,05 & 6,44 \\
\hline P1 & 27,39 & 29,98 & 0,019 & 0,0020 & 172,32 & 5,75 \\
\hline
\end{tabular}

Nas figuras 3.20 à 3.22 estão apresentadas as séries temporais do sinal da elevação do nível do mar para a estação \#106, enquanto as figuras 3.23 à 3.25 as séries do sinal da estação \#506. A linha pontilhada nas figuras, representa a série filtrada no 
período inercial. É possível observar nos resultados a modulação quinzenal das marés devido as fases da Lua. Os sinais filtrados salientam a variabilidade sub-inercial do nível médio. Apesar desta da banda explicar no máximo 4\% da variabilidade do nível do mar, a mesma é responsável pelas características não determinísticas deste campo.

Através dos resultados podemos observar oscilações próximas a $40 \mathrm{~cm}$ em varias ocasiões. Estas oscilações estão em grande parte associadas à ação da componente longitudinal dos ventos sobre a superfície marinha, que através do transporte de Ekman geram um empilhamento ou rebaixamento de água junto à costa.

Como esperado, o rebaixamento do nível médio do mar esta associado a ventos de N-NE, enquanto que a elevação do nível médio ocorre com ventos de S-SE. Esta correlação entre o vento e as oscilação do nível do mar pode ser observado em diversas ocasiões quando se comparam as séries temporais do vento paralelo à costa (Figuras 3.10 a 3.12) com as séries de elevação.

Como exemplos de empilhamento de água junto a costa associados a ventos podemos citar o dia 4 de fevereiro de 2002, quando um vento de $2 \mathrm{~m} \cdot \mathrm{s}^{-1}$ produziu uma elevação de $10 \mathrm{~cm}$ em ambas as estações ou os dias 13 a 22 de abril de 2003 quando um vento de $4 \mathrm{~m} \cdot \mathrm{s}^{-1}$, gerou uma elevação de $30 \mathrm{~cm}$.

Já para os casos de rebaixamento do nível do mar, podemos citar os eventos dos dias 21 de julho de 2002 e 17 de janeiro de 2004 , onde ventos de -7 e -5 m.s ${ }^{-1}$ deram origem a reduções no nível médio do mar de aproximadamente $40 \mathrm{~cm}$ e $30 \mathrm{~cm}$.

As grandes falhas existentes nas séries no mês de setembro de 2002 e entre os dias 18 de outubro e 15 de novembro do mesmo ano, estão relacionadas a falhas do equipamento de registro dos dados.

De forma geral, o coeficiente de correlação da série temporal do nível médio do mar com a componente sub-inercial do vento paralela à costa (v) apresenta um coeficiente de 0,76 na estação \#106 e 0,71 na estação \#506. Esta diferença no coeficiente de correlação se deve ao fato da estação \#106 estar mais confinada dentro 
do canal.

As estatísticas anuais do campo de elevação do nível do mar para as estações \#106 e \#506 estão apresentados nas tabelas 3.8 e 3.9. Para o cálculo destas estatísticas foi utilizado a componente sub-inercial dos dados. Infelizmente devido as mudanças na posição das estações, aparentemente mais freqüentes na \#106, os valores médios anuais, bem como as porcentagens de elevações positivas e negativas, parecem estar sub-estimados. Fica evidente que as oscilações são negativas na maior parte do período observado devido a maior ocorrência de ventos de nordeste, que favorecem um transporte de Ekman em direção a mar aberto e rebaixamente do nível do mar junto à costa.
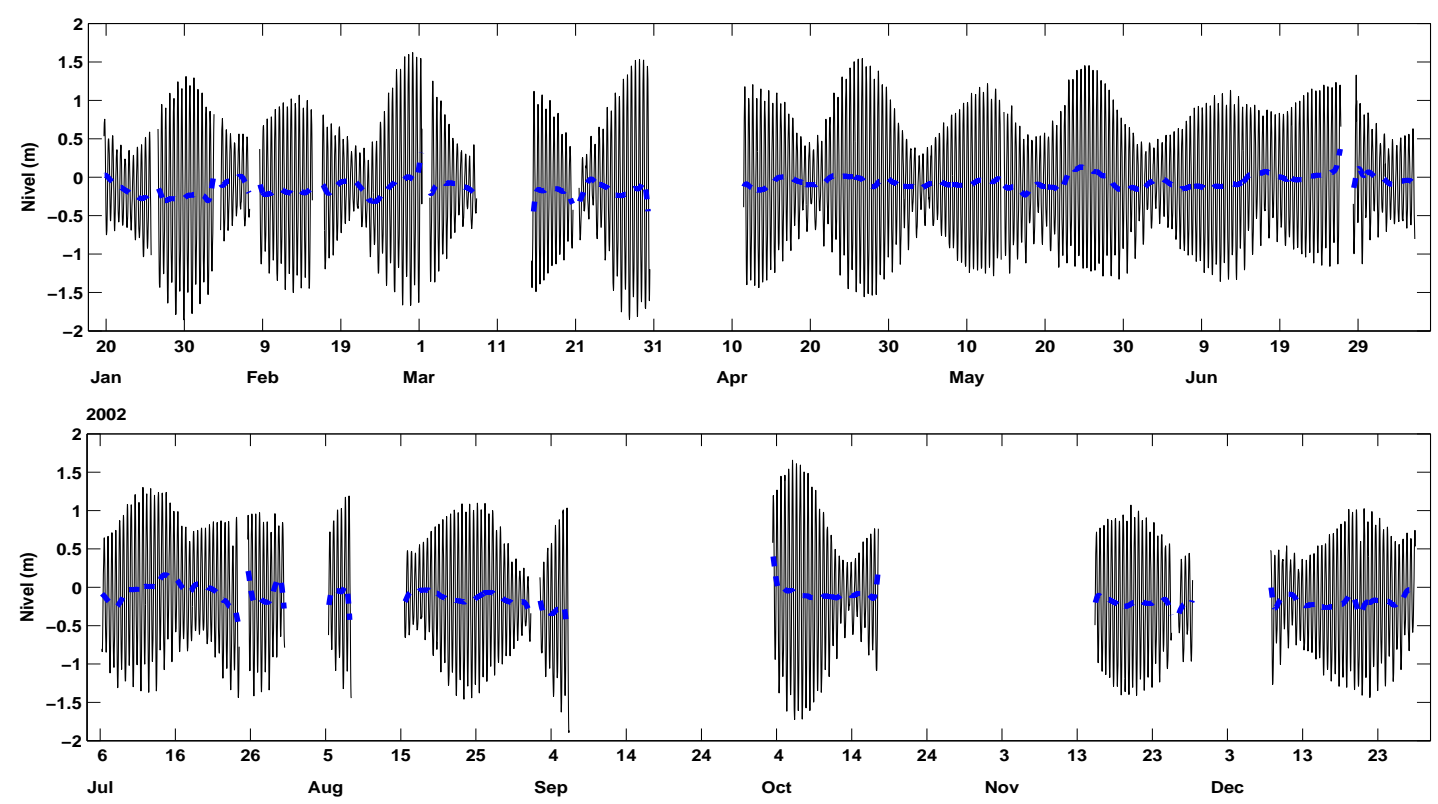

Figura 3.20: Série temporal da elevação do nível do mar para a estação \#106 para o ano de 2002. A linha tracejada demonstra a série filtrada no período inercial (m). 

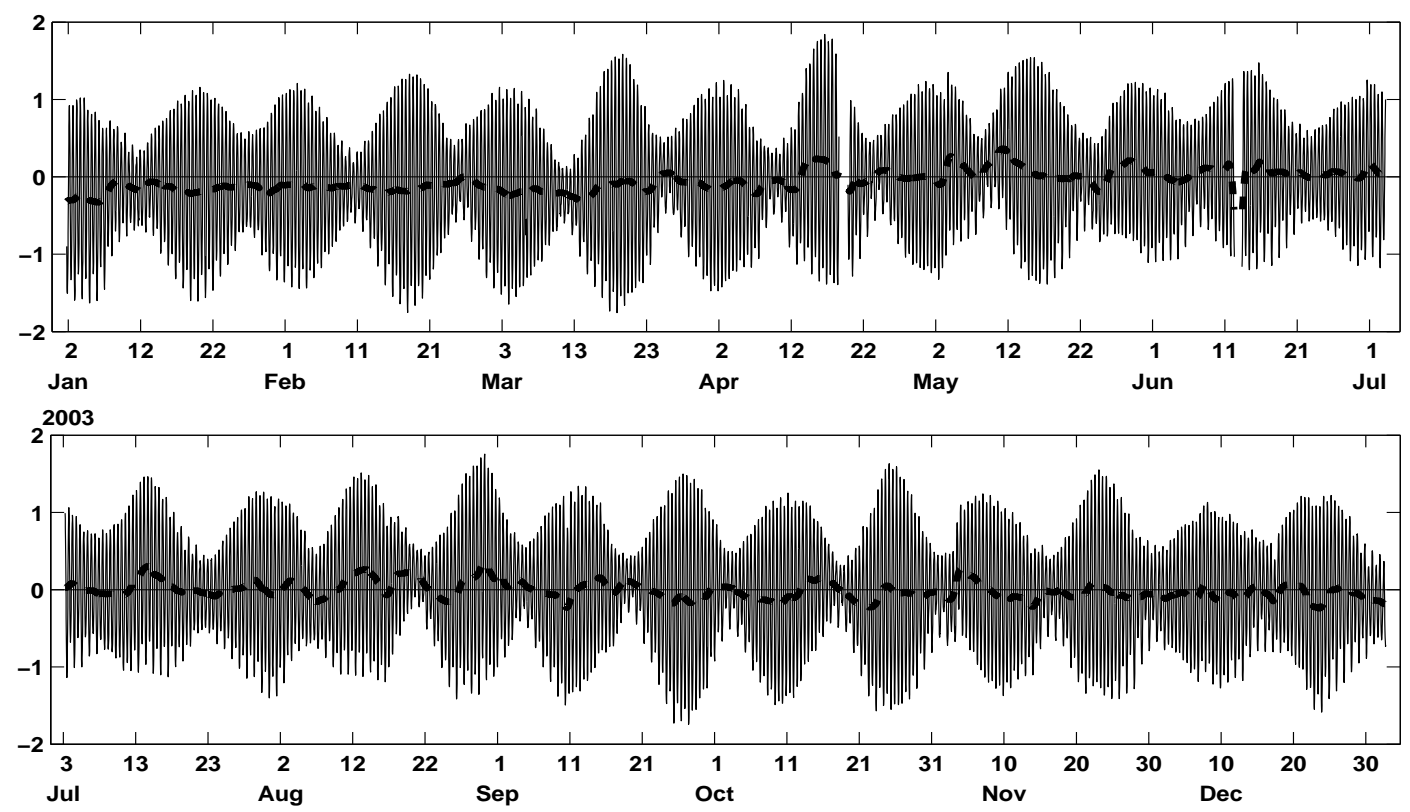

Figura 3.21: Similar a figura anterior, porém para o ano $2003(\mathrm{~m})$.
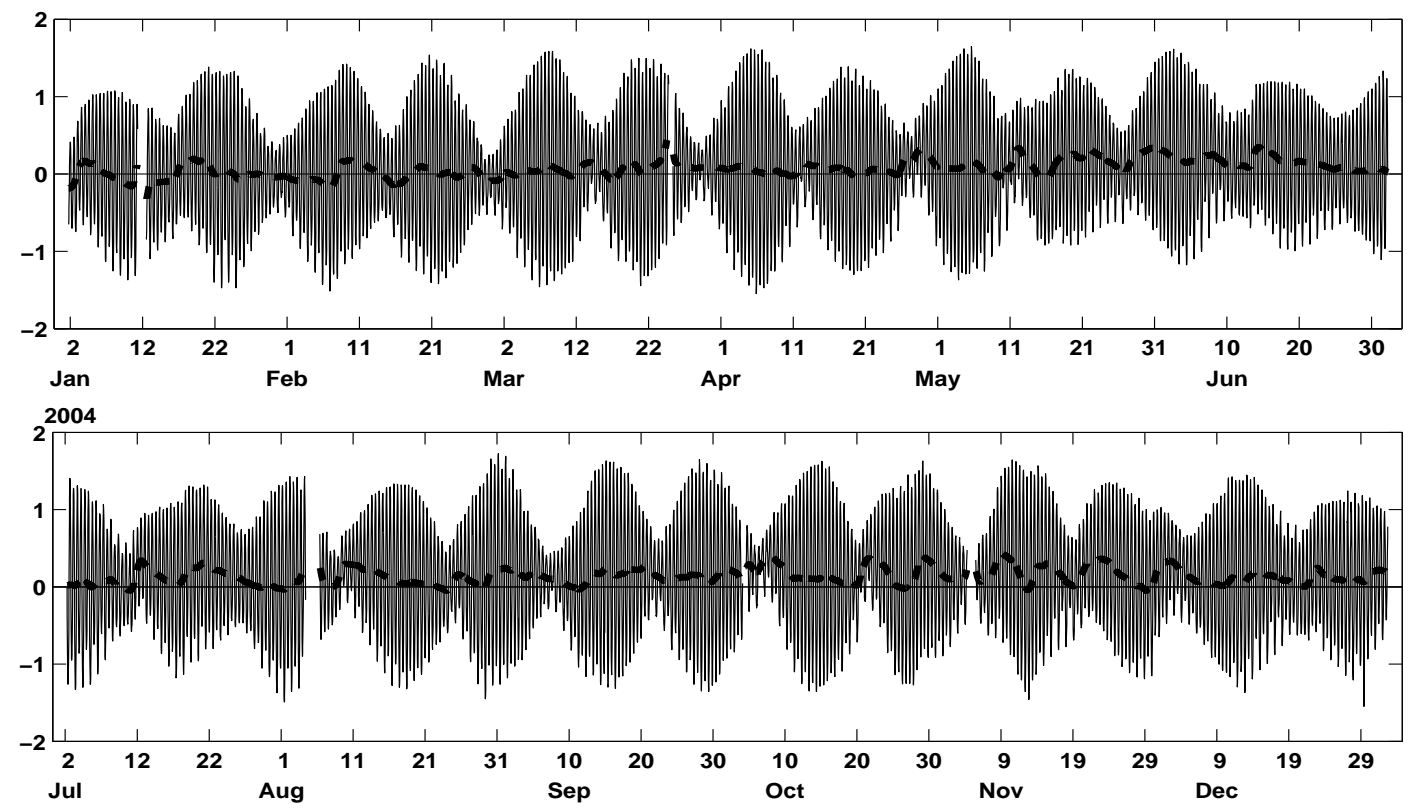

Figura 3.22: Similar a figura anterior, porém para o ano 2004 (m). 

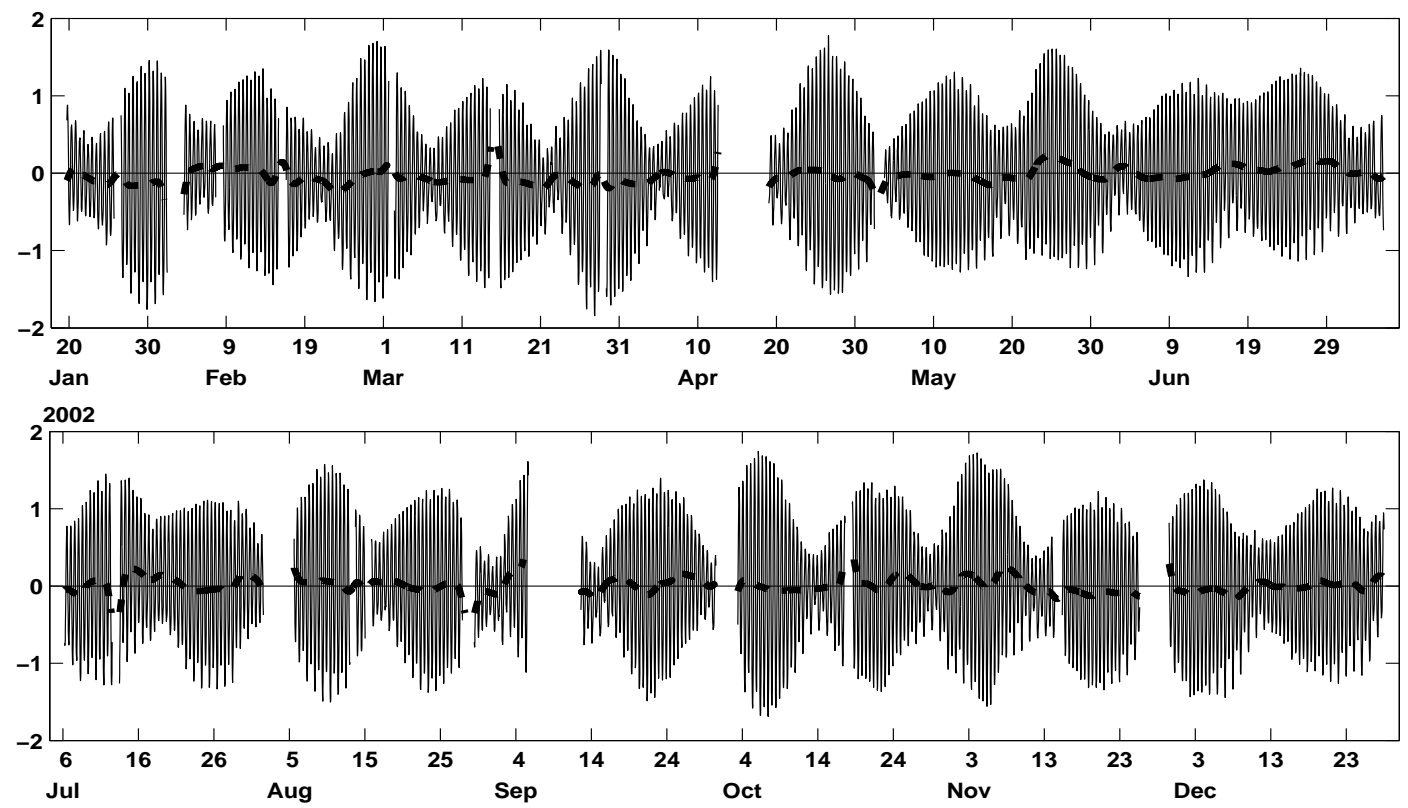

Figura 3.23: Série temporal do nível do mar para a estação \#506 para o ano de 2002. A linha tracejada demonstra a série filtrada no período inercial (m).

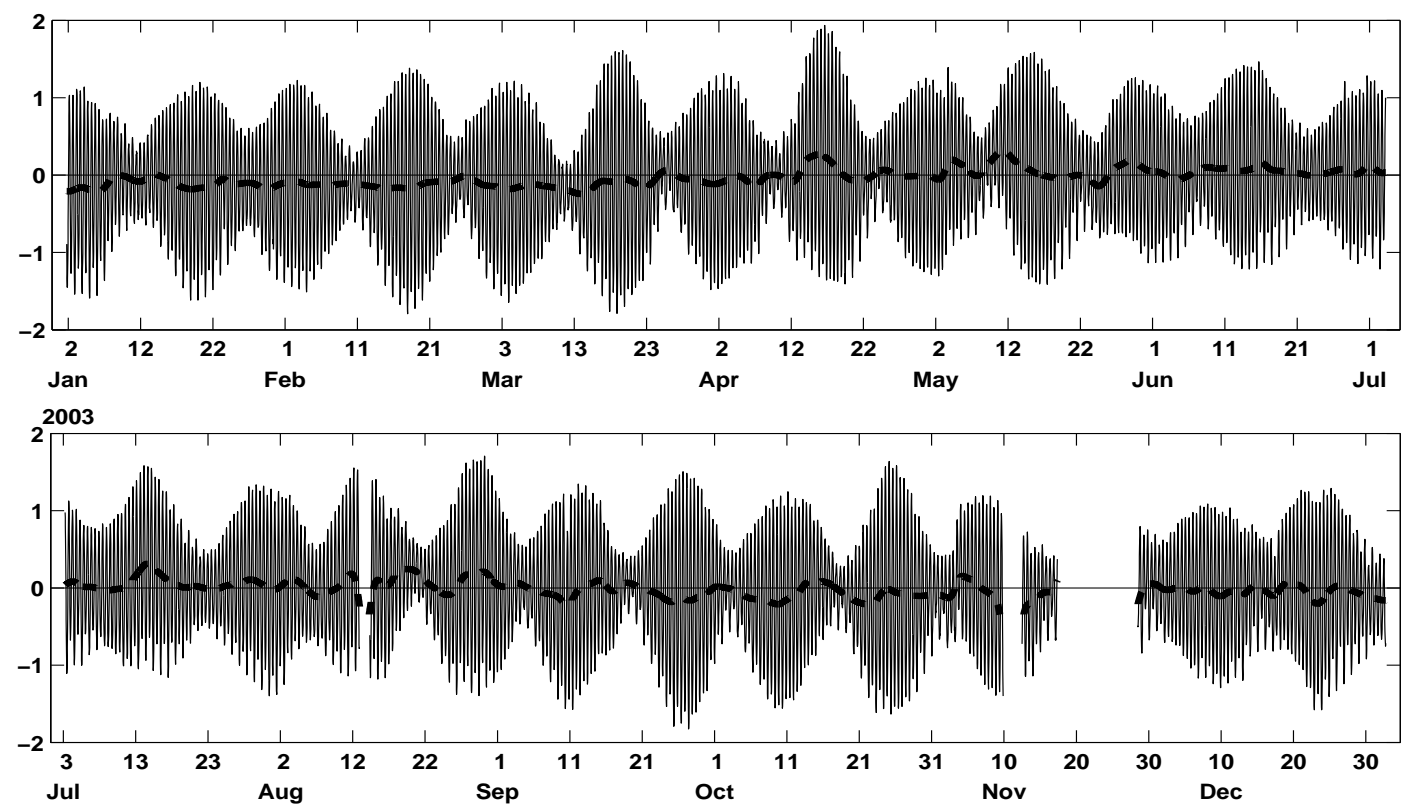

Figura 3.24: Similar a figura anterior, porém para o ano $2003(\mathrm{~m})$. 


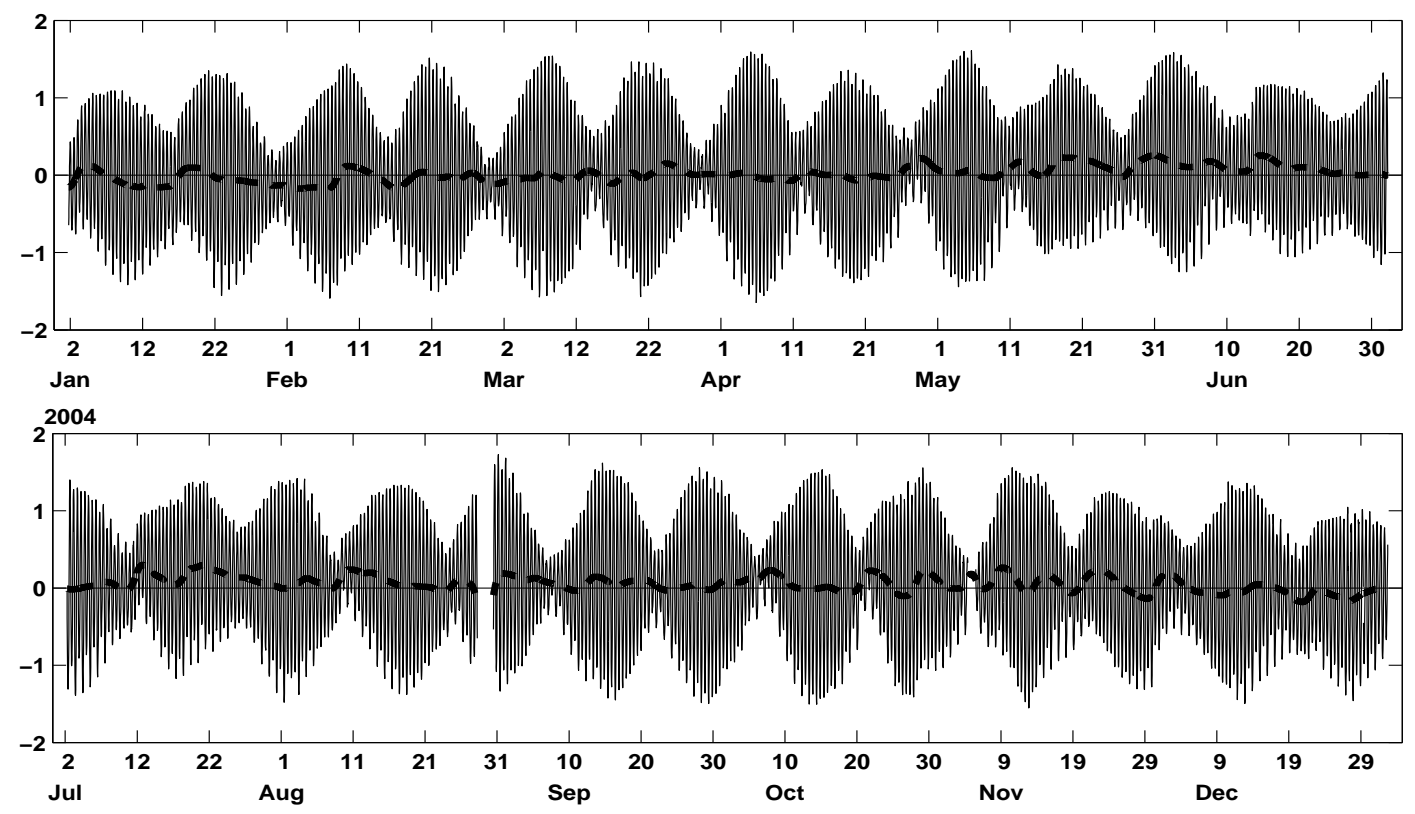

Figura 3.25: Similar a figura anterior, porém para o ano de 2004 (m).

Tabela 3.8: Estatísticas anuais da banda sub-inercial dos dados de elevação do nível do mar para estação \#106. Média = Média anual $(\mathrm{m})$, Desvio = Desvio padrão $(\mathrm{m})$, Max. $\mathrm{P}=$ Máximo valor positivo Observado $(\mathrm{m})$, Max. $\mathrm{N}=$ Máximo valor negativo observado $(\mathrm{m})$, Freq. $\mathrm{P}=$ Porcentagem total de eventos positivos(\%), Freq. $\mathrm{N}=$ Porcentagem total de eventos negativos (\%).

\begin{tabular}{|c|c|c|c|c|c|c|}
\hline \multicolumn{7}{|c|}{ Elevação do Nível do Mar } \\
\hline Ano & Média & Desvio & Max. P & Max. N & Freq. P & Freq. N \\
\hline $\mathbf{2 0 0 2}$ & $-0,01$ & 0,11 & 0,39 & $-0,40$ & 29,96 & 71,04 \\
\hline $\mathbf{2 0 0 3}$ & $-0,00$ & 0,12 & 0,37 & $-0,39$ & 36,21 & 64,79 \\
\hline $\mathbf{2 0 0 4}$ & $-0,01$ & 0,11 & 0,40 & $-0,36$ & 43,37 & 57,63 \\
\hline
\end{tabular}

Tabela 3.9: Idem tabela anterior, porém para estação \#506

\begin{tabular}{|c|c|c|c|c|c|c|}
\hline \multicolumn{7}{|c|}{ Elevação do Nível do Mar } \\
\hline Ano & Média & Desvio & Max. P & Max. N & Freq. P & Freq. N \\
\hline $\mathbf{2 0 0 2}$ & $-0,01$ & 0,10 & 0,35 & $-0,35$ & 36,01 & 53,99 \\
\hline $\mathbf{2 0 0 3}$ & $-0,03$ & 0,11 & 0,32 & $-0,35$ & 41,52 & 58,48 \\
\hline $\mathbf{2 0 0 4}$ & $-0,02$ & 0,10 & 0,30 & $-0,21$ & 52,62 & 47,38 \\
\hline
\end{tabular}

Nas figuras 3.26 e 3.27 estão apresentadas as médias mensais e os desvios padrões 
da elevação do nível do mar, das estações \#106 e \#506, respectivamente. Nota-se que assim como campo de vento as oscilações possuem um ciclo sazonal de um ano com aproximadamente $22 \mathrm{~cm}$ de altura. Níveis médios mais elevados ocorrem nos meses de outono e inverno (quando predominam ventos de S-SE), e níveis médios mais baixos ocorrem na primavera e verão (quando predominam ventos de N-NE).

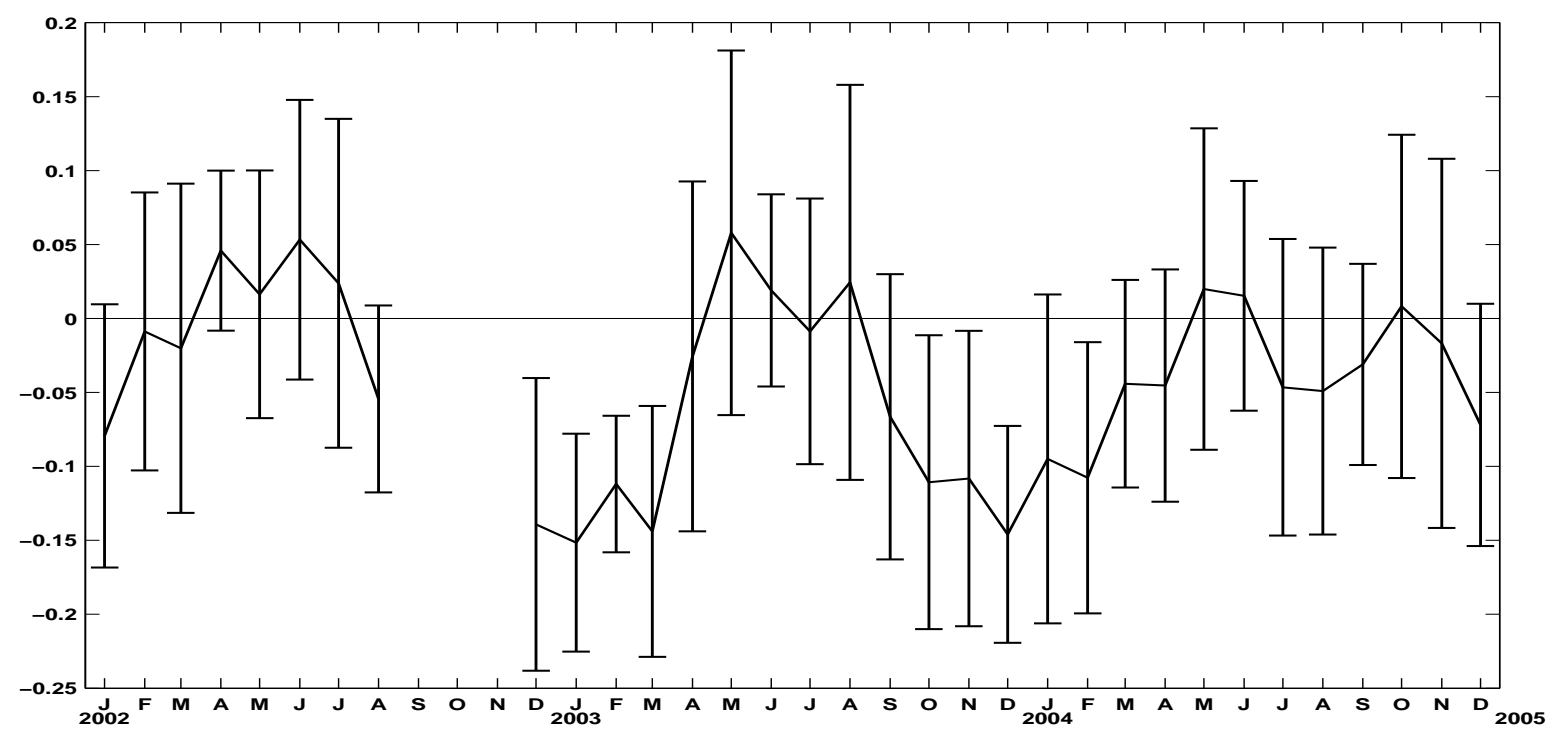

Figura 3.26: Médias mensais da elevação do nível do mar para a estação \#106 (m). 


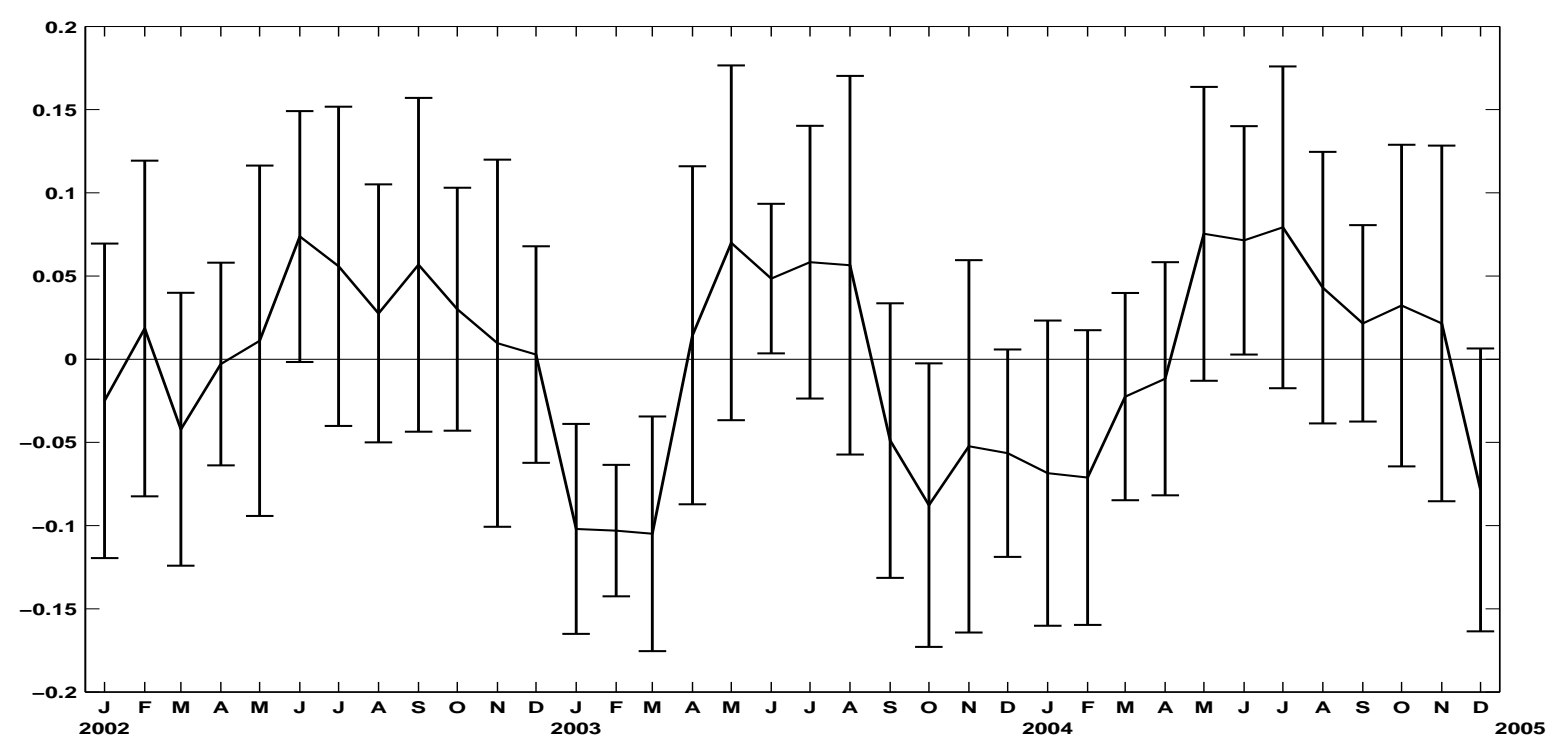

Figura 3.27: Similar a figura anterior, porém para a estação \#506 (m).

Nesta seção concluímos que as componentes de maré semi-diurna, M2 e S2 e as componentes diurnas $\mathrm{O} 1$ e S1 são as mais importantes da região, gerando modulações quinzenais típicas de maré semi-diurna. A amplitude local da maré pode ser considerada a mais alta de toda costa leste brasileira. Como esperado, a componente longitudinal do vento é o fator mais importante na geração das oscilações do nível do mar na banda sub-inercial, sendo o coeficiente de correlação entre as duas séries aproximadamente 0,70 . O empilhamento de água junto à costa pode gerar desníveis positivos de até $40 \mathrm{~cm}$, sendo estes mais comuns nos meses de abril a agosto quando há a predominância de ventos do quadrante sul. A sazonalidade da componente longitudinal do vento, gera oscilações no nível do mar de aproximadamente 0,22 m com período próximo a um ano. 


\subsection{Correntes:}

Nesta seção, primeiramente serão apresentados e discutidos os resultados das correntes de maré das estações e sua importância na variabilidade total das correntes observadas. Numa segunda etapa o campo de corrente será filtrado e sua variabilidade sub-inercial analisada. Por fim a variabilidade inter-anual dos dados será apresentada e discutida.

A análise harmonica das correntes de maré foi feita utilizando-se o campo de velocidade alinhado com à costa de acordo com Pawlowicz et al. (2002). Os resultados das quatro principais constituintes de maré das estações \#106 e \#506, estão apresentados nas tabelas 3.10 e 3.11, respectivamente. Através destes resultados nota-se que as elipses das componentes diurnas da maré são aproximadamente perpendiculares à costa em ambas as estações. Já as componentes semi-diurnas são quase paralelas à costa na estação \#506 e próximas a 50 na estação \#106.

Comparando-se a variância do campo de correntes observadas com a de correntes previstas pela análise harmonica, observa-se que na estação \#106 as correntes de maré explicam 36,4 \% da variabilidade total das correntes, sendo 70,8\% na direção perpendicular à costa e 29,8 \% na direção longitudinal à costa. Neste ponto de observação a corrente de maré prevista possui valores máximos de $0,43 \mathrm{~m} . \mathrm{s}^{-1}$ na direção longitudinal e $0,21 \mathrm{~m} \cdot \mathrm{s}^{-1}$ na direção transversal.

Já na estação \#506 o percentual de explicação sobe para 41,7\%, com 69,4\% na direção perpendicular à costa e $31,6 \%$ na direção longitudinal à costa. O valor máximo da componente longitudinal da velocidade foi de $0,30 \mathrm{~m} \cdot \mathrm{s}^{-1}$ e da componente transversal $0,22 \mathrm{~m} \cdot \mathrm{s}^{-1}$.

Os resultados dos valores máximos da corrente de maré são muito superiores aos encontrados por Amorim (2005) ao estudar a região costeira adjacente a Bahia de Camamu. A autora encontrou valores máximos próximos a $0,05 \mathrm{~m} \cdot \mathrm{s}^{-1}$ na componente longitudinal e $0,04 \mathrm{~m} \cdot \mathrm{s}^{-1}$ na componente transversal das correntes. 
Tabela 3.10: Resultados da análise harmônica do do campo de velocidade na estação \#106. Maior e Menor são as amplitudes do maior e do menor eixo da elipse em $\left(\mathrm{m} . \mathrm{s}^{-1}\right)$, onde o sinal valores positivos representam giro no sentido horário e negativos sentido anti-horário. Ema e Eme são os erros para o maior e o menor eixo. Incl e ein são a inclinação em relação a linha de costa e o erro associado. Fase e epha são a fase e o erro da fase em graus. Resultados de fase expressos em relação ao meridiano de Greenwich.

\begin{tabular}{|l|c|c|c|c|c|c|c|c|}
\hline Comp & Maior & ema & Menor & eme & Incl & ein & Fase & epha \\
\hline M2 & 0.160 & 0.002 & -0.066 & 0.01 & 49.54 & 1.06 & 158.44 & 1.05 \\
\hline S2 & 0.083 & 0.002 & -0.027 & 0.00 & 53.95 & 1.54 & 176.45 & 1.66 \\
\hline O1 & 0.036 & 0.003 & -0.002 & 0.01 & 85.37 & 2.32 & 123.17 & 4.93 \\
\hline K1 & 0.020 & 0.003 & 0.001 & 0.00 & 86.80 & 4.43 & 156.63 & 9.02 \\
\hline
\end{tabular}

Tabela 3.11: Similar a tabela anterior, porém para os dados da estação \#506.

\begin{tabular}{|l|c|c|c|c|c|c|c|c|}
\hline Comp & Maior & ema & Menor & eme & Incl & ein & Fase & epha \\
\hline M2 & 0.114 & 0.002 & -0.091 & 0.01 & 177.06 & 3.60 & 336.26 & 3.87 \\
\hline S2 & 0.059 & 0.002 & -0.036 & 0.00 & 9.24 & 3.79 & 162.73 & 3.59 \\
\hline O1 & 0.023 & 0.003 & -0.003 & 0.01 & 88.27 & 4.71 & 93.74 & 7.19 \\
\hline K1 & 0.020 & 0.003 & 0.003 & 0.00 & 90.69 & 5.20 & 138.16 & 7.85 \\
\hline
\end{tabular}


A magnitude média das correntes observadas para toda a série de dados foi de $0,18 \pm 0,10 \mathrm{~m} \cdot \mathrm{s}^{-1}$ na estação $\# 506$ e de $0,23 \pm 0,13 \mathrm{~m} \cdot \mathrm{s}^{-1}$ na estação $\# 106$, com velocidades máximas alcançando $0,66 \mathrm{~m} \cdot \mathrm{s}^{-1}$ e $0,93 \mathrm{~m} \cdot \mathrm{s}^{-1}$ nestas mesmas estações. A estação \#106 apresentou maiores velocidades pois no local do fundeio o Canal Sueste é mais estreito e menos profundo, gerando um afunilamento no fluxo o que resulta em maiores velocidades.

O eixo principal (eixo de maior variância) das correntes ficou orientado na direção do canal Sueste com um ângulo de orientação próximo a $40^{\circ}$ em relação ao norte verdadeiro em ambas as estações.

As figuras 3.28 e 3.29 ilustram a distribuição de freqüência das direções de corrente para as estações \#106 e \#506. A direção das correntes é nitidamente bi-modal em ambas as estações, orientadas preferencialmente ao longo de um eixo NE-SW, sendo que a estação \#506 possui um menor número de ocorrências de eventos de SW e um aumento nas direções E, W e NW. Isto se deve a configuração do canal Sueste, onde instalado o fundeio \#506. Próximo a este ponto existe a presença de recifes de corais que limitam o fluxo da direção sudoeste (Figura 1.1). Além disto, a costa próxima ao local de fundeio possui uma orientação mais próxima ao eixo leste-oeste, favorecendo os fluxos nesta direção.

De forma geral, as correntes direcionados para SW prevaleceram em ambas as estações, representando um total de 24,8\% das observações na estação \#506 e 38,4\% na estação \#106. Conseqüentemente, o fluxo residual em ambas as estações foi

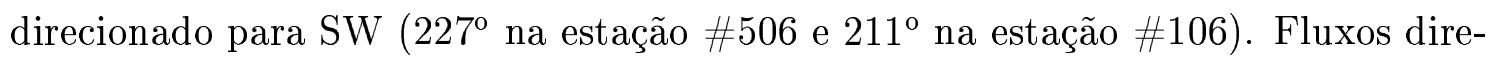
cionados para NE estiveram associados a 14,5 \% das observações na estação \#506 e a 14,7\% na estação \#106. 


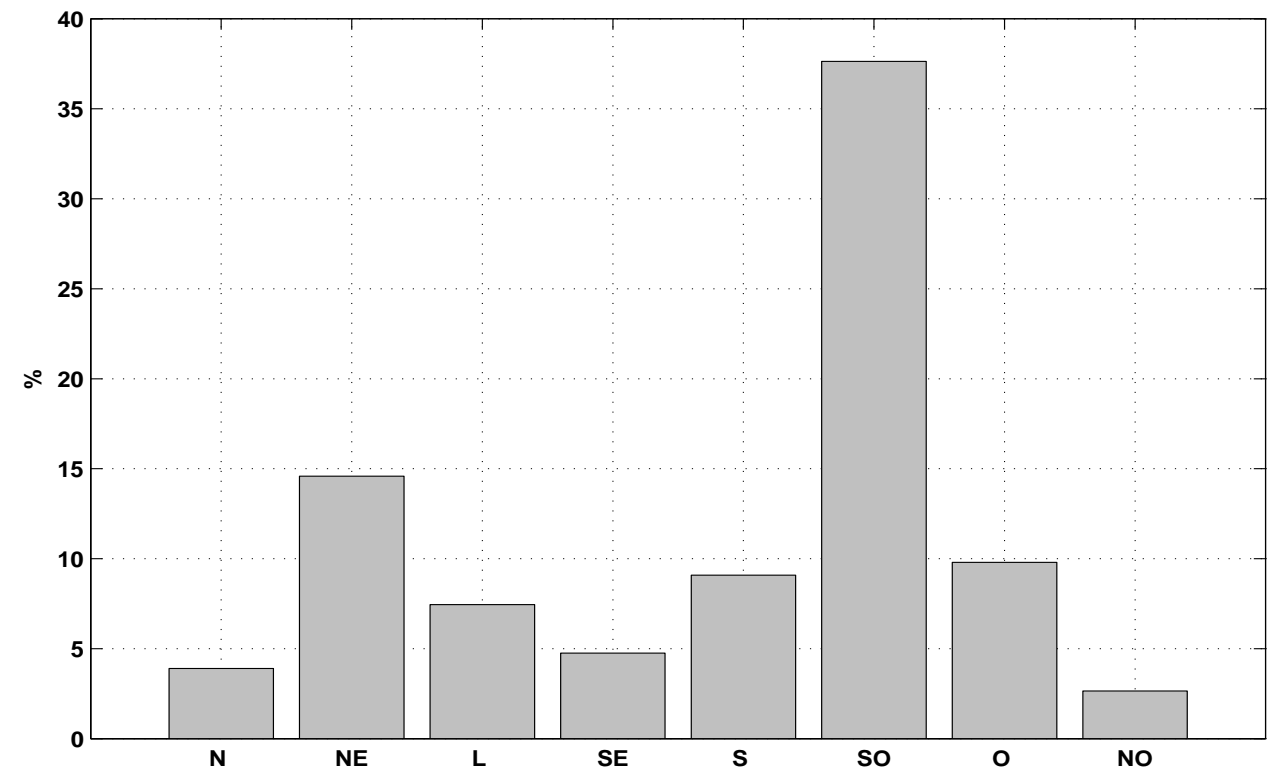

Figura 3.28: Histograma de freqüência das direções das correntes para estação \#106.

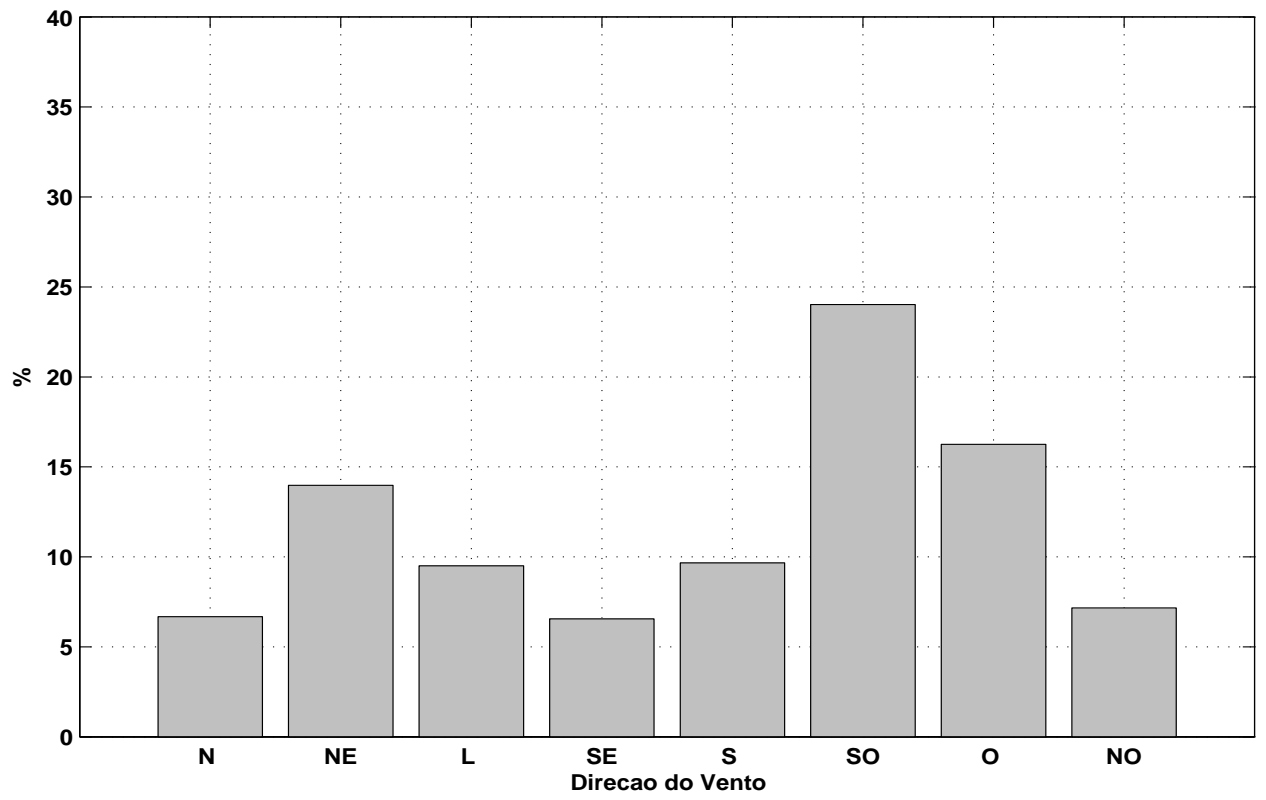

Figura 3.29: Histograma de freqüência das direções das correntes para estação \#506. 
Após os dados terem sido alinhados com à costa foram calculadas as correntes longitudinal $(\mathrm{v})$ e transversal $(\mathrm{u})$ à costa. Nas figuras 3.30 à 3.35, estão apresentadas as séries temporais das correntes longitudinais para as duas estações. Através de um filtro passa baixa com um período de corte de 39 hs foram calculadas as componentes sub-inercial das correntes, as quais estão plotadas como uma linha tracejada nos gráficos.

A estação \#106 apresentou correntes longitudinais na banda sub-inercial com magnitudes médias de 0,11 $\pm 0,22 \mathrm{~m} . \mathrm{s}^{-1}$; enquanto a estação \#506 as magnitudes são de $0,04 \pm 0,16 \mathrm{~m} \cdot \mathrm{s}^{-1}$. Os valores máximos desta componente ocorreram em Novembro de 2004 e foram 1,04 m.s ${ }^{-1}$ e $0,78 \mathrm{~m} . \mathrm{s}^{-1}$, para as estações \#106 e \#506 respectivamente. A banda sub-inercial explica 74,8 \% e 67,5\% da variabilidade total das correntes longitudinais nas estações \#106 e \#506.

Como observado em estudos anteriores sobre a circulação na plataforma interna (Lentz et al., 2001; Lentz, 1994; Lee et al., 1984), a componente sub-inercial das correntes longitudinais, seguem preferencialmente a direção da componente longitudinal do vento, podendo ser modificada em menor grau por gradientes de pressão. Isto pode ser verificado na comparação das figuras das séries temporais de vento e corrente longitudinais.

Como exemplos de velocidades longitudinais positivas (na direção nordeste) podemos citar o dia 4 de fevereiro de 2002 , quando um vento de $2,0 \mathrm{~m} . \mathrm{s}^{-1}$ produziu uma corrente com intensidade de $0,4 \mathrm{~m} . \mathrm{s}^{-1}$ na estação \#106 e $0,30 \mathrm{~m} . \mathrm{s}^{-1}$ na estação \#506 ou ainda os dias 13 a 22 de Abril de 2003 quando um vento de 4,0 m.s ${ }^{-1}$, gerou correntes de intensidades de $0,70 \mathrm{~m} . \mathrm{s}^{-1}$ e $0,40 \mathrm{~m} \cdot \mathrm{s}^{-1}$ respectivamente.

Já para os casos de velocidades longitudinais negativas podemos citar os eventos dos dias 21 de Julho de 2002 e 17 de Janeiro de 2004, onde ventos longitudinais de $-7.0 \mathrm{~m} . \mathrm{s}^{-1} \mathrm{e}-5,0 \mathrm{~m} . \mathrm{s}^{-1}$ deram origem a correntes longitudinais de respectivamente $-0,4 \mathrm{~m} \cdot \mathrm{s}^{-1} \mathrm{e}-0,2 \mathrm{~m} \cdot \mathrm{s}^{-1}$ na estação \#106 e -0,3 m.s ${ }^{-1}$ e $-0,1 \mathrm{~m} \cdot \mathrm{s}^{-1}$ na estação \#506. 

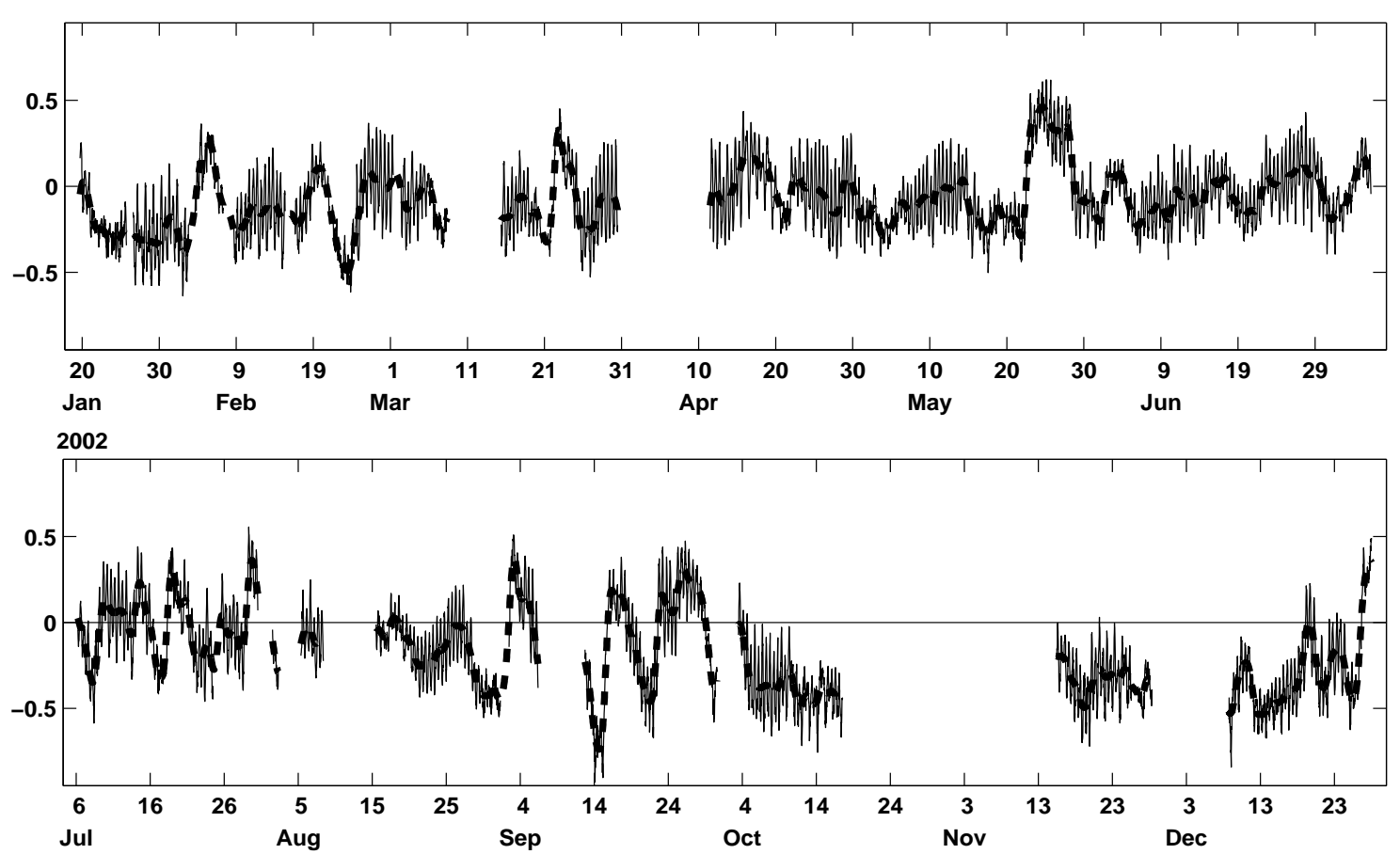

Figura 3.30: Série Temporal da corrente paralela à costa na estação \#106 para o ano 2002. A linha tracejada demonstra a série filtrada no período inercial. $\left(\mathrm{m} . \mathrm{s}^{-1}\right)$.
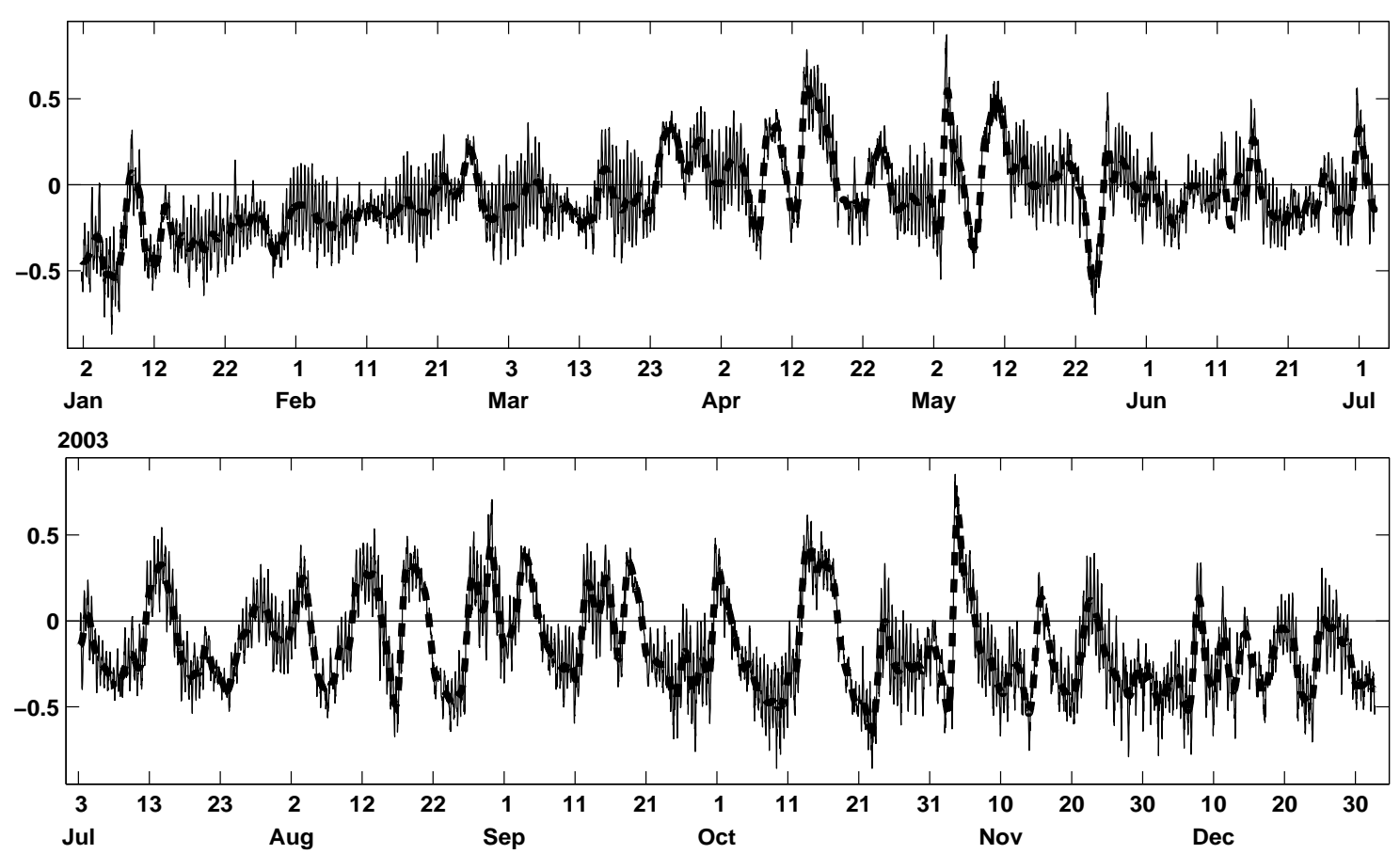

Figura 3.31: Similar a figura anterior, porém para o ano 2003. 

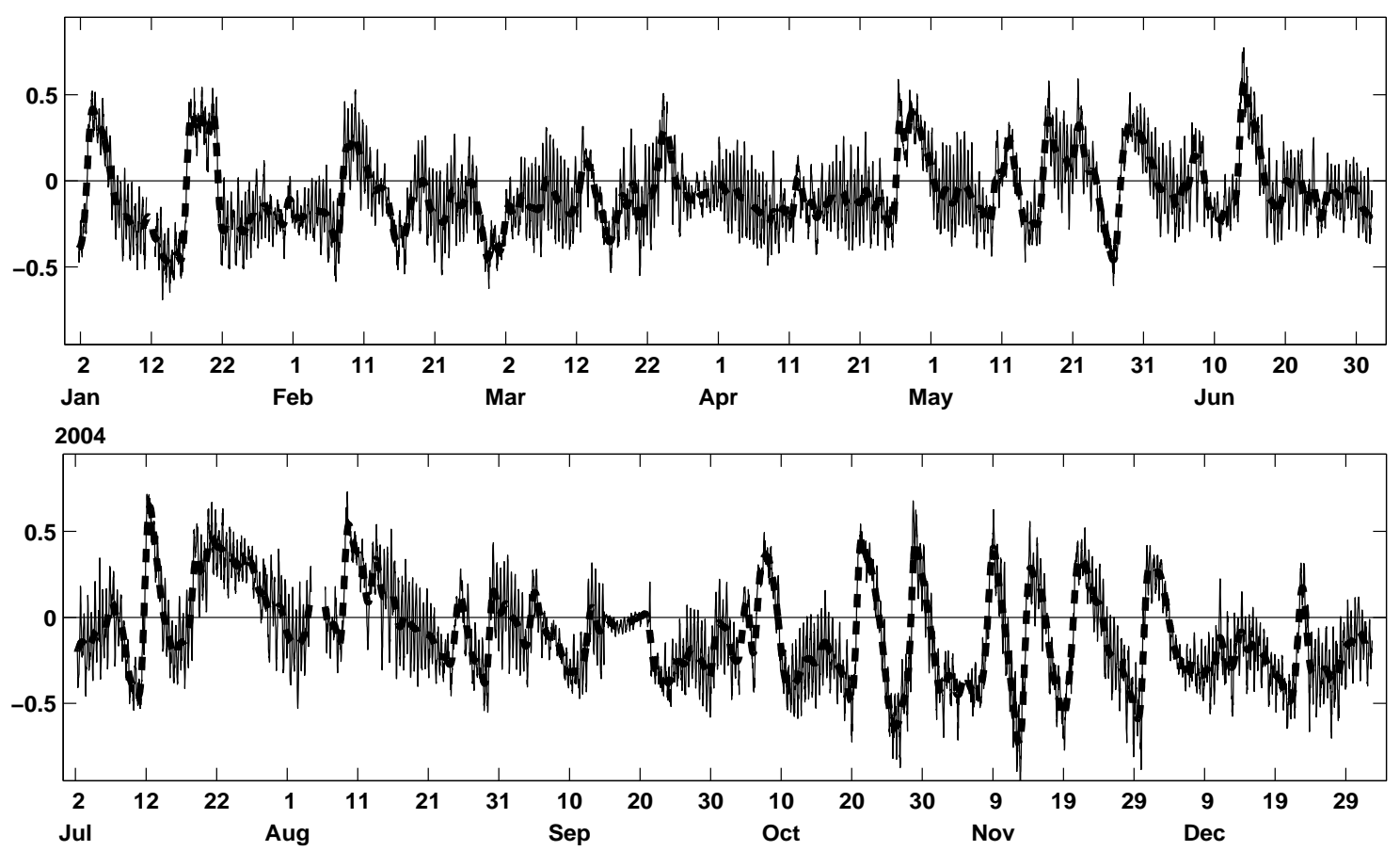

Figura 3.32: Similar a figura anterior, porém para o ano 2004.
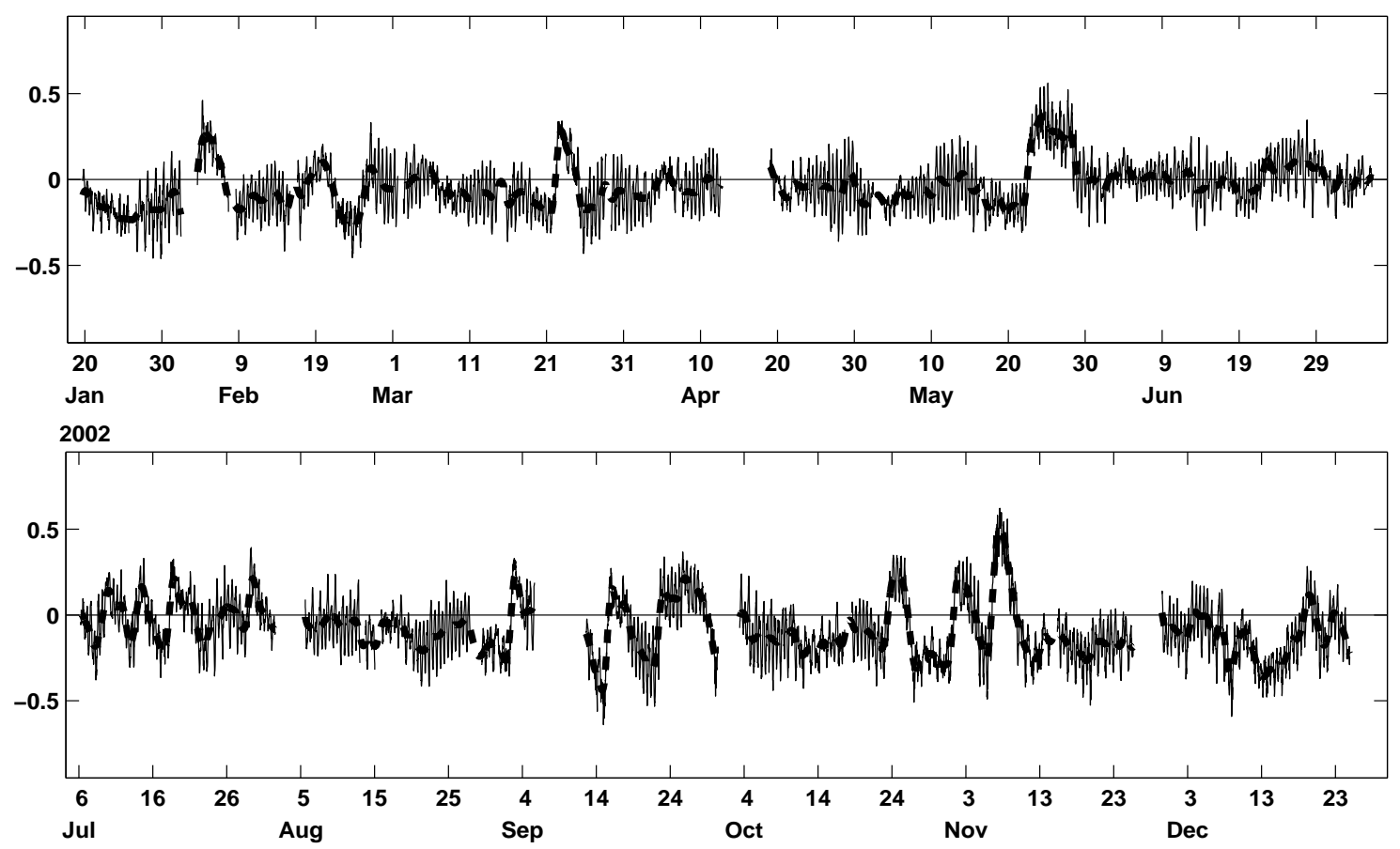

Figura 3.33: Série Temporal da corrente paralela à costa na estação \#506 para o ano 2002. A linha tracejada demonstra a série filtrada no período inercial.(m.s $\left.\mathrm{s}^{-1}\right)$. 

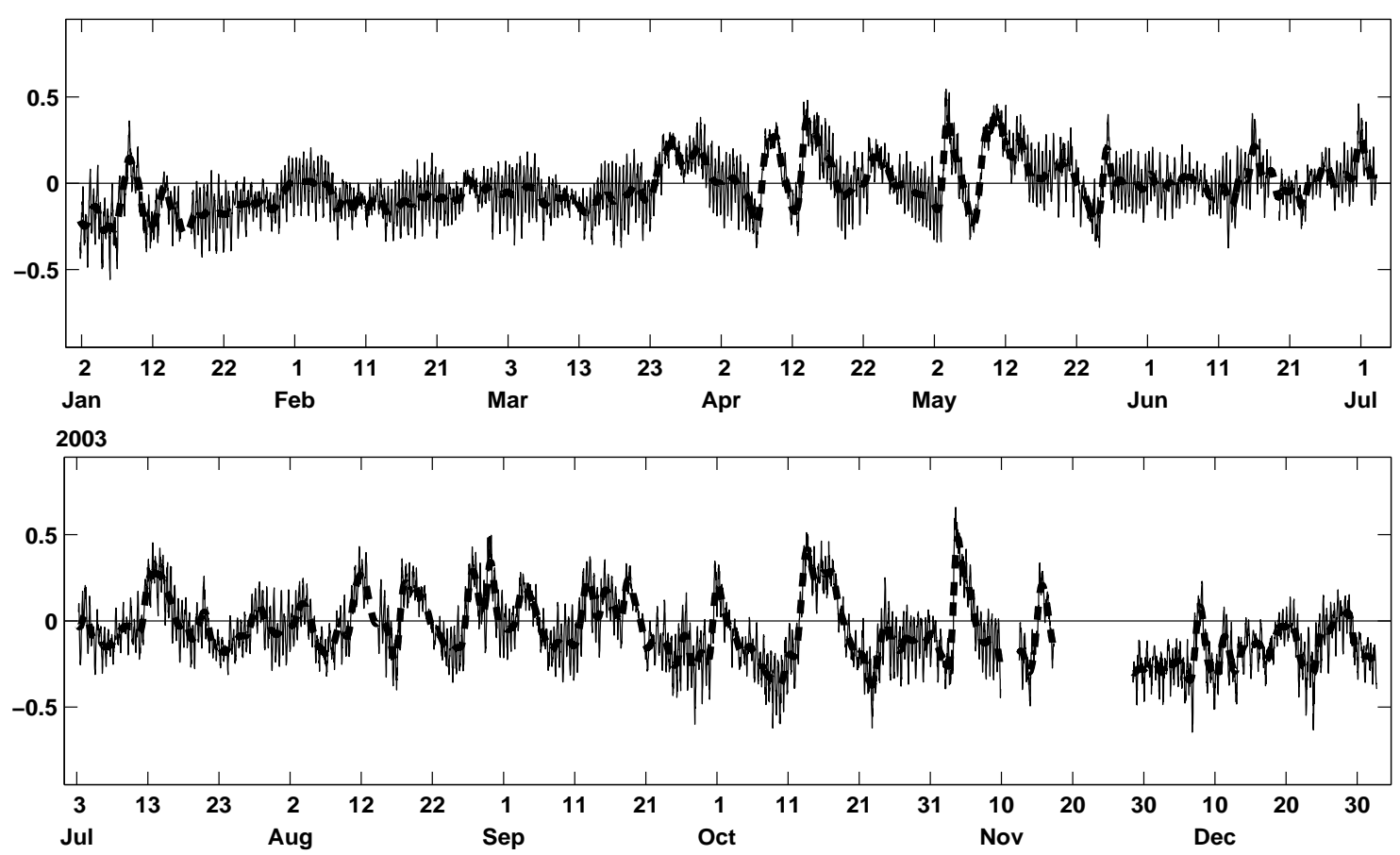

Figura 3.34: Similar a figura anterior, porém para o ano 2003.
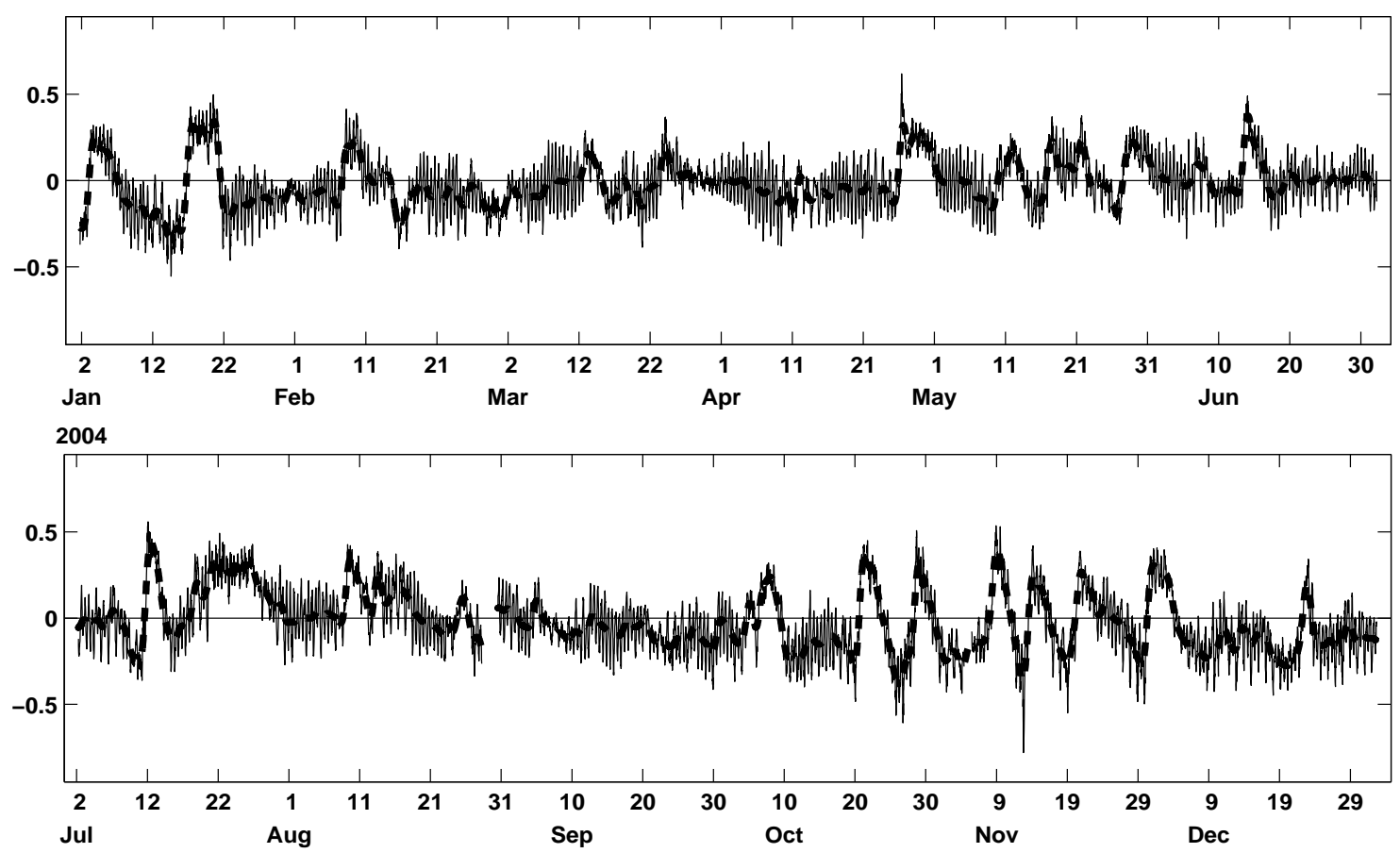

Figura 3.35: Similar a figura anterior, porém para o ano 2004. 
As séries temporais da componente transversal das velocidades das estações \#106 e \#506 estão apresentadas nas figuras 3.36 à 3.41. Como nas figuras anteriores, a linha tracejada representa o sinal filtrado. Os valores da componente longitudinal foram 2 vezes maiores que a magnitude média da componente da velocidade transversal à linha de costa, os quais tiveram valores médios de 0,02 $\pm 0,10 \mathrm{~m} \cdot \mathrm{s}^{-1} \mathrm{e}$ $0,04 \pm 0,11 \mathrm{~m} \cdot \mathrm{s}^{-1}$ com máximos de 0,78 e 0,40 m.s ${ }^{-1}$, nas estações \#506 e \#106. No caso das correntes transversais a componente sub-inercial explicou 24,30\% e 20,30 \% da variabilidade total do sinal, nas estações \#506 e \#106 respectivamente.

De acordo com Lentz et al. (2001) a componente transversal sub-inercial das correntes na plataforma interna, é forçada pelo gradiente de pressão e em menor grau pela componente transversal tensão de cizalhamento do vento. No presente estudo, os gradientes de pressão barotrópicos, na banda inercial, são gerados pelas oscilações do nível do mar, que por sua vez são oriundos do transporte de Ekman.

Em condições de ventos positivos, que geram acumulo de água junto à costa, o gradiente de pressão é na direção do oceano aberto gerando velocidades positivas. No caso de ventos negativos existe uma diminuição do nível do mar junto à costa e o gradiente de pressão é em direção ao continente gerando velocidades negativas.

No trabalho de Lentz et al. (2001) ainda é levantada a possibilidade do tensão de cizalhamento das ondas afetar a componente transversal das correntes. De acordo com o trabalho isto ocorre apenas em situações em que a relação altura significativa da onda dividido pela profundidade local for menor que 0,33 .

Considerando a menor profundidade das estações $(7,7 \mathrm{~m})$, seria necessário ondas com alturas significativas maiores que 2,56 m para afetar o campo de corrente. De acordo com os registros de onda instalados nos fundeios, esta situação ocorreu em menos de $1 \%$ das medições.

Apesar das forçantes serem um pouco mais complexas no caso das correntes transversais, ainda assim é possível observar visualmente uma relação quando se comparam as figuras de correntes tranversal com o campo de vento e o de elevação 
do nível do mar.

Tomando-se como exemplo as mesmas datas expostas acima para a corrente longitudinal, nota-se que no dia 04/02/2002 a componente transversal da velocidade em ambas estações tinha intensidade igual a $0,10 \mathrm{~m} \cdot \mathrm{s}^{-1}$, enquanto a mesma componente do vento era igual a $3,0 \mathrm{~m} \cdot \mathrm{s}^{-1}$. Neste mesmo dia a componente longitudinal do vento era igual a $2,0 \mathrm{~m} \cdot \mathrm{s}^{-1}$ o que gerou uma elevação de $0,10 \mathrm{~m}$.

Nos dias 12 a 22 Abril de 2004 houve uma maior variação nesta componente do vento do que na componente longitudinal. O vento transversal variou entre $-2,0$ e 2,0 $\mathrm{m} . \mathrm{s}^{-1}$, gerando velocidades transversais entre $-0,15$ e $0,10 \mathrm{~m} \cdot \mathrm{s}^{-1}$ nas duas estações. Nestas mesmas datas a componente longitudinal do vento e do nível tiveram valores próximos a $4,0 \mathrm{~m} \cdot \mathrm{s}^{-1}$ e $0,4 \mathrm{~m}$, respectivamente.

Já no dia 21/07/2002 a componente transversal das correntes apresentou valores de $-0,09$ e $-0,05 \mathrm{~m} \cdot \mathrm{s}^{-1}$, respectivamente nas estações \#106 e \#506, para um vento de $-2,0 \mathrm{~m} \cdot \mathrm{s}^{-1}$. A intensidade do vento longitudinal era de $-5,0 \mathrm{~m} \cdot \mathrm{s}^{-1}$ gerando um desnível de $-0,25 \mathrm{~m}$.

Diferente do que aconteceu nas datas acima, no dia 17/01/2004, as velocidades transversais nas estações \#506 e \#106 tiveram intensidades distintas com valores de 0,05 e $0,10 \mathrm{~m} \cdot \mathrm{s}^{-1}$,respectivamente. O vento transversal nesta data teve intensidade de $-5,0 \mathrm{~m} \cdot \mathrm{s}^{-1}$ e o vento longitudinal de $-7,0 \mathrm{~m} \cdot \mathrm{s}^{-1}$, por sua vez o desnível estava próximo a zero. 

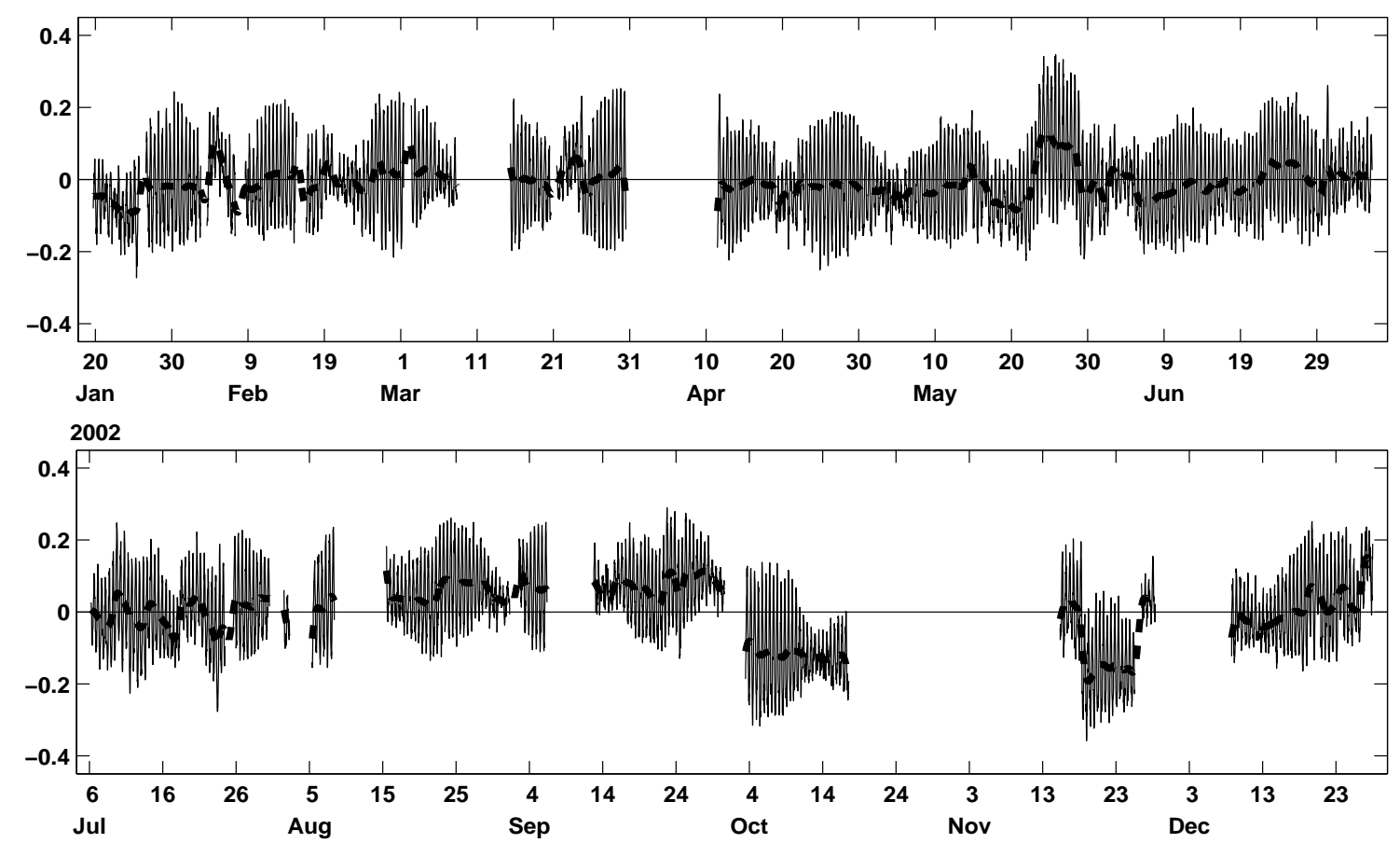

Figura 3.36: Série Temporal da corrente perpendicular à costa na estação \#106 para o ano 2002. A linha tracejada demonstra a série filtrada no período inercial.

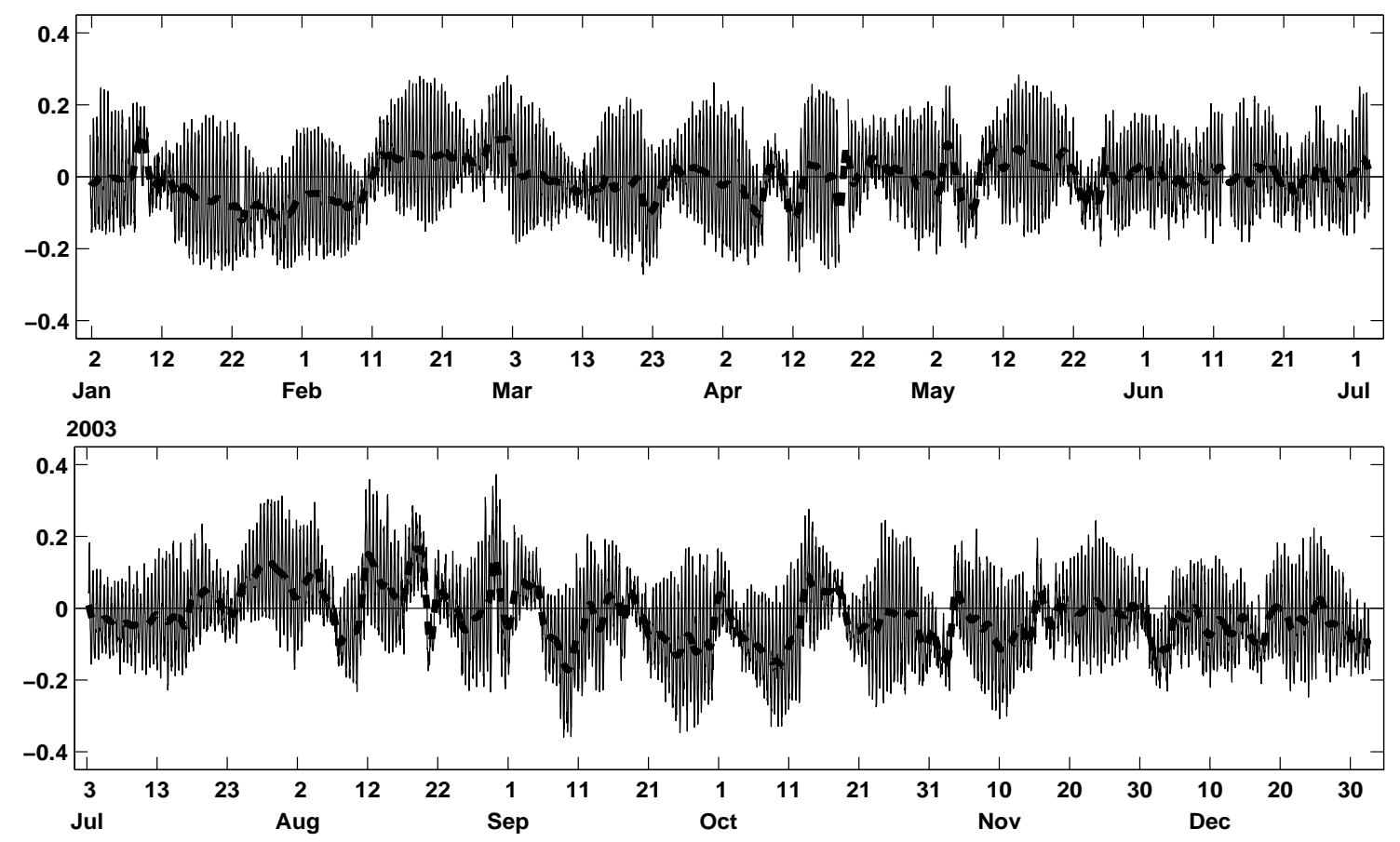

Figura 3.37: Similar a figura anterior, porém para o ano 2003. 


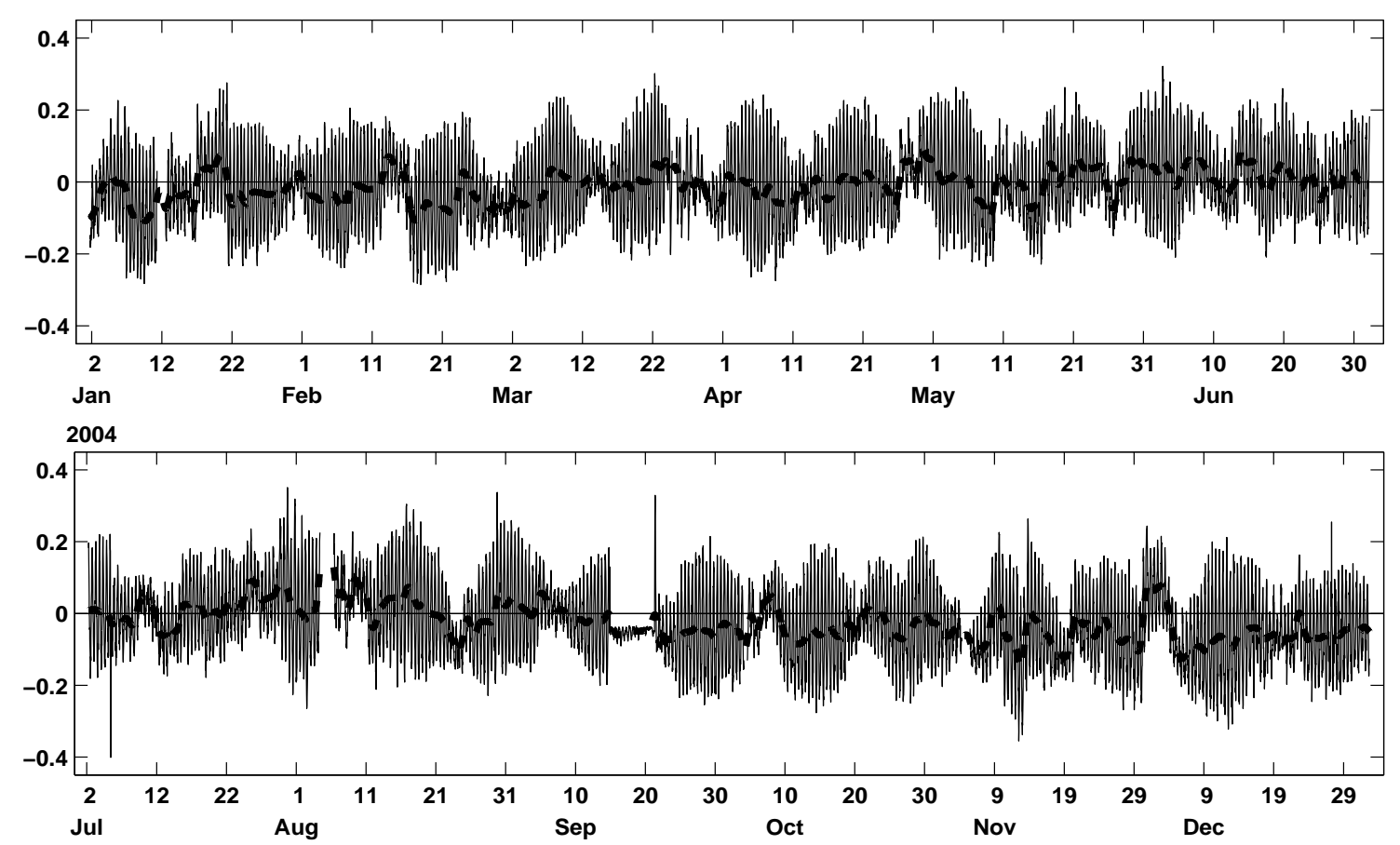

Figura 3.38: Similar a figura anterior, porém para o ano 2004.
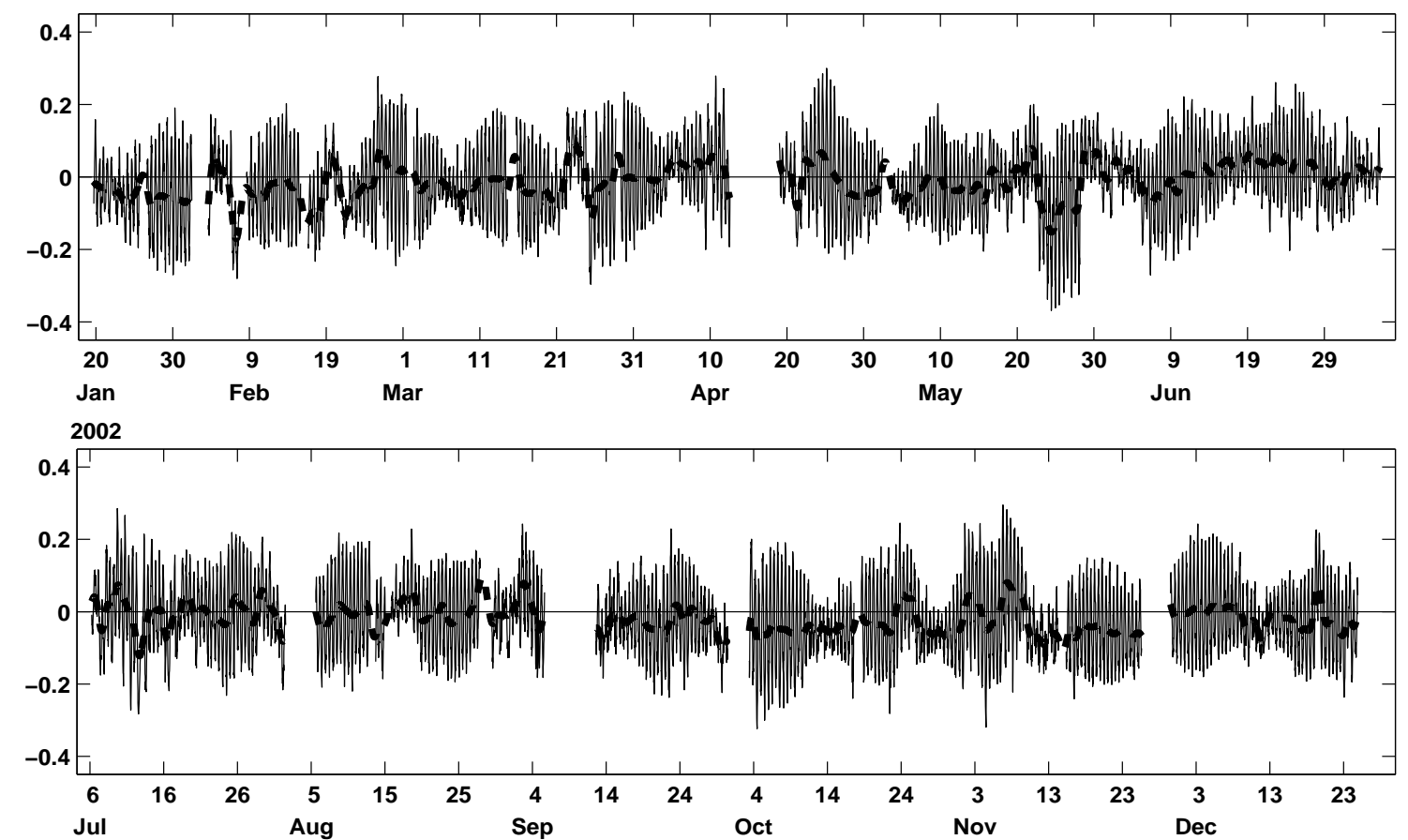

Figura 3.39: Série Temporal da corrente perpendicular à costa na estação \#506 para o ano 2002. A linha tracejada demonstra a série filtrada no período inercial. 


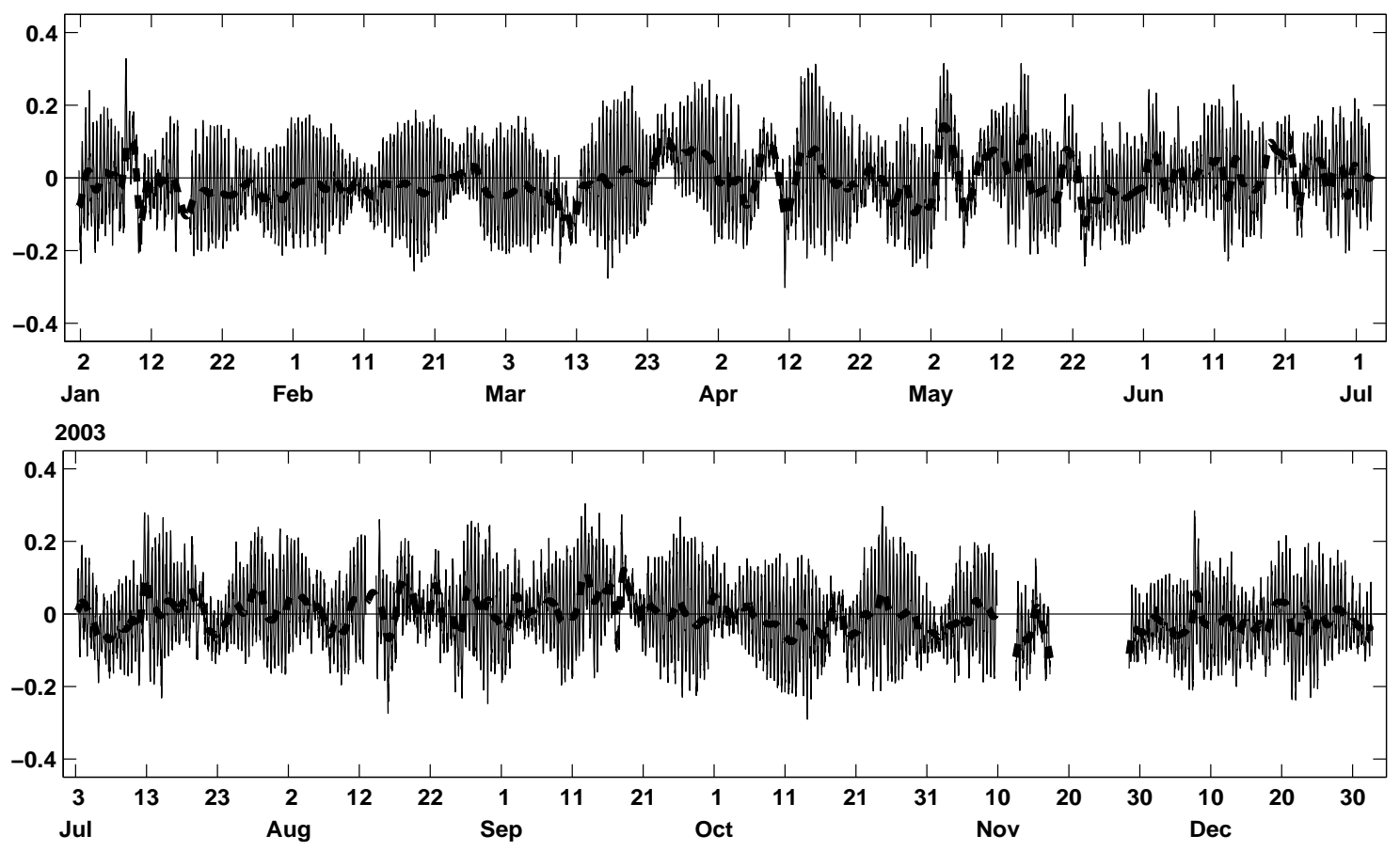

Figura 3.40: Similar a figura anterior, porém para o ano 2003.

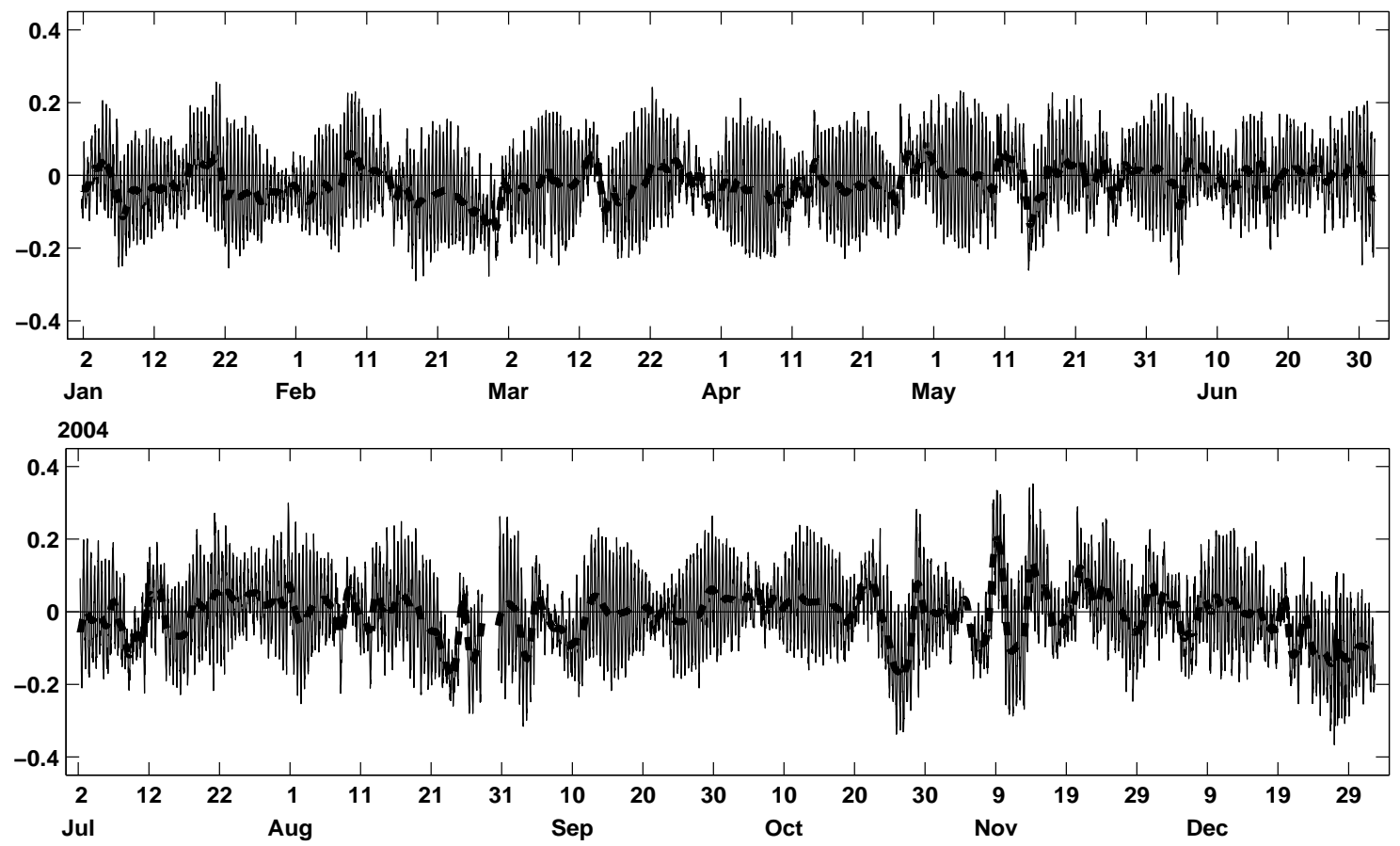

Figura 3.41: Similar a figura anterior, porém para o ano 2004. 
Nas tabelas 3.12 e 3.13 estão tabulados algumas das estatísticas anuais das componentes longitudinal e transversal das correntes na banda sub-inercial.

Através da tabela percebemos que a componente longitudinal das correntes tem média anual negativa em todos os anos e que esta média vai aumentando ao longo do período de estudo. Como esperado, o fato das correntes serem negativas está diretamente relacionado a maior incidência de ventos de NE durante os três anos de estudo. Já o aumento da freqüência dos ventos positivos (de SW) gerou um aumento na velocidade média anual ao longo dos três anos de estudo. Este mesmo fator explica a redução dos valores máximos positivos e aumento dos valores máximos negativos ao longo do período. O desvio padrão foi em média três vezes maior do que a média na estação \#106 e três vezes e meio maior do que a média na estação \#506. Na estação \#106 o fluxo é mais canalizado devido ao afunilamento do canal e portanto menos sucessível a perturbações, gerando menores devios padrões.

A freqüência de ocorrência de eventos longitudinais positivos foi aproximadamente $30 \%$ maior no campo de correntes em relação ao campo de ventos.

A intensidade da componente transversal das correntes se manteve relativamente constante durante o período de monitoramento, apresentando um leve aumento absoluto ao longo do período. O mesmo aconteceu com os valores máximos positivos e negativos. O desvio padrão se manteve relativamente constante no período, sendo em geral cinco vezes maior do que a média da corrente na estação \#106 e quatro vezes na estação \#506. Apesar de não ser possível encontrar uma relação direta entre o aumento das médias anuais da corrente transversal e a elevação do nível do mar (tabelas 3.8 e 3.9), é visível a relação com as médias anuais do vento longitudinal. No decorrer do período de estudo, a freqüência de ocorrência de ventos longitudinais positivos se tornou maior, favorecendo o empilhamento de água junto a costa, com conseqüente aumento da velocidades transversais negativas (tabela 3.1 pg.24). 
Tabela 3.12: Estatísticas anuais da banda sub-inercial do campo de correntes para estação \#106. Média $=$ Média anual $\left(\mathrm{m} . \mathrm{s}^{-1}\right)$, Desvio $=\operatorname{Desvio~padrão~}\left(\mathrm{m} . \mathrm{s}^{-1}\right)$, Max. $\mathrm{P}=$ Máximo valor positivo Observado $\left(\mathrm{m} . \mathrm{s}^{-1}\right)$, Max. $\mathrm{N}=$ Máximo valor negativo observado $\left(\mathrm{m} . \mathrm{s}^{-1}\right)$, Freq. $\mathrm{P}=$ Porcentagem total de eventos positivos $(\%)$, Freq. N. = Porcentagem total de eventos negativos (\%).

\begin{tabular}{|c|c|c|c|c|c|c|}
\hline \multicolumn{7}{|c|}{ Componente Longitudinal das Correntes } \\
\hline Ano & Média & Desvio & Max. P & Max. N & Freq. P & Freq. N \\
\hline $\mathbf{2 0 0 2}$ & $-0,12$ & 0,20 & 0,46 & $-0,74$ & 37,14 & 62,85 \\
\hline $\mathbf{2 0 0 3}$ & $-0,11$ & 0,23 & 0,63 & $-0,64$ & 40,18 & 59,81 \\
\hline $\mathbf{2 0 0 4}$ & $-0,08$ & 0,22 & 0,64 & $-0,74$ & 45,95 & 54,05 \\
\hline \hline \multicolumn{7}{|c|}{ Componente Transversal das Correntes } \\
\hline Ano & Média & Desvio & Max. P & Max. N & Freq. P & Freq. N \\
\hline $\mathbf{2 0 0 2}$ & 0,00 & 0,06 & 0,15 & $-0,19$ & 26,36 & 73,64 \\
\hline $\mathbf{2 0 0 3}$ & $-0,01$ & 0,06 & 0,17 & $-0,17$ & 29,66 & 70,34 \\
\hline $\mathbf{2 0 0 4}$ & $-0,02$ & 0,05 & 0,13 & $-0,15$ & 28,20 & 71,80 \\
\hline
\end{tabular}

Tabela 3.13: Idem tabela anterior porém para estação \#506

\begin{tabular}{|c|c|c|c|c|c|c|}
\hline \multicolumn{7}{|c|}{ Componente Longitudinal das Correntes } \\
\hline Ano & Média & Desvio & Max. P & Max. N & Freq. P & Freq. N \\
\hline $\mathbf{2 0 0 2}$ & $-0,06$ & 0,13 & 0,50 & $-0,44$ & 34,30 & 65,70 \\
\hline $\mathbf{2 0 0 3}$ & $-0,04$ & 0,15 & 0,48 & $-0,38$ & 41,06 & 58,94 \\
\hline $\mathbf{2 0 0 4}$ & $-0,02$ & 0,14 & 0,44 & $-0,37$ & 44,35 & 55,65 \\
\hline \hline \multicolumn{7}{|c|}{ Componente Transversal das Correntes } \\
\hline Ano & Média & Desvio & Max. P & Max. N & Freq. P & Freq. N \\
\hline $\mathbf{2 0 0 2}$ & $-0,01$ & 0,04 & 0,10 & $-0,17$ & 40,38 & 56,62 \\
\hline $\mathbf{2 0 0 3}$ & $-0,01$ & 0,04 & 0,14 & $-0,13$ & 38,92 & 61,08 \\
\hline $\mathbf{2 0 0 4}$ & $-0,02$ & 0,05 & 0,20 & $-0,18$ & 62,39 & 37,61 \\
\hline
\end{tabular}


As médias mensais da componente da corrente sub-inercial paralela à costa foram calculadas para ambas as estações e estão expostas nas figuras 3.42 e 3.43. Observase que as velocidades máximas negativas da componente paralela à costa (sentido NE-SW) ocorrem no período compreendido entre os meses de outubro e janeiro, forçadas pelo ventos de N-NE, com valores máximos de $-0,30,-0,25$ e -0,18 m.s ${ }^{-1}$ para a estação \#106 e para os anos de 2002, 2003 e 2004,respectivamente. Já as maiores velocidades positivas ocorrem nos meses de outono e inverno associadas aos ventos de S-SE. De forma geral as médias mensais das correntes longitudinais na estação \#106 foram duas vezes maiores que na estação \#506.

Através das figuras percebe-se um ciclo sazonal na componente longitudinal das correntes, com uma amplitude aproximada de 0,40 e 0,20 m.s ${ }^{-1}$ nas estações \#106 e \#506 respectivamente. Este padrão ocorre devido a migração anual da ACAS que gera um ciclo sazonal no campo de vento (Chaves, 1999).

As figuras 3.44 e 3.45 apresentam as médias mensais da componente perpendicular à costa. De forma contrária à componente paralela à costa, as velocidades positivas da componente perpendicular (sentido W-E) ocorrem no período de outono, enquanto velocidades negativas são registradas no verão. O padrão sazonal é menos evidente do que na componente longitudinal e possui uma amplitude de 0,10 $\mathrm{m} \cdot \mathrm{s}^{-1}$.

As intensidades médias das componentes das correntes se mostraram inferiores a trabalhos realizados sobre a circulação na plataforma em locais próximos a Caravelas.

Leipe et al. (1999) utilizou seis dias de dados de fundeios durante um cruzeiro entre 14 e 20 de Janeiro de 1995 e encontrou valores médios de cerca de $0,25 \mathrm{~m} . \mathrm{s}^{-1}$ para a componente longitudinal e $0,04 \mathrm{~m} \cdot \mathrm{s}^{-1}$ para a componente transversal no Canal Sueste. Os resultados médios aqui encontrados para a componente longitudinal da estação \#506 nos meses de janeiro $\left(0,12 \mathrm{~m} \cdot \mathrm{s}^{-1}\right)$, foram cerca de $50 \%$ inferiores aos encontrados por Leipe et al. (1999), porém a estação \#106 apresentou valores 
muito próximos $\left(0,22 \mathrm{~m} \cdot \mathrm{s}^{-1}\right)$. O mesmo acontece com a componente longitudinal das correntes, que em ambas as estações apresentaram valores médios de $0.04 \mathrm{~m} . \mathrm{s}^{-1}$. A maior diferença dos resultados em relação a estação \#506 é conseqüência da maior proximidade da estação \#106 com o local de coleta dos dados usados por Leipe et al. (1999).

Quando comparamos os resultados aqui apresentados com os encontrados por Amorim (2005), coletados num fundeio realizado na frente do estuário de Camamu (sul da Bahia) no verão de 2003, a situação é bastante parecida. Amorim (2005) encontrou valores de $-0,21$ e $-0,05$ m.s ${ }^{-1}$ para as componentes longitudinal e transversal, enquanto os intensidades aqui encontradas estão e torno de $-0,15$ e $0,08 \mathrm{~m} . \mathrm{s}^{-1}$ para a componente longitudinal nas estações \#106 e \#506 respectivamente e cerca de -0,02 para a componente transversal em ambas as estações. Esta diferença ocorre provavelmente devido a dois fatos: os dados usados por Amorim (2005) foram coletados a uma profundidade de cinco metros e as intensidades dos dados de ventos em Camamu serem liceiramente mainres nue Caravelas.

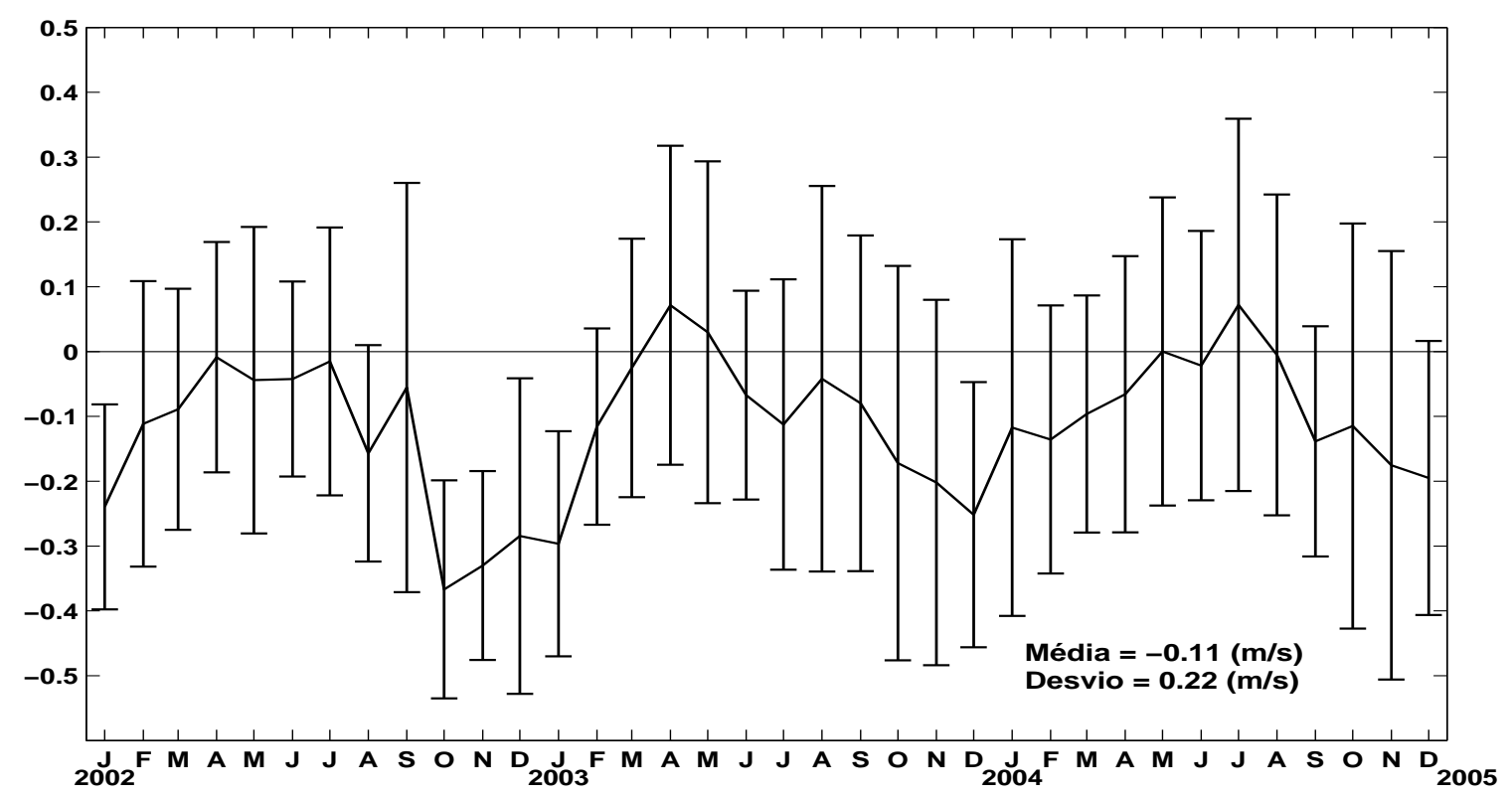

Figura 3.42: Médias e Desvios Padrões mensais da corrente paralela à costa na estação $\# 106$. 


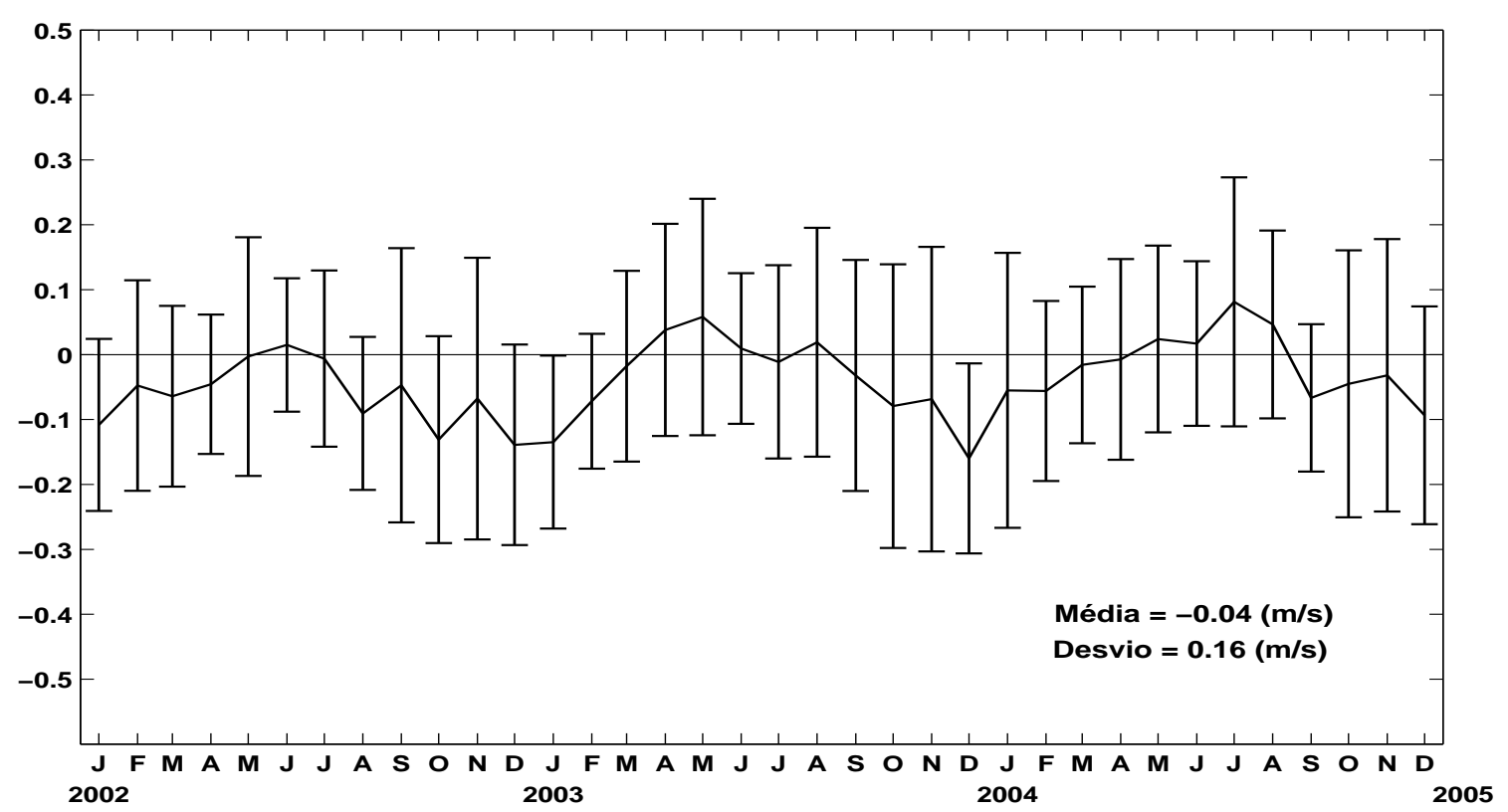

Figura 3.43: Médias mensais da corrente paralela à costa na estação \#506.

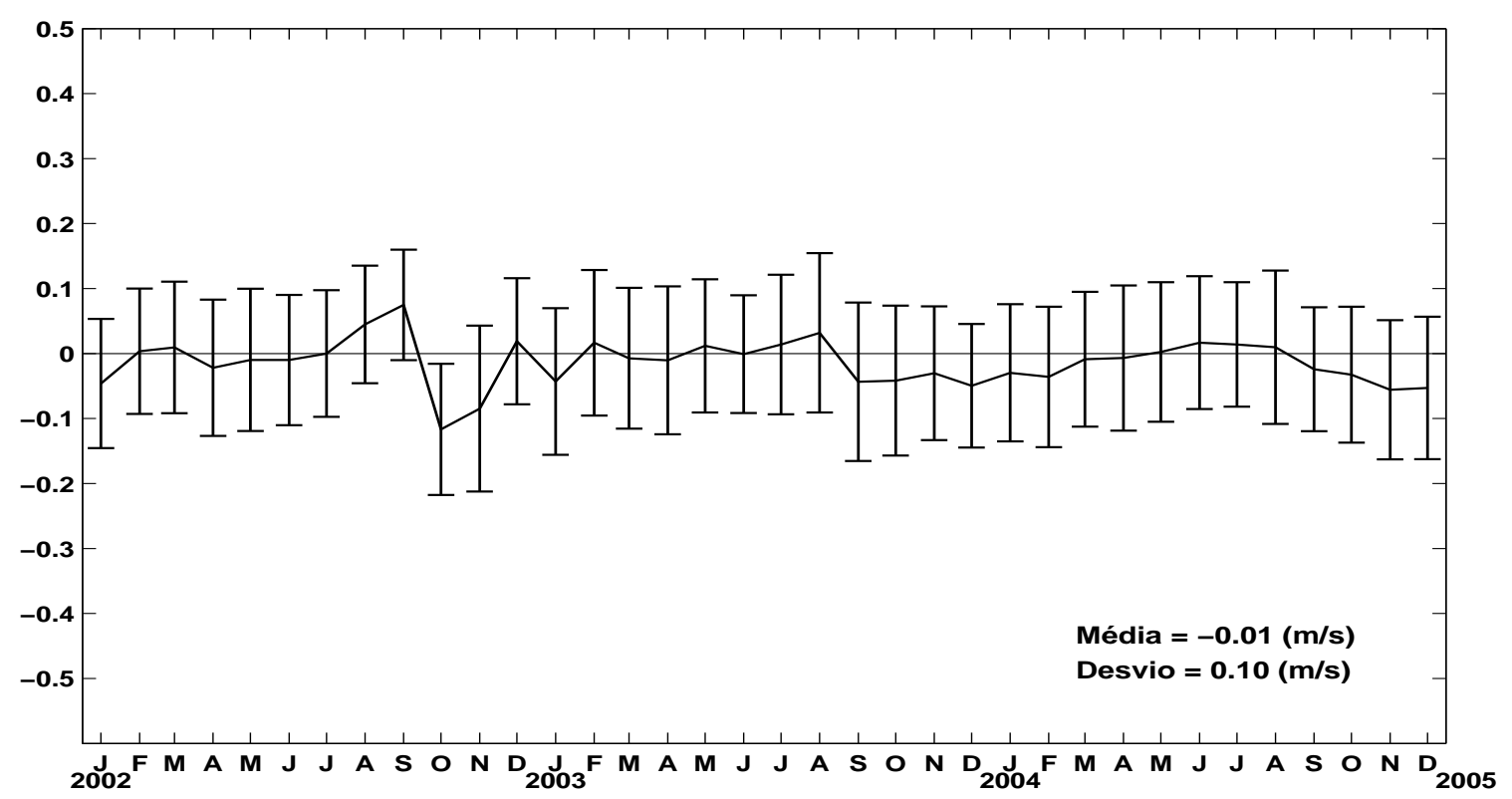

Figura 3.44: Médias e Desvios Padrões mensais da corrente perpendicular à costa na estação \#106. 
CAPÍTULO 3. RESULTADOS E DISCUSSÃO:

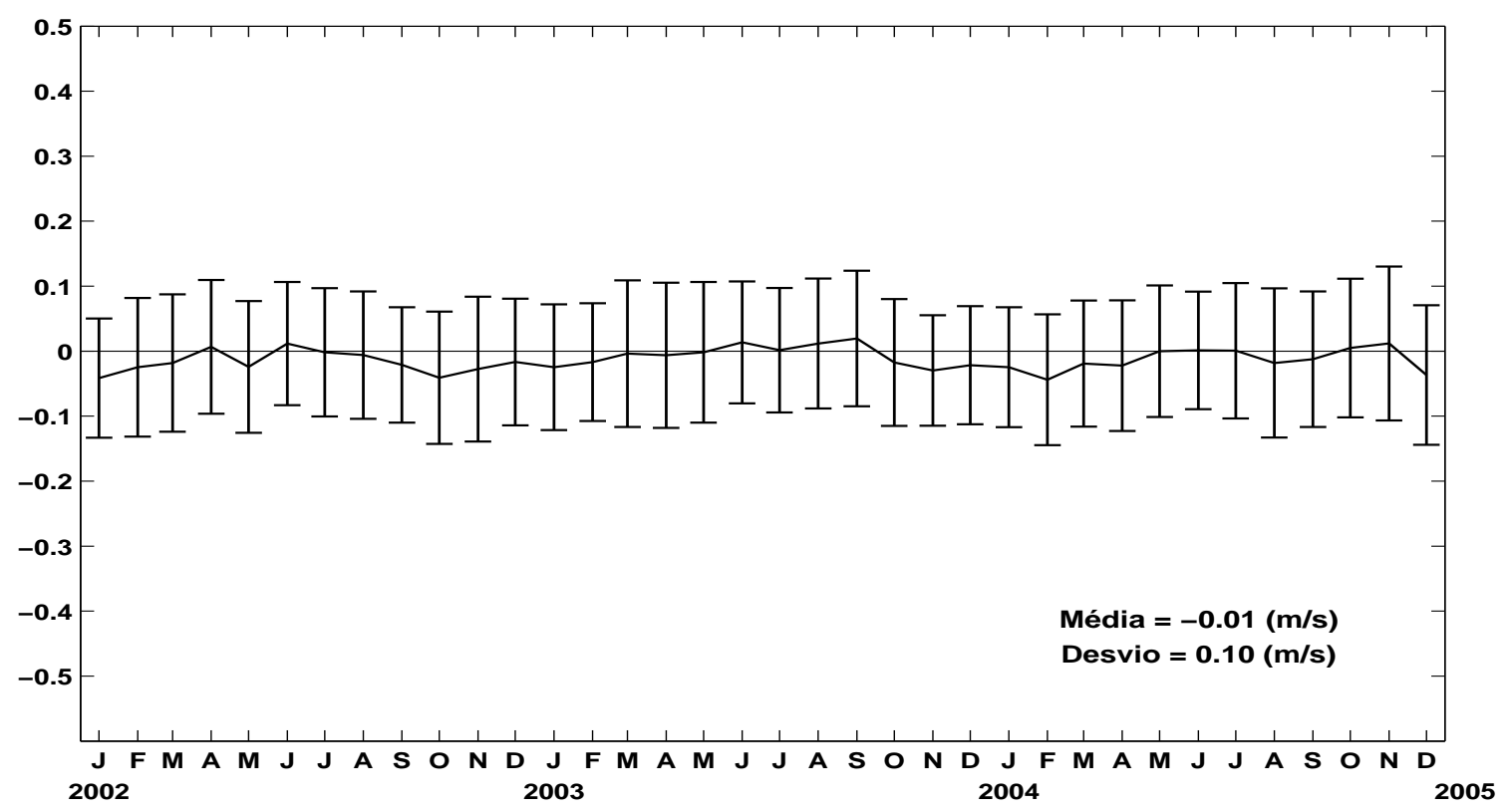

Figura 3.45: Médias e Desvios Padrões mensais da corrente perpendicular à costa na estação \#506. 
Com os resultados encontrados nesta seção, conclui-se que a maré é a principal responsável pela variabilidade das correntes perpendiculares à costa na região de estudo e possuem importância secundaria no caso das correntes paralelas a costa. O campo de correntes observado se alinhou com o eixo do canal, tendo uma resultante voltada para SE na maior parte do tempo. A componente longitudinal na banda sub-inerciais é forçada principalmente pelo vento longitudinal, estando sucessível aos eventos meteorológicos que influenciaram o padrão de ventos. As maiores intensidades das correntes nesta componente tem valores negativos e ocorrem nos meses de outubro à janeiro associadas a ventos de NE. Os máximos valores positivos acontecem nos meses de outono e inverno, associados ao vento de SW, que são gerados pela penetração de frentes frias. O vento longitudinal e as oscilações do nível do mar foram os principais responsáveis pela variabilidade da corrente transversal. As maiores intensidades desta componente das correntes acontecem em eventos negativos, associado a ventos de NE e a reduções do nível do mar junto a costa. Ambas as componentes, apresentaram um padrão sazonal com um período de um ano, sendo este padrão mais evidente na componente longitudinal dos ventos.

\subsection{Correlação entre os dados:}

Afim de se confirmar os resultados obtidos através da comparação visual entre as séries, foi calculado o coeficiente de explicação com defasagem zero e a correlação cruzada entre as séries de vento, nível e correntes. A diferença entre as metodologias é que o coeficiente de determinação é calculado através da razão entre a covariância entres os dados pela autocovariância dos dados; enquanto a correlação cruzada é calculada através de análises de Fourier cruzadas. Ambos as metodologias foram aplicadas para um intervalo de confiança de $95 \%$. 
As tabelas 3.14 e 3.15 apresentam os resultados dos indices de determinação e o máximo valor de correlação encontrado e o respectivo lag para as estações \#106 e \#506 respectivamente.

Como esperado os maiores valores dos coeficientes de explicação se dão entre as componentes longitudinais do vento e corrente, com valores de 0,77 e 0,79 para as estações \#106 e \#506 respectivamente. Os máximos índices de correlação são iguais a 0,82 com uma defasagem de 2,5 hs e 0,86 com defasagem de 4 hs, nas mesmas estações.

A correlação entre a componente sub-inercial do nível e a componente do vento paralelo à costa nas estações \#106 e \#506 forneceu um coeficiente de determinação de 0,76 e 0,71 , com índices de correlação iguais à 0,75 para uma defasagem de 5 hs e 0,64 para um defasagem de 2,5 hs. Este resultado mostra como é grande a importância da circulação eólica remota no estabelecimento de fluxos costeiros na área de estudo. Quando se comparam os campos de corrente longitudinal e nível os valores também se mostraram altos. Isto ocorre principalmente devido a relação direta entre os campos longitudinais de corrente e de vento.

A componente transversal das correntes apresentou os maiores índices de correção e determinação com o vento transversal, apresentando valores de correlação cruzada de 0,57 na estação \#106 e 0,60 na estação \#506, ambos com defasagem de 4 hs. Ao contrario do esperado, os valores da correlação entre os campos de nível e corrente transversal se mostraram pequenos apresentando correlações de 0,40 na estação \#506 para uma defasagem de 8 hs e 0,35 na estação \#106 com defasagem de 5,5 hs.

Os resultados aqui apresentados estão de acordo com a literatura sobre a circulação em plataformas internas (Lentz et al., 2001; Lentz, 1994; Lee et al., 1984), porém os coeficientes foram ligeiramente menores do que o encontrado na literatura. A exceção ocorre entre os dados de corrente transversal e nível, onde os índices de correlação se mostraram muito baixos. 
Tabela 3.14: Índices de determinação, coeficientes de correlação cruzada e defasagem entre os campos da estação \#106. CL = Corrente Longitudinal, CT $=$ Corrente Transversal, N $=$ Nível, $\mathrm{VL}=$ Vento Longitudinal, $\mathrm{VC}=$ Vento Transversal. Defasagem em horas.

\begin{tabular}{|c|c|c|c|}
\hline & $r^{2}$ & Coef. correleção & Defasagem \\
\hline \hline CL x N & 0.56 & 0.44 & 8.00 \\
\hline CT x N & 0.33 & 0.34 & 5.50 \\
\hline VL x N & 0.76 & 0.75 & 5.00 \\
\hline VT X N & 0.32 & 0.42 & 1.00 \\
\hline VL x CL & 0.77 & 0.82 & 2.50 \\
\hline VL x CT & 0.53 & 0.57 & 6.00 \\
\hline VT x CT & 0.32 & 0.30 & 0.00 \\
\hline
\end{tabular}

Tabela 3.15: Similar a tabela anterior, porém para os campos da estação \#506

\begin{tabular}{|c|c|c|c|}
\hline & $r^{2}$ & Coef. Correleção & Defasagem \\
\hline \hline CL x N & 0.57 & 0.55 & 8.00 \\
\hline CT x N & 0.40 & 0.39 & 8.00 \\
\hline VL x N & 0.71 & 0.64 & 2.50 \\
\hline VT X N & 0.37 & 0.33 & 1.50 \\
\hline VL x CL & 0.79 & 0.86 & 4.00 \\
\hline VL x CT & 0.59 & 0.60 & 6.00 \\
\hline VT x CC & 0.35 & 0.27 & 3.50 \\
\hline
\end{tabular}




\subsection{Espectro de Ondeletas:}

A metodologia da TO foi utilizada inicialmente para determinar os principais períodos de variabilidade dos campos de vento, corrente e elevação do nível do mar. A análise foi aplicada sobre a componente inercial do dados no período de Janeiro de 2002 a Janeiro de 2005. As figuras apresentadas são espectogramas de potência de ondeleta, onde o eixo x representa o tempo em que a série foi amostrada e o eixo y os períodos de variabilidade. O padrão de cores representa a energia associada a um período para um determinado momento da série temporal. O cone externo delimita a área de influência da análise e os contornos preto regiões com um limite de confiança maior que $90 \%$. Os gráficos a direita do espectros representam os resultados globais de ondeleta, que são as médias da energia ao longo do tempo para cada período.

Os resultados do espectro de ondeletas, covariância de ondeletas e espectro cruzado foram muito semelhantes para as estações \#106 e \#506. Desta forma optou-se por apenas analisar a série de dados da estação \#506, pois a mesma possui um menor número de lacunas quando comparada com a estação \#106.

Nas figuras 3.46 e 3.47 estão apresentados os espectro de potência de ondeleta das componentes longitudinal e transversal do vento, respectivamente. Através dos resultados, nota-se uma distribuição não homogênea da energia ao longo do tempo, caracterizando o aspecto não estacionário dos processos. No espectro de ondeletas da componente longitudinal a maior parte da energia está concentrada nos períodos próximos a 4, 12, 22, 45, 70 e 360 dias. 
Os meses de setembro a dezembro apresentam uma distribuição mais homogênea de energia ao longo do espectro, apresentando escalas de variabilidade entre 4 e 70 dias. De acordo com Vitorino (2002) a alta energia concentrada entre os períodos de 45 à 70 dias esta relacionada a Oscilação de Madden-Julian (OMJ). A OMJ é o modo de variabilidade tropical mais importante, com potencial influência sobre o tempo de médio a longo período nas regiões extratrópicais (Maddlen and Julian, 1994). Os resultados apresentados pela autora para o campo Radiação de Onda Longa Emergente sugerem que esta escala de variabilidade de OMJ ocorre principalmente nos meses de inverno.

Nos meses de junho à agosto a maior concentração de energia acontece nas freqüências mais altas, entre 4 e 22 dias, fato relacionado a passagem de frentes frias sobre a região.

Já na componente transversal do vento percebe-se uma concentração de energia nos períodos mais baixos, entre 4 e 16 dias, relacionados a passagens de frentes. O espectro global da componente transversal, apresentou picos de energia menores que a componente longitudinal, devido a menor variabilidade desta componente do vento.

Em ambos espectogramas ocorrem altos valores de energia próximos ao período de 365 dias, demonstrando o padrão sazonal do campo de vento. Como dito anteriormente este padrão sazonal esta relacionado as migrações da AAS.

Com intuito de mensurar a amplitude e a fase desta variação sazonal, foi modelado um sinal através de um harmônico senoidal de 365.25 dias (Lentini et al., 2000). Infelizmente esta análise foi invalidada pois o coeficiente de correlação entre o sinal modelado e os dados medidos foi muito pequeno, com valores máximos de $48 \%$ e $33 \%$ para as componentes longitudinal do vento e corrente, respectivamente. 


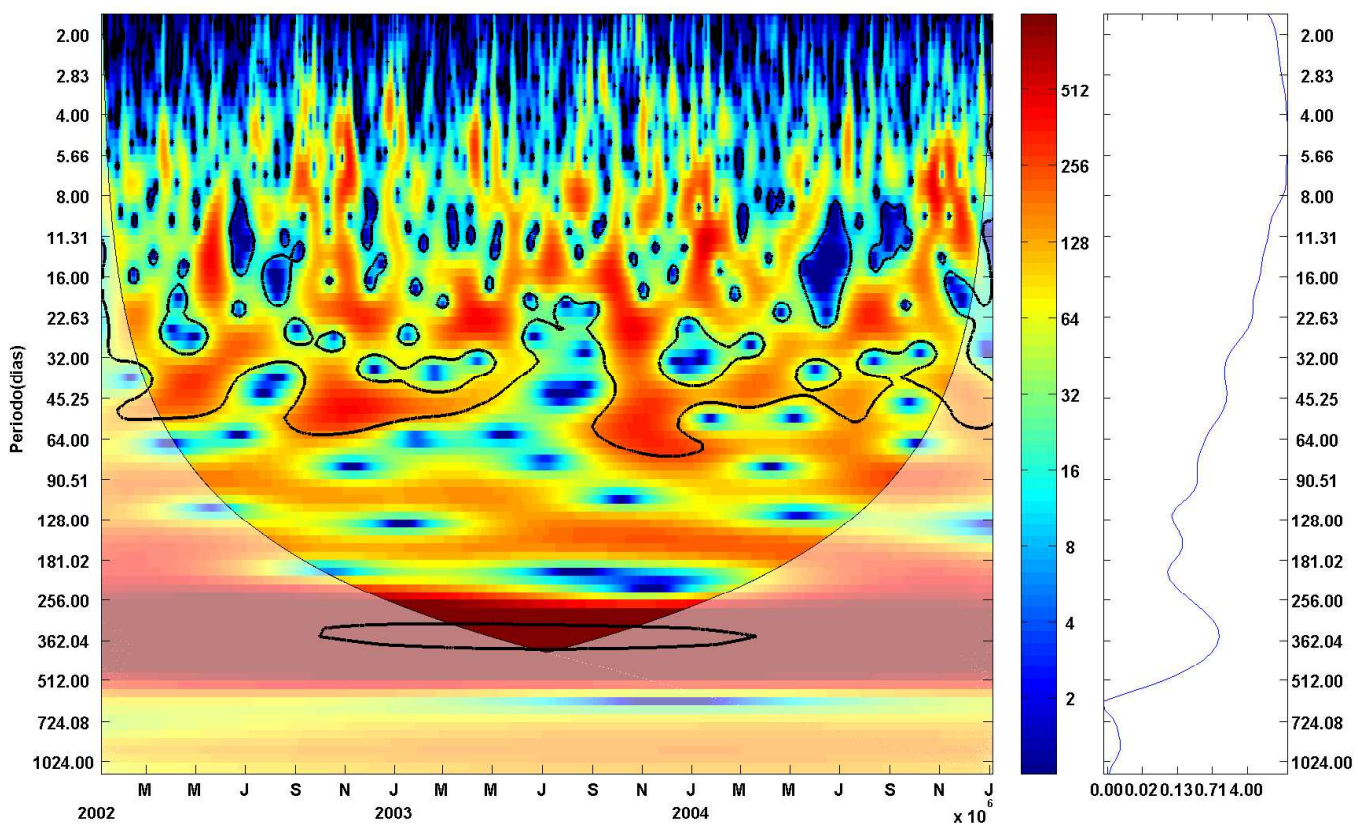

Figura 3.46: Espectro de Potência de Ondeleta da componente longitudinal do vento. A barra de cores representa a energia do espectro (adimensional). O cone externo delimita a área fora de interesse da análise. as linhas realçadas indicam regiões com limite de confiança superior a $90 \%$. O gráfico auxiliar, à direita, mostra o espectro global de ondeletas

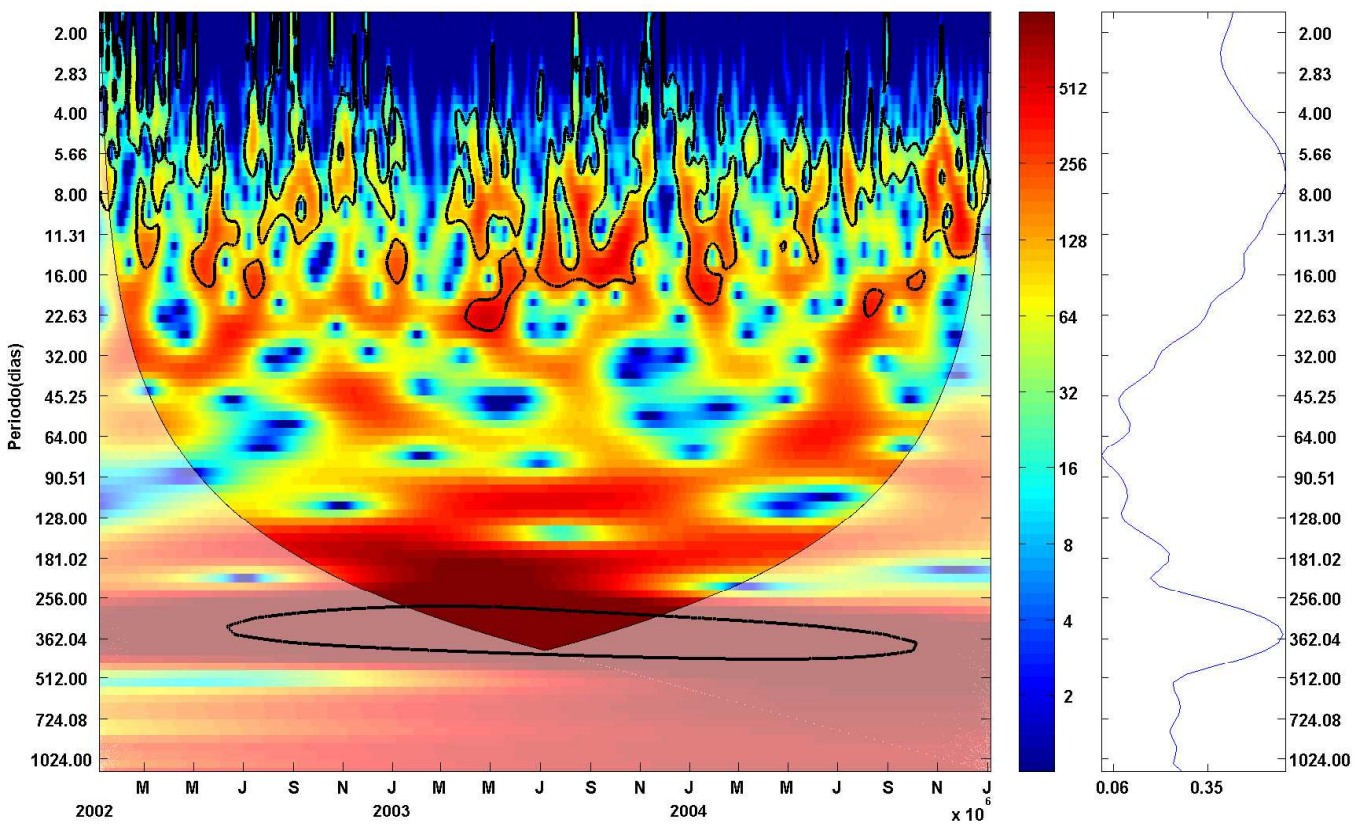

Figura 3.47: Similar a figura anterior, porém para a componente transversal do vento. 
Os resultados do espectro de potência de ondeletas das componentes longitudinal e transversal das correntes são mostrados nas figuras 3.48 e 3.49 respectivamente. Através dos espectogramas nota-se que as maiores concentrações de energia acontecem nos períodos menores que 32 dias. A distribuição energética no campo de correntes foi muito mais heterogêneo do que o campo de ventos. Assim como o vento longitudinal as duas componentes das correntes apresentam uma diminuição de energia nos períodos maiores que 16 dias entre os meses de julho e setembro. O campo de correntes apresentou altos valores de energia no período de um ano, porém estes valores não possuem significância maior do que $90 \%$. Isto deve pode estar ocorrendo pois o ciclo anual não é tão pronunciado no campo de correntes quando comparado ao campo de ventos.

A componente longitudinal das correntes possui picos de energia ocorrendo em períodos de 5 a 32 dias, os quais estão associados a passagens de frentes frias sobre a região. A componente transversal do vento possui regiões de maior energia localizadas em períodos menores que 22 dias, com exceção dos meses de março à junho de 2003, quando os picos de energia acontecem em períodos de 45 dias. Em setembro de 2004 a componente transversal das correntes apresentou um máximo local de energia no período próximo a 64 dias. 


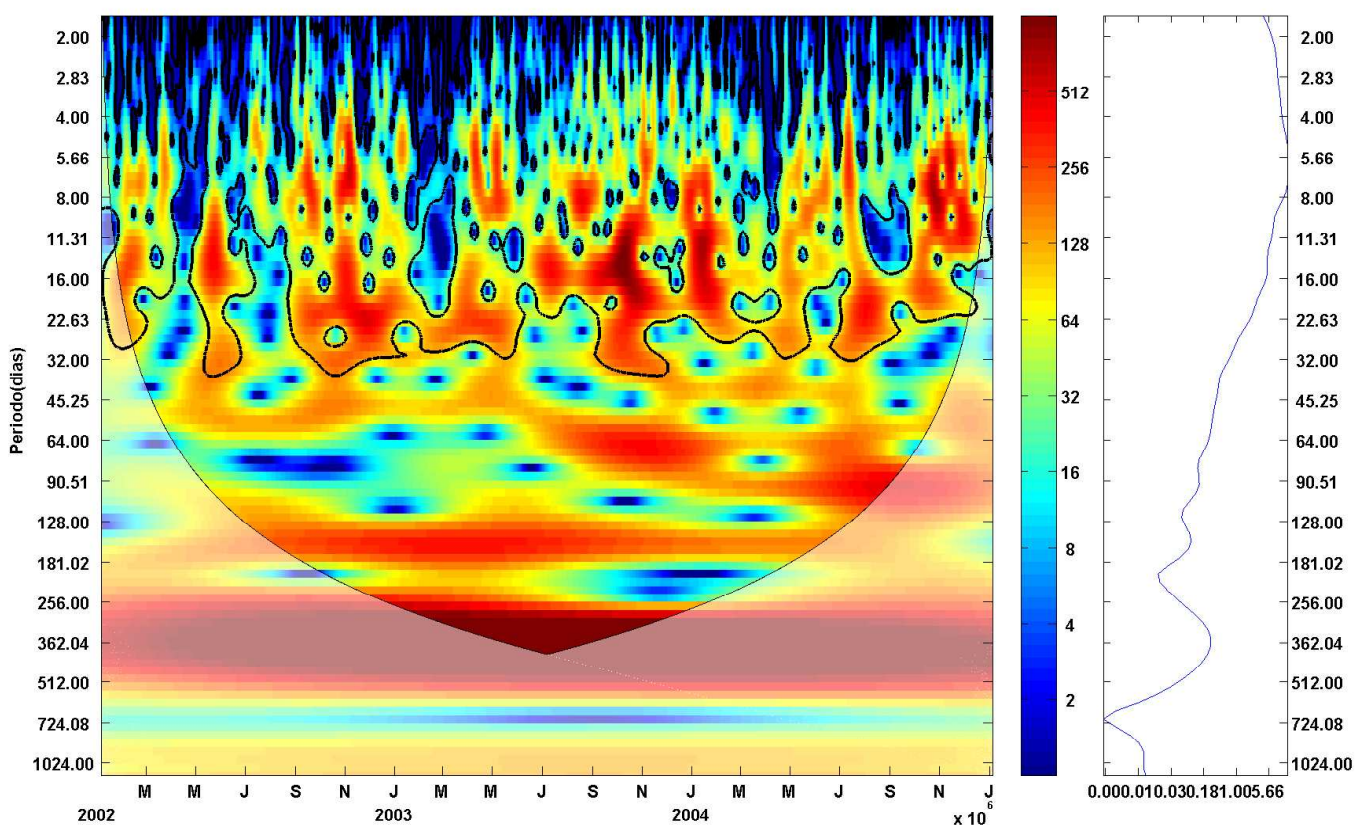

Figura 3.48: Similar a figura anterior, porém para a componente longitudinal da corrente na estação \#506.

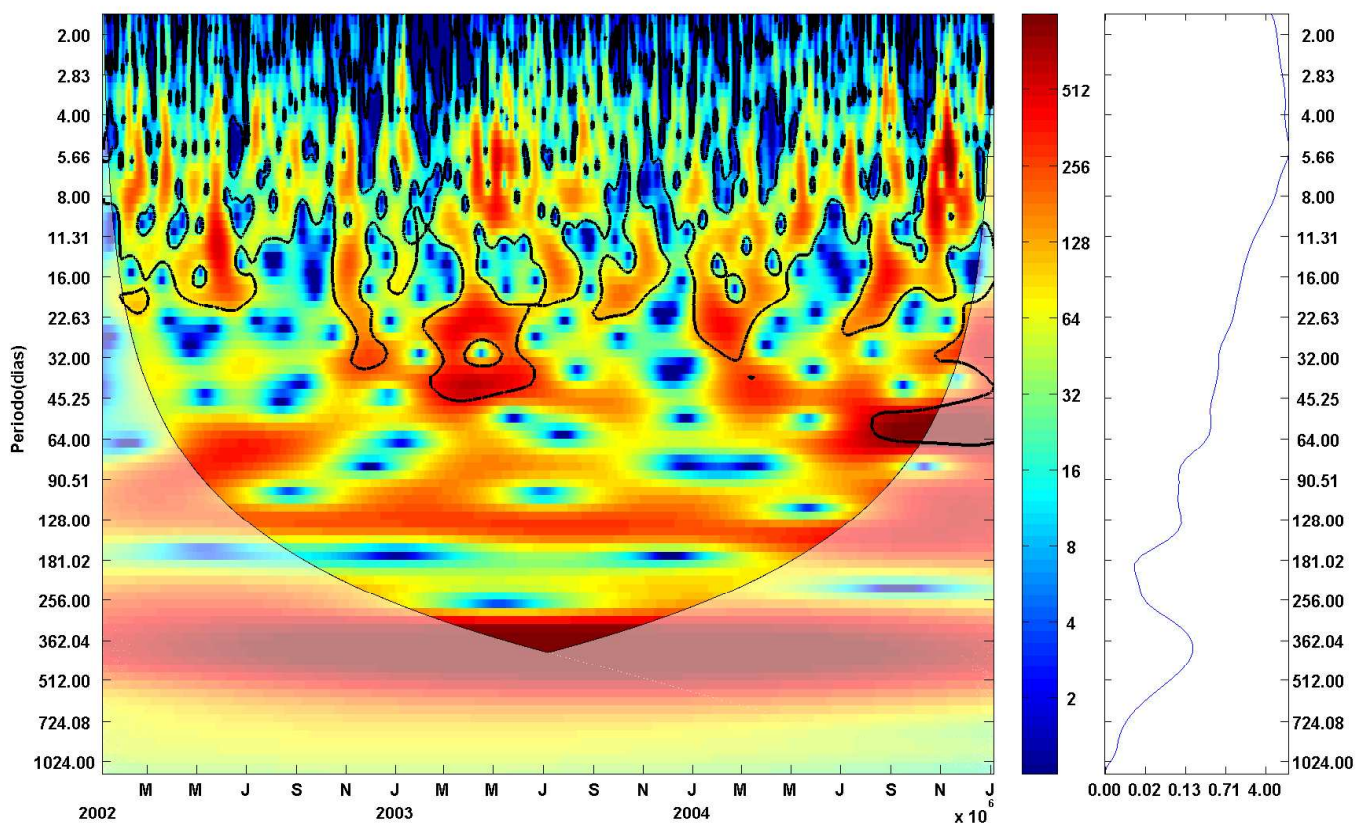

Figura 3.49: Similar a figura anterior, porém para a componente transversal das correntes na estação \#506. 
A figura 3.50 apresenta os resultados do espectro de energia de ondeletas para os dados de elevação do nível do mar. Através dos resultados percebe-se que existe uma grande heterogeneidade temporal na localização dos picos com significância maior que $90 \%$. As regiões de alta energia ocorrem em períodos menores que 16 dias e junto ao período de um ano. Estes resultados sugerem que os principais causadores da variabilidade do campo de elevação do nível do mar são as frentes frias que chegam a região e o ciclo migratório da AAS que agem sobre o campo de ventos gerando alterações no nível do mar. De forma geral o espectro de energia global possui baixos valores, quando comparados com os campos de vento e correntes.

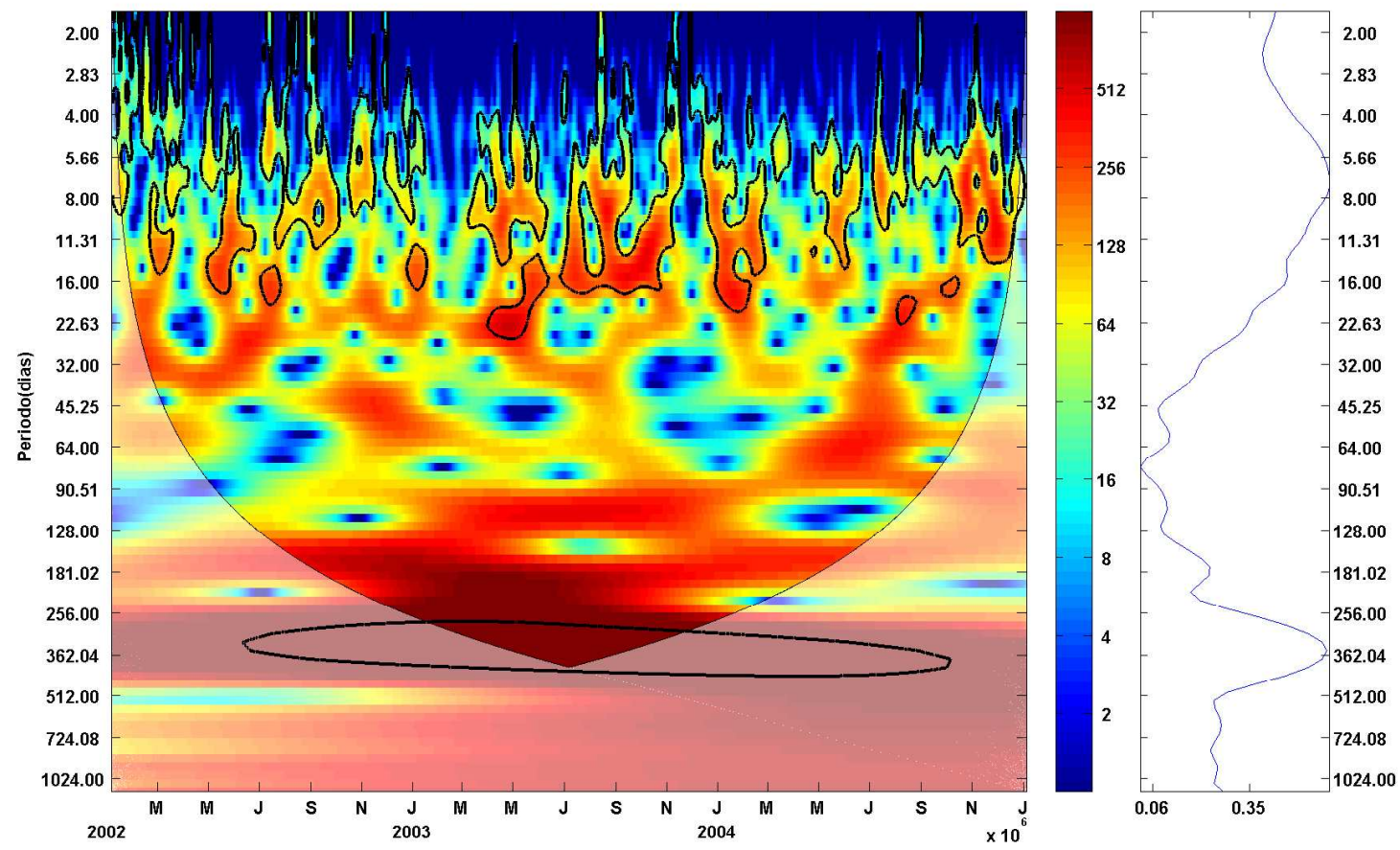

Figura 3.50: Similar a figura anterior, porém para aos dados de elevação do nível do mar na estação \#506. 
Através desta seção foi possível verificar que os campos de ventos, correntes e elevação do nível do mar, possuem uma distribuição heterogênea de energia ao longo da série. Isto significa que diferentes períodos atuam ao longo da série, ressaltando a não estacionaridade destes sinais. Todos os sinais apresentaram altos valores de energia para o período de um ano. Através deste resultado concluímos que existe um ciclo anual de variação dos campos. Além do sinal anual, os períodos de variabilidade mais energéticos se dão entre 4 e 20 dias, estando relacionados com a passagem de frentes frias sobre a região. Devido a influência do OMJ, o campo de ventos apresentou altos valores energéticos nos períodos compreendidos entre 45 e 70 dias. A metodologia de TO se mostrou uma ferramenta eficiente na determinação dos períodos de variabilidade das séries e determinação de sua distribuição ao longo do tempo.

\subsection{Espectro Cruzado de Ondeletas:}

A metodologia do espectro cruzado de ondeleta (ECO) foi utilizada para o entendimento do grau de relação entre a variabilidade de dois campos e na determinação das escalas de tempo onde esta relação acontece. O ECO nos fornece as regiões, no domínio da freqüência e do tempo, onde ambas as séries possuem alta energia.

A metodologia de correlação cruzada utilizada no capítulo anterior utiliza a transformada de Fourier em seus cálculos, esta metodologia considera os sinais estacionários (Emery and Thomson, 1997), o que pode levar a sub-estimação dos valores de correlação entre os dados. Através da metodologia da ECO (Grinsted et al., 2004; Moore et al., 2005) pretende-se sanar esta deficiência e encontrar em quais períodos 
e em qual local da série, os sinais analisados possuem alta energia em comum.

O espectro cruzado entre os dados das componentes longitudinal do vento e corrente (Figura 3.51), corrobora com os resultados sobre os períodos de variabilidade acima. Os maiores valores energéticos ocorrem nos períodos compreendidos entre 4 e 64 dias. É possível notar que assim como nas análises anteriores, existe uma diminuição de energia nos maiores períodos entre os meses de julho a agosto e uma maior homogeneidade ao longo do eixo das freqüências entre os meses de setembro e dezembro.

Ao contrario do esperado o período de um ano não apresentou valores com significância maior do que $90 \%$, apesar da alta energia associada a este período. Este resultado é devido a componente longitudinal do vento não ter apresentado valores significativos no espectro de ondeletas.

As setas nas figuras indicam a fase entre os sinais. Nas regiões do gráfico com maior densidade de energia observa-se que a componente longitudinal do vento e da corrente encontram-se em fase, ressaltando a relação entre os dois campos. 


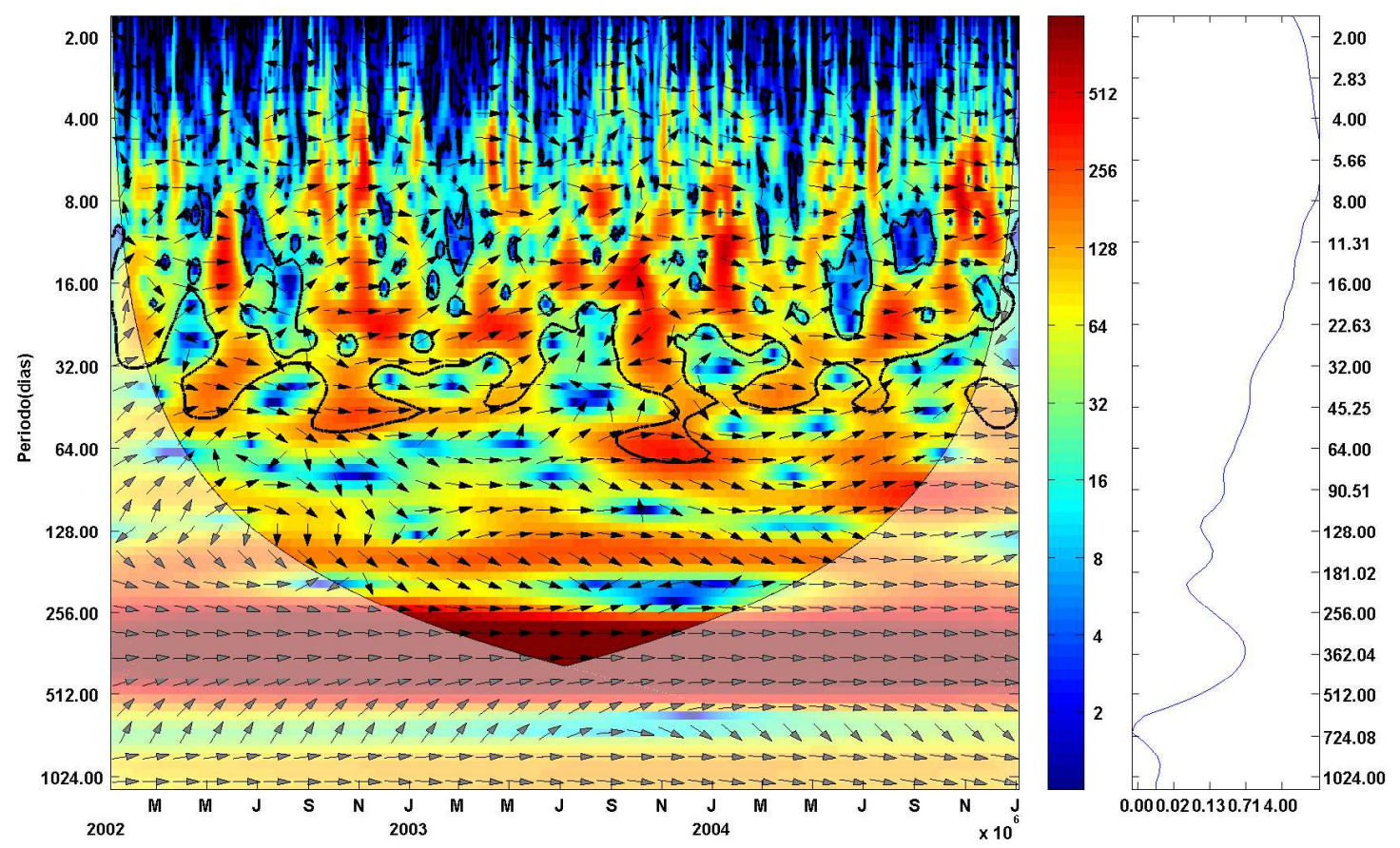

Figura 3.51: Espectro cruzado de ondeleta e espectro global de ondeleta (gráfico auxiliar) entre os dados das componentes longitudinais do vento e das correntes para estação \#506. O cone externo delimita a área de influência da a análise e os contornos preto regiões com um limite de confiança maior que $90 \%$. As setas indicam a fase entre os dados, onde as setas que apontam a direita significam dados em fase e a esquerda em anti-fase.

Na figura 3.52 estão apresentados o espectro cruzado de ondeletas entre a componente longitudinal do vento e a componente transversal da corrente. Os maiores picos de energia ocorrem entre 4 e 45 dias. Assim como na correlação com a componente longitudinal das correntes, existe uma diminuição na energia nos meses de julho à agosto, com exceção do ano de 2004. Neste ano, nos meses de julho à dezembro houve um pico de energia próximo ao período de 64 dias. Na maioria das regiões em que ocorrem altos valores de energia, os sinais estão defasados. As setas entre $0^{\circ}$ e $180^{\circ}$ (sentido anti-horário) representam defasagem em relação ao vento e entre $0^{\circ} \mathrm{e}$ $-180^{\circ}$ (sentido horário) em relação a corrente transversal. Assim, percebe-se que na maioria das vezes a defasagem ocorre em relação ao sinal do vento longitudinal. Isso ocorre, pois primeiro é necessário a ação do vento longitudinal para gerar desníveis na elevação. Após estes desníveis estarem estabelecidos, cria-se um gradiente de 
pressão que dará origem as correntes transversais.

Os resultados da correlação cruzada entre a corrente transversal e o nível estão apresentados na figura 3.53. Como na correlação com o vento longitudinal, o nível apresenta altos valores de correlação com a corrente transversal em diversos períodos ao longo da série. Estes períodos são em geral mais baixos que na figura anterior, estando compreendidos entre 4 e 32 dias. Embora menos homogênea do que na correlação entre o nível e o vento longitudinal, a distribuição das setas demonstra que os sinais de corrente transversal e nível também estão defasados na maior parte do tempo, sendo esta defasagem deslocada em relação ao elevação do nível do mar. Como dito anteriormente esta defasagem se deve ao mecanismo do transporte de Ekman, que necessita de um tempo igual ao período inercial para o estabelecimento dos desníveis que irão dar origem as correntes transversais.

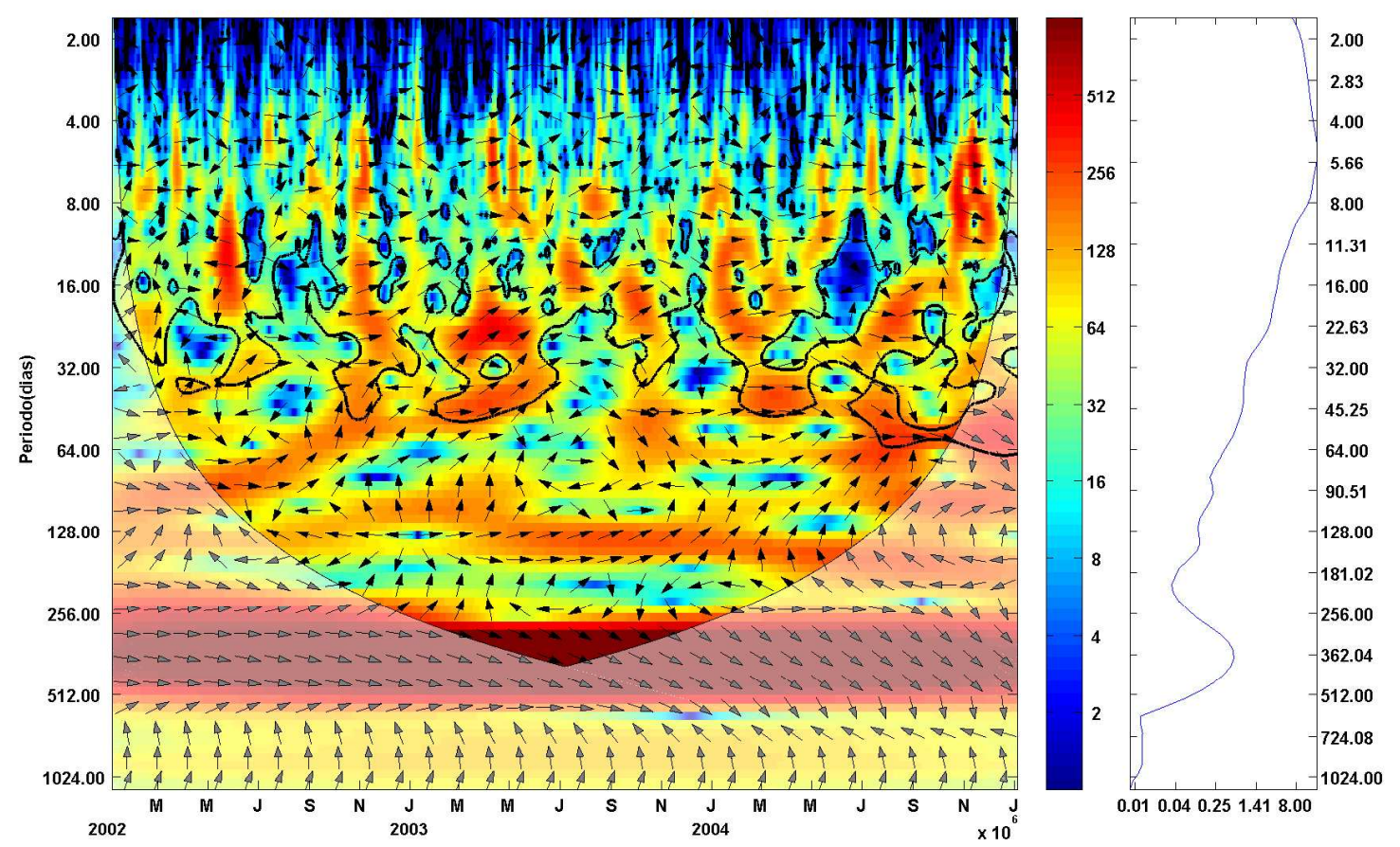

Figura 3.52: Similar a figura anterior, porém para os dados da componente longitudinal do vento e transversal das correntes para estação \#506. 


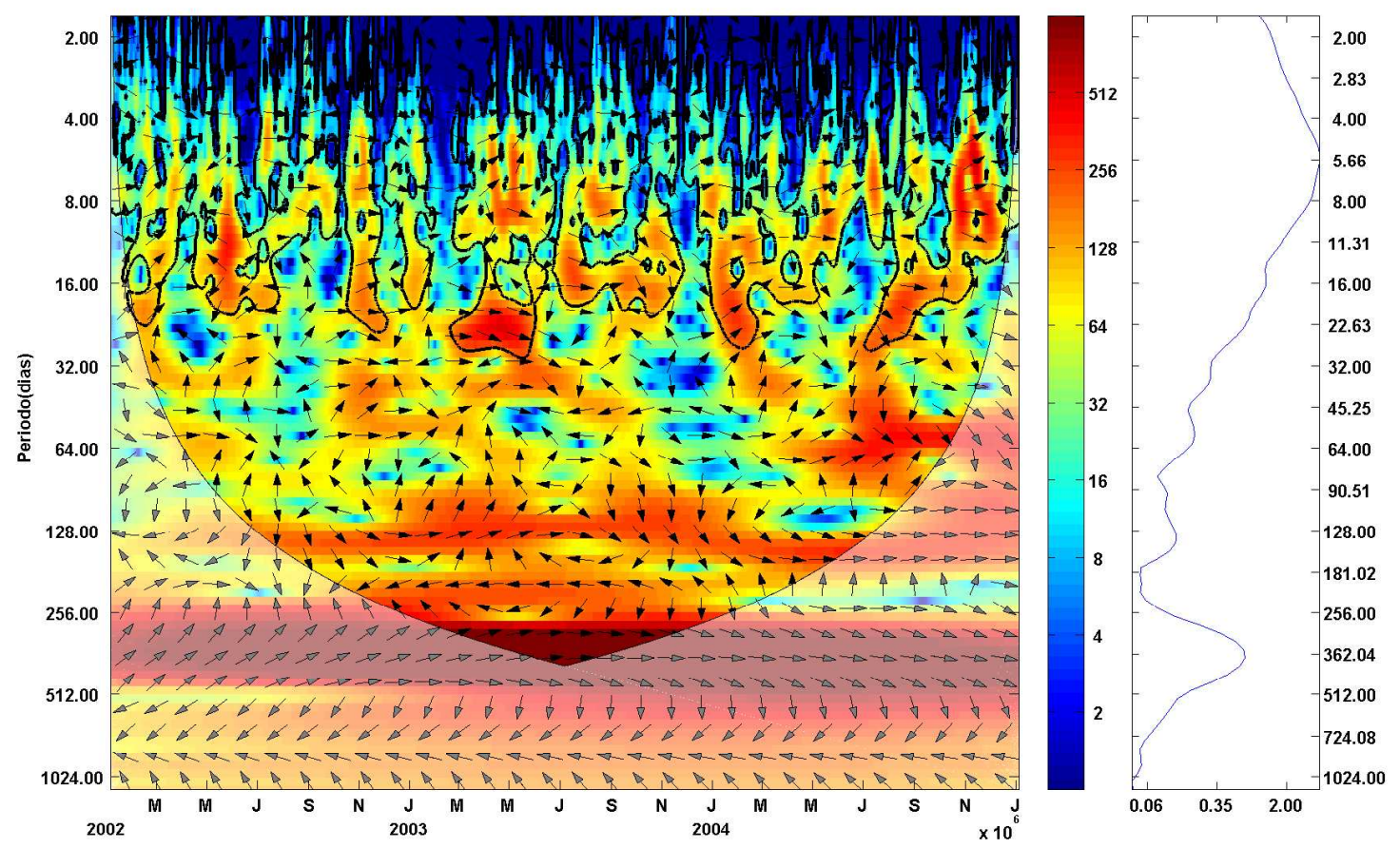

Figura 3.53: Similar a figura anterior, porém para os dados das componente transversal das correntes e elevação do nível do mar para estação \#506.

A figura 3.54 apresenta os resultados do espectro cruzado entre a componente longitudinal do vento e a elevação do nível do mar. Na maior parte do tempo os períodos mais energéticos se encontram entre 4 e 32 dias. Assim como no espectro cruzado anterior os dois sinais analisados encontram-se defasados, sendo a defasagem em relação a componente longitudinal do vento. O espectograma apresenta ainda altos valores de energia próximos ao período de um ano.

O espectro cruzado entre os sinais do vento e corrente transversal à costa (Figura 3.55) e entre o vento transversal a costa e o nível (Figura 3.56) não mostram uma coerência de fase, sendo esta altamente variável entre os diferentes períodos e ao longo da série. Isto sugere que apesar de haver regiões em comum com valores altos de energia, não existe uma relação direta entre os estes campos. 


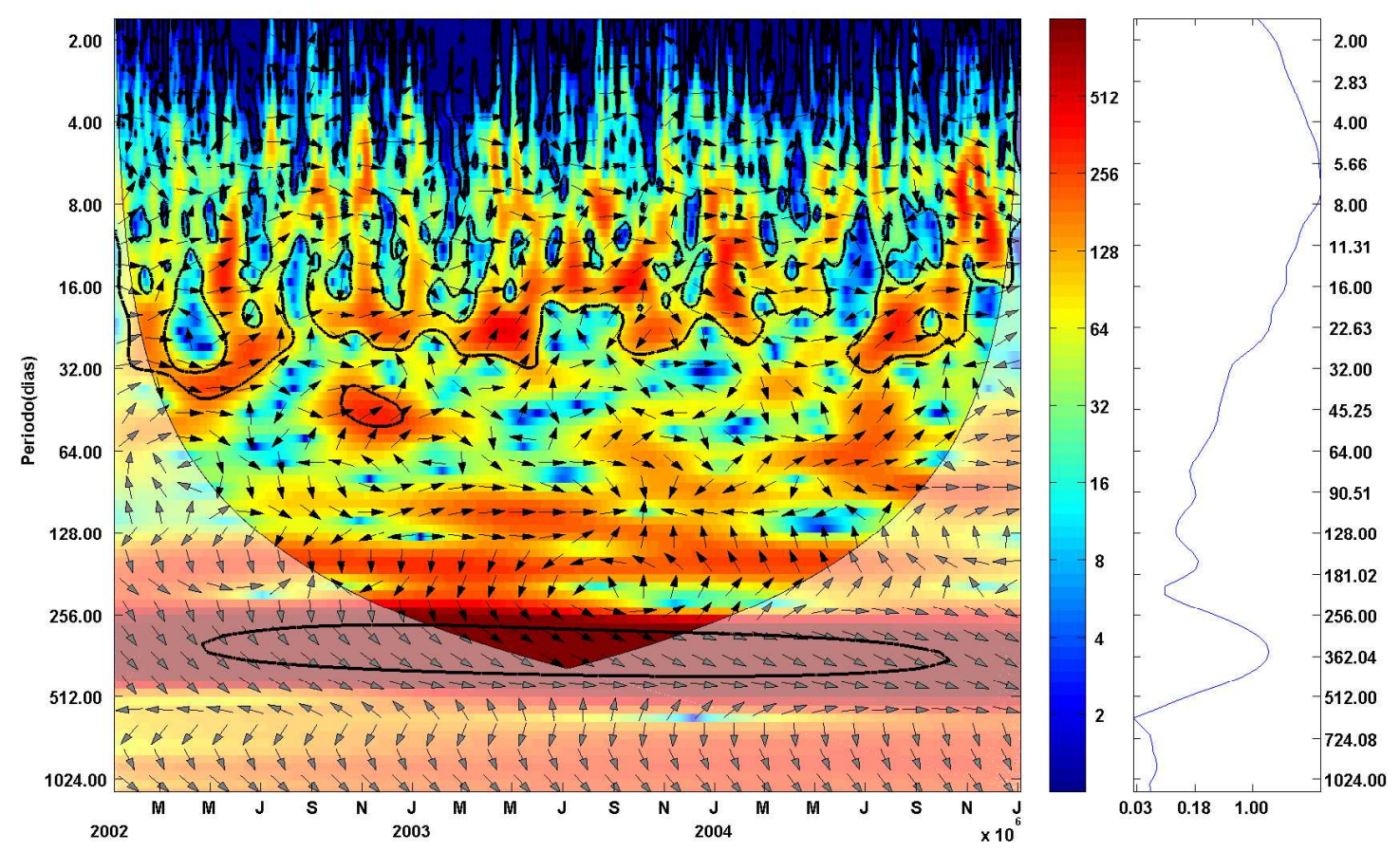

Figura 3.54: Similar a figura anterior, porém para os dados da componente longitudinal do vento e da elevação do nível do mar para estação \#506.

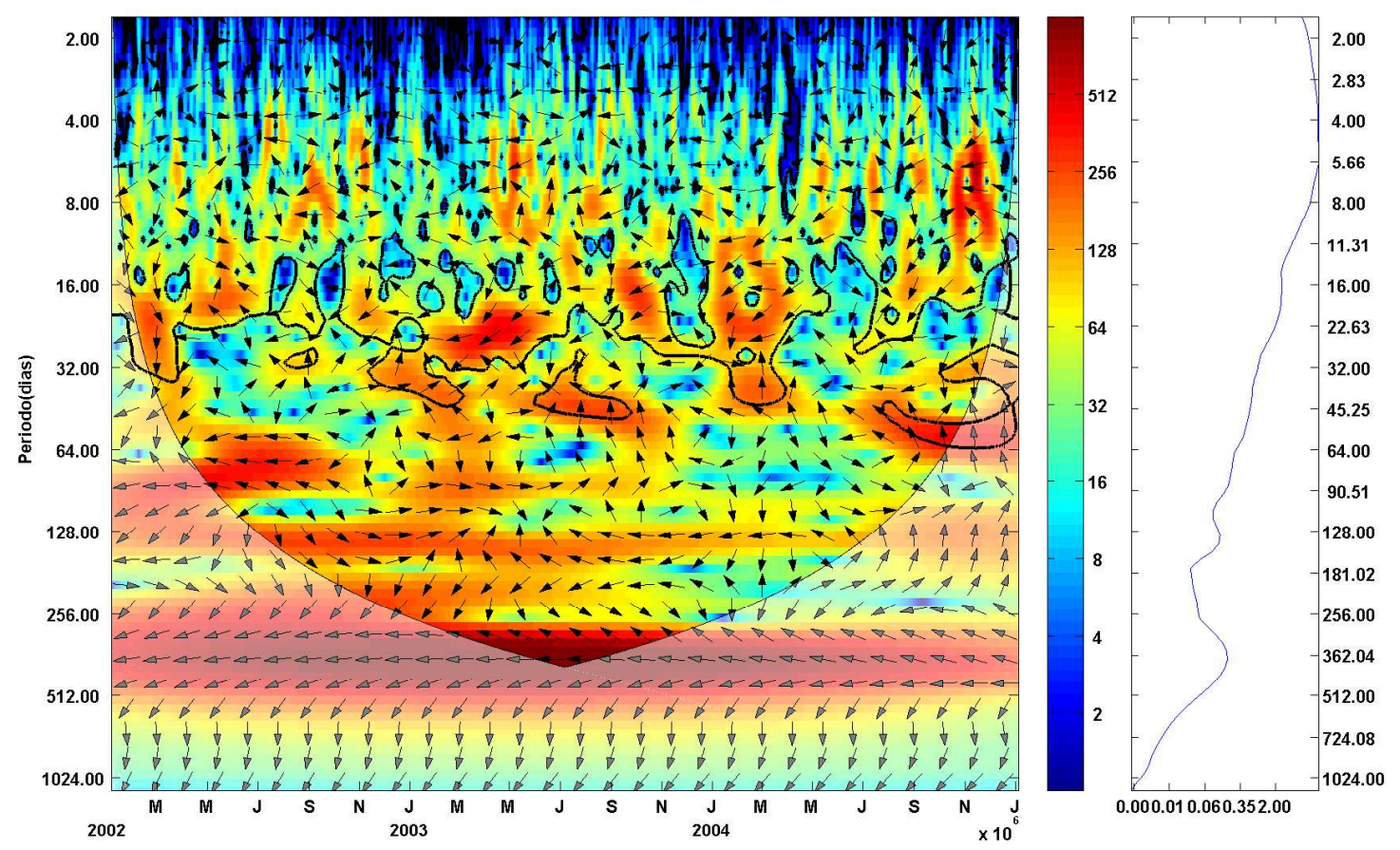

Figura 3.55: Similar a figura anterior, porém para os dados das componentes transversais do vento e das correntes para estação \#506. 


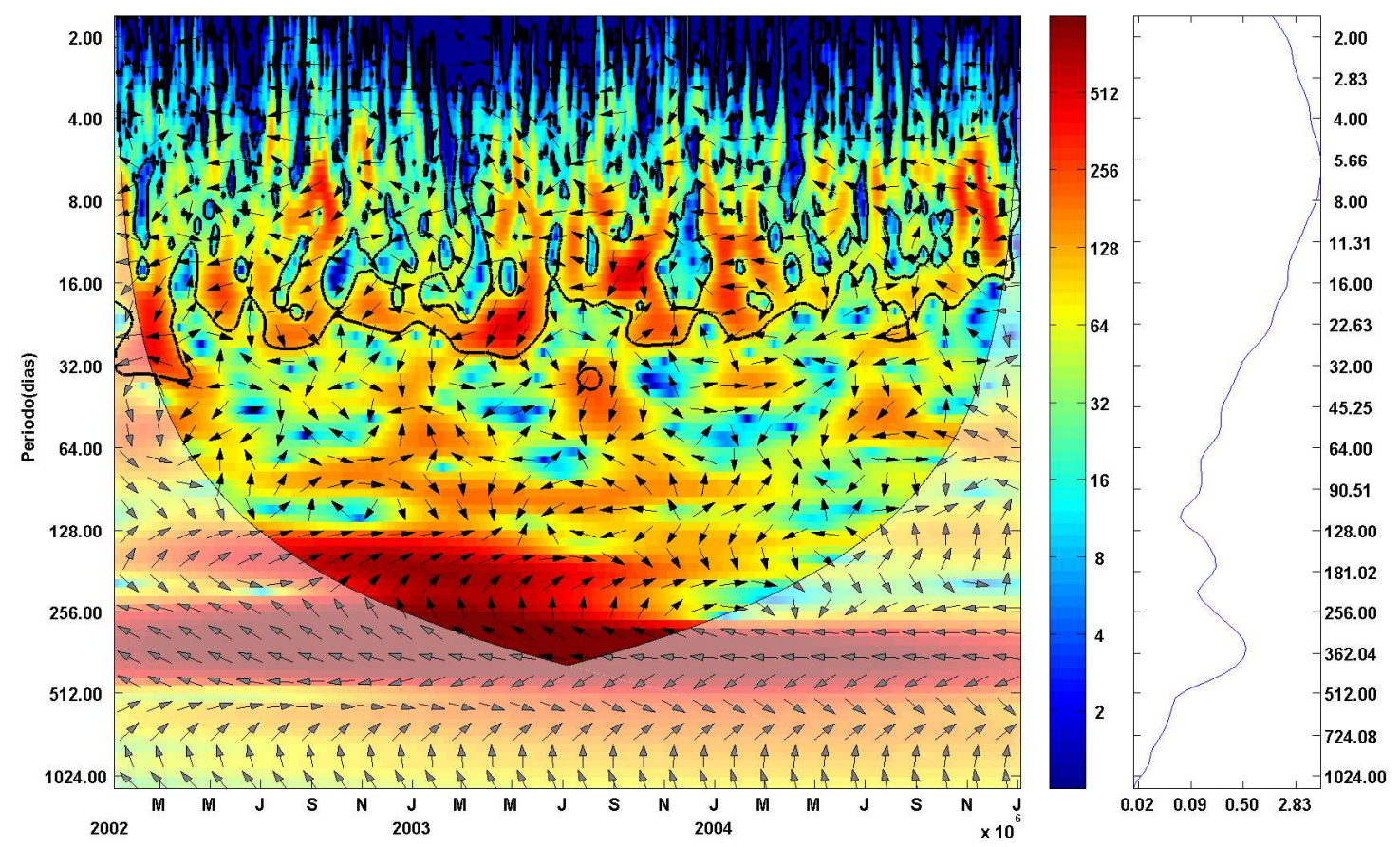

Figura 3.56: Similar a figura anterior, porém para os dados das componente transversal do vento e elevação do nível do mar para estação \#506.

Como esperado os resultados desta seção sugerem que o vento longitudinal é mais influente na variabilidade dos campos de correntes e nível. A elevação do nível do mar, também apresenta grande influência sobre a componente transversal das correntes. Através dos resultados de fase pode-se confirmar que existe uma defasem entre a ocorrência do vento longitudinal, a geração de oscilações no nível do mar e o estabelecimento das correntes transversais. Não houve, coerência de fase entre o vento transversal, as correntes e o nível, sugerindo que esta componente do vento não possui uma relação direta com os demais campos. Os principais períodos de variabilidade estão compreendidos entre 4 e 64 dias. 


\subsection{Covariância de Ondeletas:}

Nesta seção serão calculados a covariância entre os dados, utilizando a metodologia da TO (Grinsted et al., 2004; Moore et al., 2005). Os resultados da covariância são dados no intervalo entre 0 e 1 , fornecendo uma medida de covariância entre duas series temporais em função da freqüência e do tempo, independentemente da diferença de fase entre as mesmas.

O calculo da covariância entre os campos de corrente e vento paralelos à costa (Figura 3.57) mostram um alto coeficiente de covariância e uma coerência de fase em quase todo o espectro e ao longo de toda a série. Exceções acontecem dos meses de maio de 2003 à maio de 2004 nos períodos de 64 a 128 dias; e nos meses de julho de 2003 à março de 2004 nos períodos de 16 a 64 dias. Existe um coerência de fase em quase todo espectro de covariância, ressaltando a correlação entre os dois campos.

Na figura 3.58 estão graficados os resultados relativos a covariância entre as componentes longitudinal do vento e transversal de corrente. Os resultados mostram um coeficiente de covariância menos homogêneo ao longo do espectro e do tempo, com valores altos em diversos períodos do espectro. Os maiores coeficientes de covariância estão concentradas principalmente entre os períodos de 4 à 64 dias e em geral, os tornam-se mais concentrados nas maiores freqüências nos meses de julho a dezembro. Ambos os gráficos mostram valores altos de covariância para os períodos próximos a um ano.

Os resultados de covariância entre os campos da corrente transversal e o nível são apresentados na figura 3.59. Notam-se padrões semelhantes aos resultados de covariância do vento longitudinal e do nível, porém os maiores coeficientes estão distribuídos em períodos menores do que 45 dias. Os resultados de fase são coerentes estando deslocados em relação ao campo de elevação do nível do mar, novamente salientando a dinâmica de Ekman no estabelecimento dos fluxos transversais à costa.

A figura 3.60 apresenta os resultados da covariância de ondeleta entre a com- 


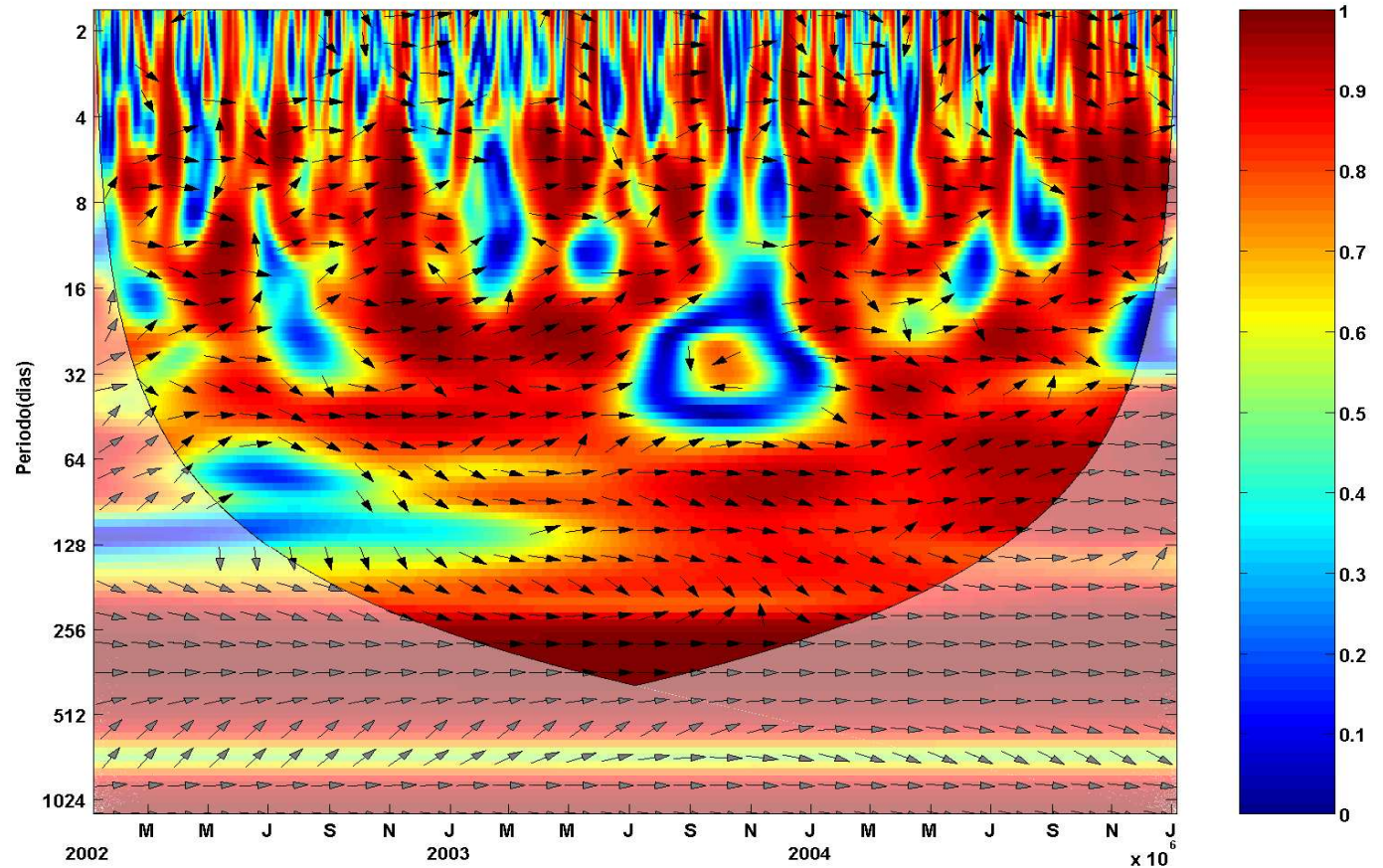

Figura 3.57: Covariância de ondeleta entre os dados das componentes longitudinais do vento e das correntes para estação \#506. O cone externo delimita a área de influência da a análise e os contornos preto regiões com um limite de confiança maior que $90 \%$. As setas indicam a fase entre os dados, onde as setas que apontam a direita significam dados em fase e a esquerda em anti-fase. 


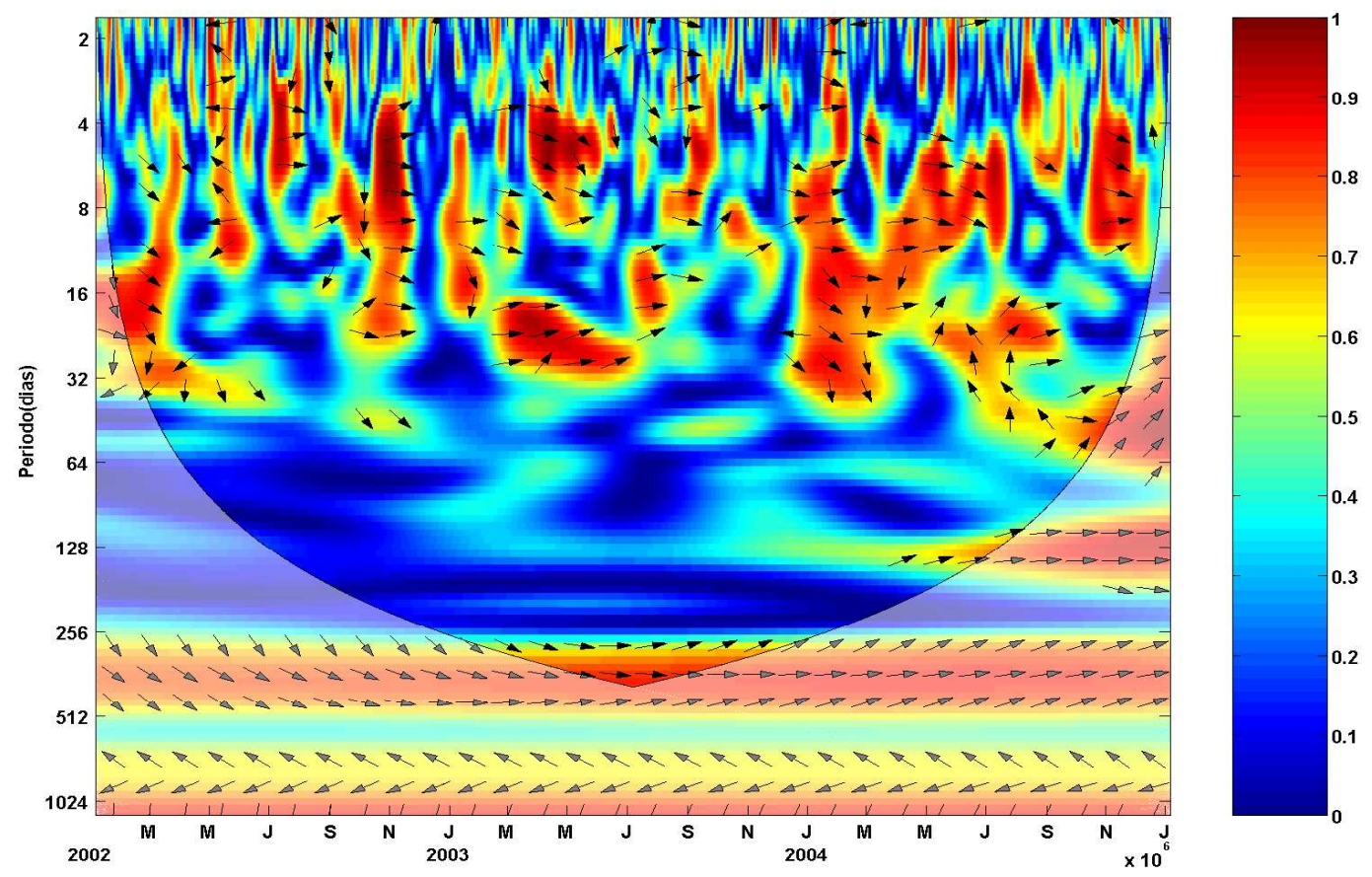

Figura 3.58: Similar a figura anterior, porém para os dados da componente transversal das correntes e a elevação do nível do mar para estação \#506.

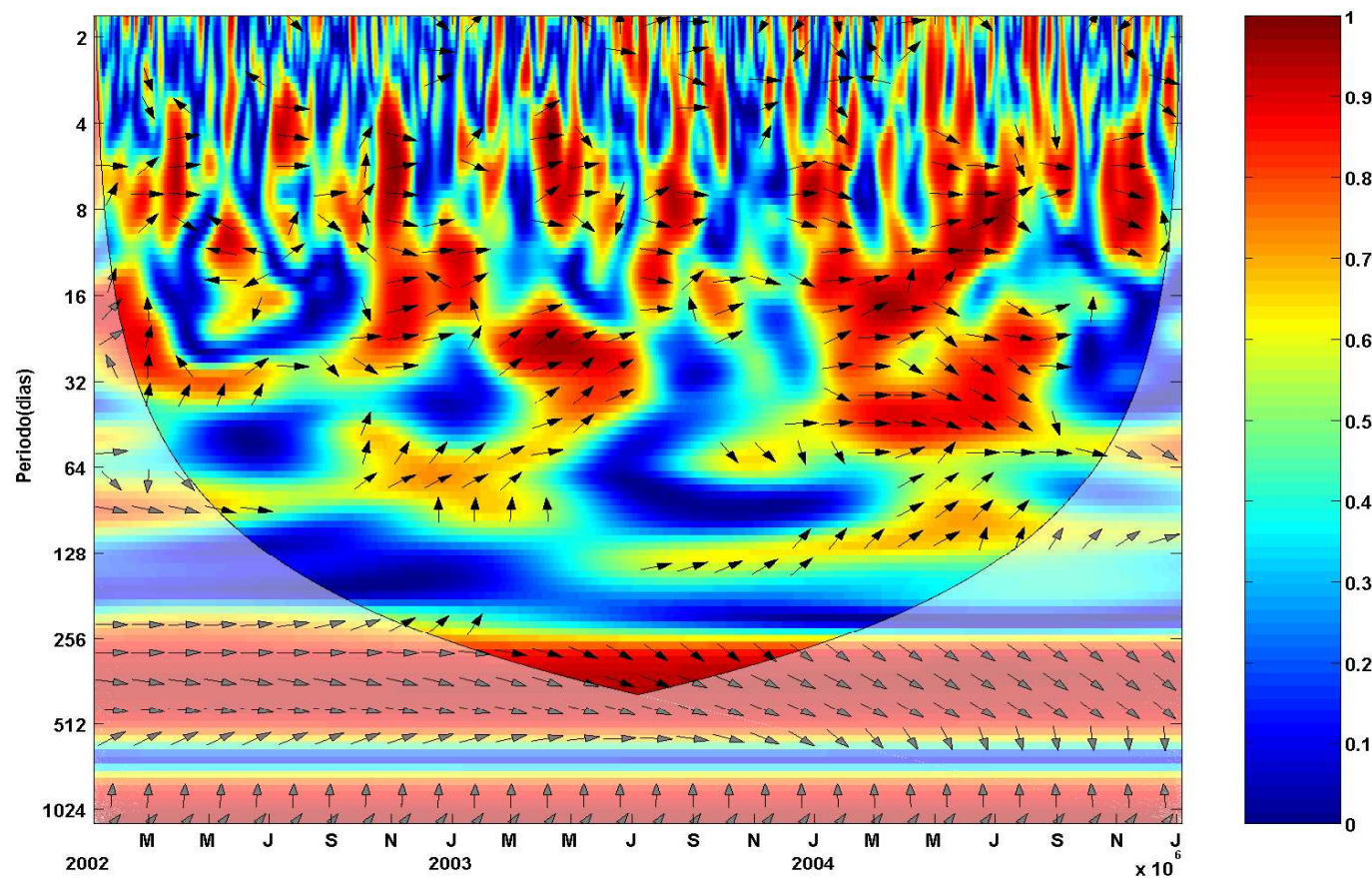

Figura 3.59: Similar a figura anterior, porém para os dados da componente longitudinal do vento e transversal das correntes para estação \#506. 
ponente longitudinal do vento e a elevação do nível do mar. Os maiores indices de covariância estão distribuídos de forma heterogênea ao longo série, estando compreendidos entre 4 e 64 dias. Estes períodos chegam a 128 dias a partir do mês maio de 2004. Entre junho de 2003 e fevereiro de 2004 houve uma redução no coeficiente de covariância nos maiores períodos. Em geral os campos estão em fase ou levemente defasados em relação ao vento longitudinal.

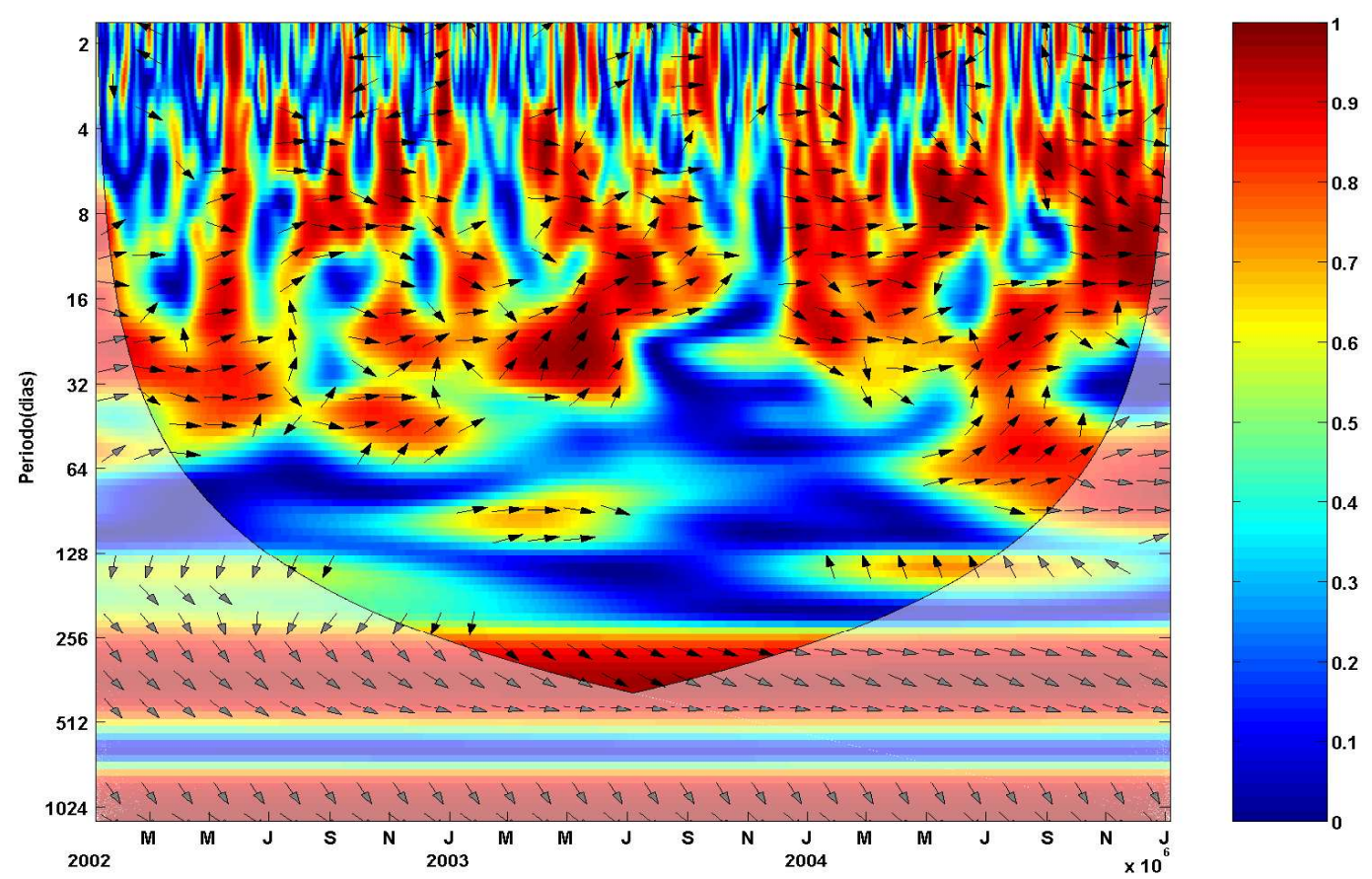

Figura 3.60: Similar a figura anterior, porém para os dados da componente longitudinal do vento e da elevação do nível do mar para estação \#506.

A covariância entre os dados das componentes transversal do vento e corrente e entre a componente transversal do vento e elevação do nível do mar estão apresentados nas figuras 3.61 e 3.62 respectivamente. Assim como os resultados relativos a correlação cruzada, a fase entre estas séries não apresenta coerência, sendo esta altamente variável ao longo da série. Isto sugere que não existe uma relação direta entre os estes campos, demonstrando a importância secundaria desta componente do vento na variabilidade do campo de correntes e elevação do nível do mar.

Os resultados de covariância apresentados nesta seção, corroboram com os obti- 
dos na seção anterior e sugerem que a componente longitudinal do vento é o mecanismo mais importante na variabilidade dos campos de corrente e elevação do nível do mar. Com exceção do gráfico de covariância entre as componentes longitudinais do vento e corrente, as demais análises apresentam concentração entre 4 e 64 dias. A falta de coerência nos resultados de fase entre a componente transversal do vento e os demais campos, sugerem que esta componente tem importância secundaria no estabelecimento de fluxos e nas oscilações do nível do mar.

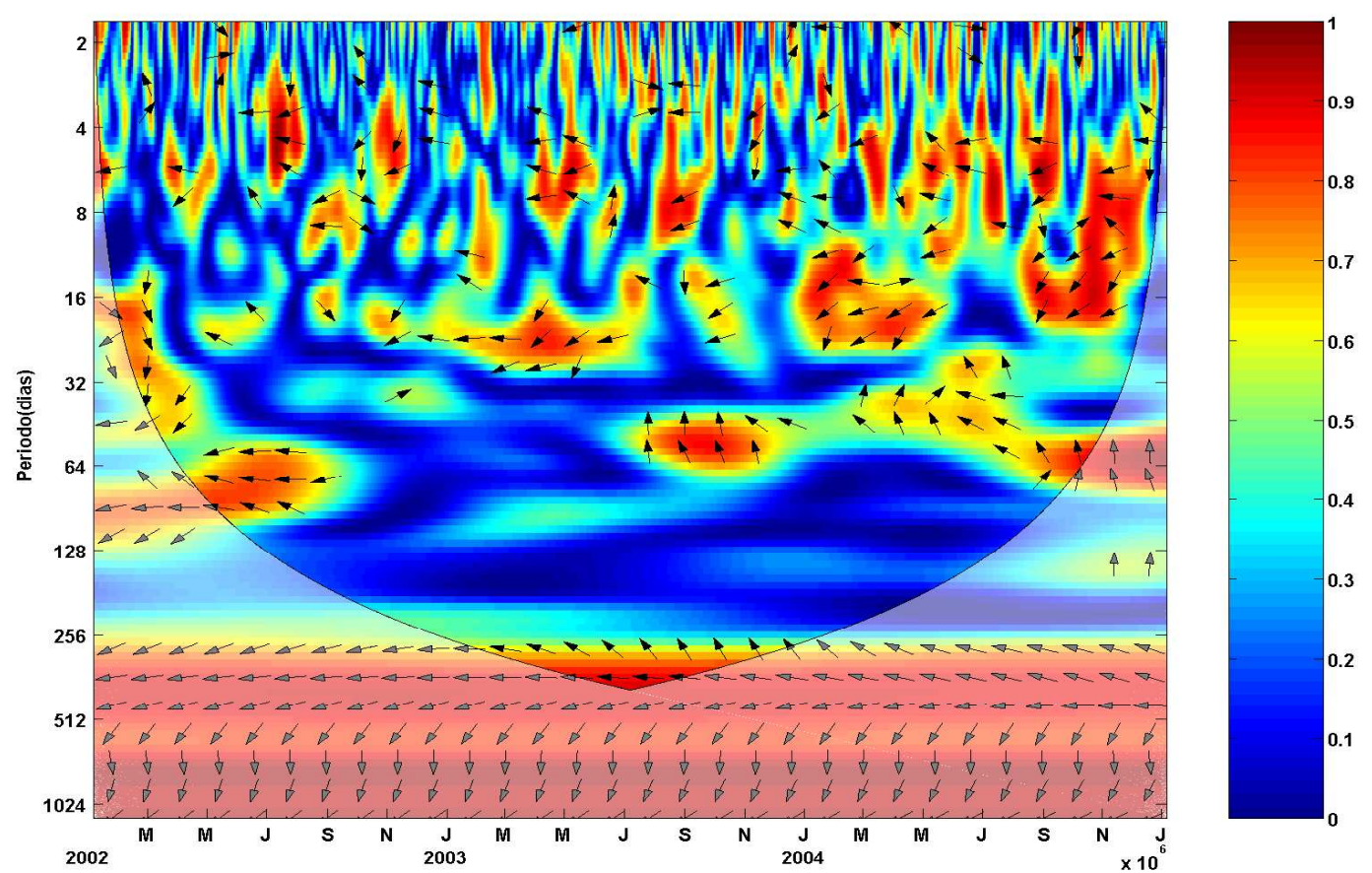

Figura 3.61: Similar a figura anterior, porém para os dados da componentes transversais do vento e das correntes para estação \#506. 


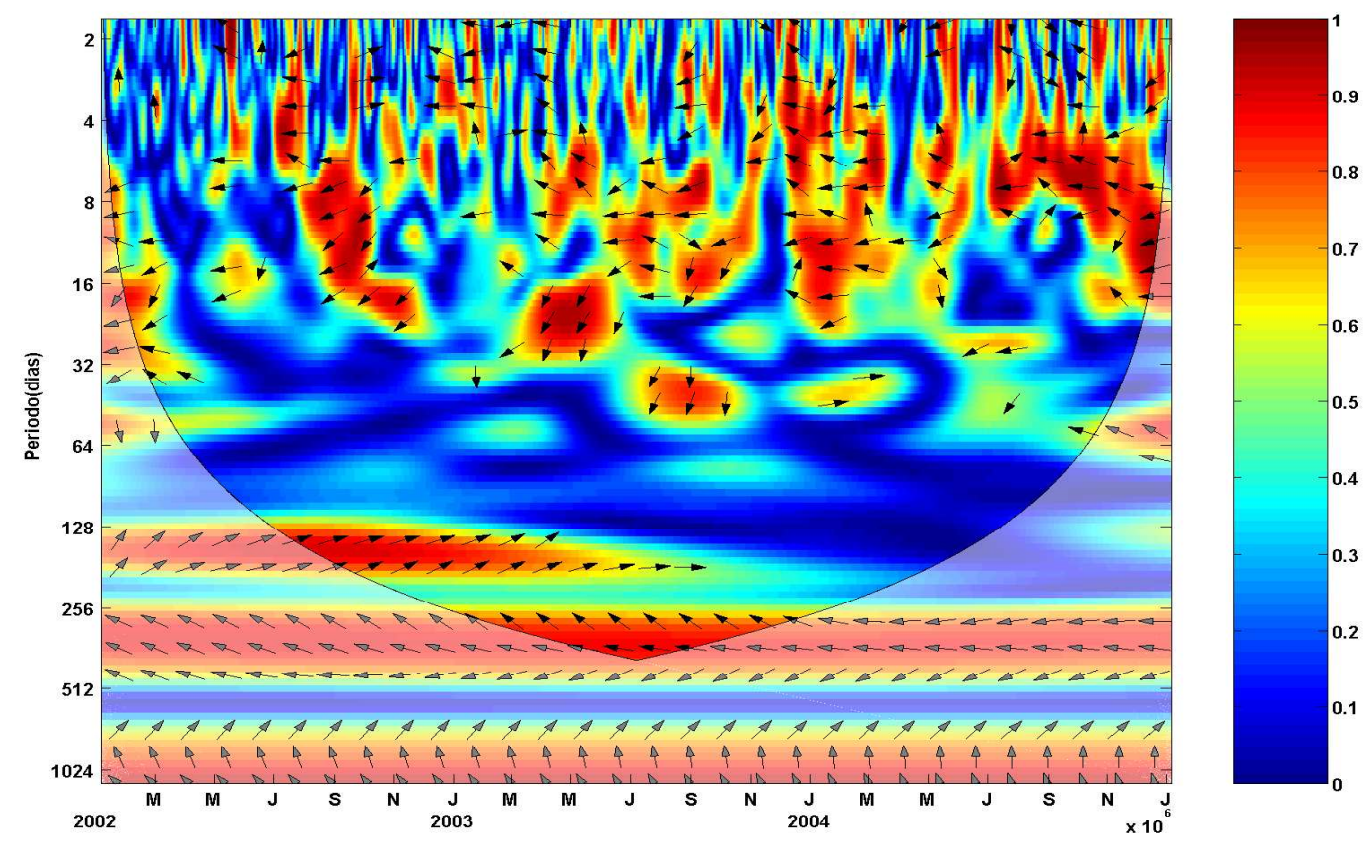

Figura 3.62: Similar a figura anterior, porém para os dados da componente transversal do vento e da elevação do nível do mar para estação \#506. 


\section{Capítulo 4}

\section{Conclusões}

Neste trabalho foram analisadas as séries temporais de correntometria e elevação do nível do mar provenientes de dois fundeios realizados no Canal Sueste, zona costeira adjacente ao Banco de Abrolhos, entre no período compreendido entre janeiro de 2003 e janeiro de 2005. Além disto foram utilizados os dados do campo de vento coletados numa estação automática a cerca de $12 \mathrm{~km}$ à oeste do ponto de fundeio. Com base nestes dados pode-se caracterizar os padrões de circulação oceânica e atmosférica da região, bem como os seus principais forçantes e modos de variabilidade. A metodologia de Transformada de Ondeletas foi empregada para determinação dos principais períodos de variabilidade dos dados e para o cálculo da correlação cruzada e covariância entre os mesmos. A Transformada de Ondeletas mostrou-se uma ferramenta eficiente, possibilitando a determinação dos períodos de variabilidade mais energéticos e em que instante da série esta variabilidade ocorre.

Com base nos dados do campo de vento, conclui-se que a circulação atmosférica no extremo sul da Bahia possui um padrão anual demarcado associado a posição da AAS. Os ventos da direção nordeste ocorrem na maior parte do ano, estando associados com as maiores velocidades. Os ventos locais são afetados pela penetração de frentes frias e pelos VCAN, os quais inferem uma variabilidade anual. Percebe-se 
que devido a um aumento na ocorrência dos ventos do quadrante sul, houve uma diminuição na intensidade dos ventos entre o período de 2002 e 2004 .

Através dos dados de elevação do nível do mar concluímos que as componentes de maré semi-diurna, M2 e S2 e as componentes diurnas O1 e S1 são as mais importantes da região. A amplitude local da maré pode ser considerada a mais alta de toda costa leste brasileira. Este fato pode estar ocorrendo devido a modificações na ondas de maré que chegam a região causadas pela geomorfologia local. Como esperado, a componente longitudinal do vento, na banda sub-inercial, se mostrou o fator mais importante na geração das oscilações do nível do mar. O empilhamento de água junto à costa pode gerar desníveis positivos de até $40 \mathrm{~cm}$, sendo estes mais comuns nos meses de abril à agosto quando há a predominância de ventos do quadrante sul. A sazonalidade da componente longitudinal do vento, gerou oscilações no nível do mar com amplitude aproximada de $22 \mathrm{~cm}$ e um período próximo a um ano.

Analisando-se os dados de correntometria, concluiu-se que a maré é a principal responsável pela variabilidade das correntes perpendiculares à costa e possuem importância secundaria no caso das correntes paralelas a costa. O campo de correntes observado se alinhou com o eixo do canal, tendo uma resultante voltada para SE na maior parte do tempo. As velocidades da estação \#106 mostraram-se maiores do que a estação \#506 devido ao afunilamento do canal nesta estação. A componente longitudinal na banda sub-inerciais é forçada principalmente pelo vento longitudinal, sendo sucessível aos eventos meteorológicos que influenciaram o padrão de ventos. As maiores intensidades das correntes nesta componente tem valores negativos e ocorrem nos meses de outubro a janeiro associadas a ventos de NE. O vento longitudinal e as oscilações do nível do mar foram os principais responsáveis pela variabilidade da corrente transversal. As maiores intensidades desta componente das correntes acontecem em eventos negativos, associado a ventos de NE e a reduções do nível do mar junto a costa.

Através dos espectogramas de ondeletas pode-se verificar que os campos de ven- 
tos, correntes e elevação do nível do mar, possuem uma distribuição heterogênea de energia ao longo da série ressaltando a característica não estacionaria destes sinais. Todos os sinais analisados apresentaram altos valores de energia para o período de um ano. Os períodos de variabilidade mais energéticos se dão entre 4 e 20 dias, estando relacionados com a passagem de frentes frias sobre a região. Devido a influência do OMJ, o campo de ventos apresentou altos valores energéticos nos períodos compreendidos entre 45 e 70 dias. Os sinais analisados apresentam altos valores energéticos nos períodos próximos a um ano, devido a sazonalidade anual dos sinais.

Como esperado os resultados da espectro cruzado e covariância de ondeletas sugerem que o vento longitudinal é mais influente na variabilidade dos campos de correntes e nível. A elevação do nível do mar, também apresenta grande influência sobre a componente transversal das correntes. Através dos resultados de fase pode-se confirmar que existe uma defasem entre a ocorrência do vento longitudinal, a geração de oscilações no nível do mar e o estabelecimento das correntes transversais. Não houve, coerência de fase entre o vento transversal, as correntes e o nível, sugerindo que esta componente do vento não possui uma relação direta com os demais campos.

Os resultados deste trabalho sugerem que o transporte de Ekman é o principal mecanismo da dinâmica sub-inercial local, sendo o vento longitudinal o principal agente modificador. Os fluxos são alterados ainda, pela presença de ilhas, canais e os recifes coralinos da região. O trabalho aqui apresentado possui vários resultados que poderão servir como uma ferramenta de manejo para o gerenciamento da zona costeira de Caravelas e do próprio Parque Nacional de Abrolhos. 


\subsection{Sugestão para trabalhos futuros:}

Esta dissertação fez uso dos três primeiros anos de dados do monitoramento. Sugere-se que as análises aqui realizadas sejam estendidas para o restante dos dados, haja vista o monitoramento ainda estar sendo realizado.

Sugere-se ainda realizar outros fundeios dentro do canal de Abrolhos o que estenderia os resultados a uma região mais próxima do Complexo de Abrolhos. Além dos correntômetros sugere-se que sejam instalados sensores termo-halinos nestes fundeios para estudar a influência das descargas continentais sobre a circulação. Estes sensores seriam usados ainda para o estudo da importância dos vortices liberados pela Corrente do Brasil na região. Também sugere-se a instalação de uma estação meteorológica automática no Parque de Abrolhos para a disponibilizarão de dados para a comunidade científica, haja vista os dados aqui utilizados serem propriedade da empresa Aracruz Celulose e não havendo garantia de continuidade do monitoramento.

Outra abordagem sugerida é a modelagem numérica da hidrodinâmica local, para se estudar a influência dos Bancos de Abrolhos e Royal Charlotte sobre a circulação.

Por ultimo sugere-se que os dados aqui apresentados sejam comparados com outros dados de regiões costeiras do Brasil para o estudo da ocorrência de ondas de plataforma sobre o sul do litoral nordeste do Brasil. 


\section{Referências Bibliográficas}

Amorim, F. N., Caracterização oceanográfica da baía de camamu e adjacências e mapeamento das áreas de risco a derrames de óleo, Master's thesis, Universidade Federal da Bahia, Salvador, Bahia,Brasil, 2005.

Andrade, K. M., Comportamento dos sistemas frontais sobre a américa do sul, Dissertação de mestrado em meteorologia, Instituto Nacional de Pesquisas Espaciais - INPE, S. J. dos Campos, SP, Brasil, 2004.

Chaves, R. R., Variabilidade da precipitação na região Sul do Nordeste e sua associação com padrões atmosféricos, Master's thesis, Instituto Nacional de Pesquisas Espaciais, 159 pp, 1999.

CLIMANALISE, ClimanÁlise, boletim de monitoramento e análise climática, Tech. rep., INPE/CPTEC, Cachoeira Paulista, SP, Brasil, 2002-2004.

DNAEE, Divisão de controle dos Recursos Hídricos , Inventário das estações fluviométricas, Tech. rep., DNAEE, Brasilia, 1987.

Emery, W. J., and R. E. Thomson, Data Analysis Methods in Physical Oceanography, Pergamon, New York, 400 pp, 1997.

Gan, M. A., Um estudo observacional sobre as baixa frias da alta troposfera, nas latitudes subtropicais do atlântico sul e leste do brasil, Dissertação de mestrado em meteorologia, Instituto Nacional de Pesquisas Espaciais - INPE, S.J. Campos, SP, Brasil., 1982. 
Ghil, M., et al., Advanced spectral methods for climatic time series, Reviews Geophysics, 40(1), 2002.

Griffin, D., J. Middleton, and L. Bode, The tidal and longer-period circulation of capricornia, southern great barrier reef, Australian Journal of Marine and Freshwater Research, 38(4), $461-474,1987$.

Grinsted, A., J. C. Moore, and S. Jevrejeva, Application of the cross wavelet transform and wavelet coherence to geophysical time series, Nonlinear Processes in Geophysics, 11, 561-566, 2004.

Lee, T. N., W. J. Ho, V. Kourafalou, and J. D. Wang, Circulation on the Continental Shelf of the Southeastern United States. Part i: Subtidal Response to Wind and Gulf Stream Forcing During Winter, J. Phys. Oceanogr., 14, 1001-1012, 1984.

Leipe, T., B. Knoppers, E. Marone, and R. Camargo, Suspended matter transport in coral reef waters of the abrolhos bank brazil, Geo-Marine Letters, 19, 186-195, 1999.

Lentini, C. A. D., E. J. D. Campos, and G. G. Podesta, The annual cycle of satellite derived sea surface temperature on the western South Atlantic shelf, Rev. bras. oceanogr., 48(2), 93-105, 2000.

Lentz, S., R. T. Guza, S. Elgar, F. Feddersen, and T. H. C. Herbers, Momentum balances on the North Carolina inner shelf, J. Geophys. Res., 104(C8), 18,20518,240, 1999.

Lentz, S., M. Carr, and T. H. C. Herbers, Barotropic Tides on the Carolina Shelf, J. Phys. Oceanogr., 31(7), 1843-1859, 2001.

Lentz, S. J., Current Dynamics Over the Northern California Inner Shelf, J. Phys. Oceanogr., 24 (12), 2461-2478, 1994. 
Lessa, G. C., and M. Cirano, On the circulation of a coastal channel within the Abrolhos Coral-Reef system - Southern Bahia, Brazil, in J. Coast. Res., vol. 39, 2006.

Leão, Z. M. A. N., and R. N. Ginsburg, Living reefs surrounded by siliciclastic sediments: the Abrolhos coastal reefs, Bahia, Brazil, in Proceedings of the 8th International Coral Reef Symposium, edited by H. Lessios and I. Macintyre, pp. 1767-1777, Panama, 1997.

Maddlen, R. A., and P. R. Julian, Observations of the 40-50 day tropical oscillation: a review, Mon. Wea. Rev., 122, 814-837, 1994.

Miranda, L. B., B. M. Castro, and B. Kjerfve, Princípios de Oceanografia Física de Estuários, Edusp, 414 pp, 2002.

Moore, J. C., A. Grinsted, and S. Jevrejeva, New Tools for Analyzing Time Series Relationships and Trends, EOS Transactions, 86, 226-232, doi: 10.1029/2005EO240003, 2005.

Pawlowicz, R., B. Beardsley, and S. Lentz, Classical tidal harmonic analysis including error estimates in Matlab using $\mathrm{T}_{-}$Tide, Computers and Geosciences, 28, 929-937, 2002.

Pereira, A. F., A. L. Belem, B. M. Castro, and R. Geremias, Tide-topography interaction along the eastern Brazilian shelf, Cont. Shelf Res., 25(12-13), 1521 $1539,2005$.

Summerhayes, C., U. D. Melo, and H. Barretto, The influence of upwelling on suspended matter and shelf sediments off southeastern Brazil, J. Sedimentary Petrology, 46(4), 819-828, 1976.

Torrence, C., and G. P. Compo, A practical guide to wavelet analysis, Bulletin of the American Meteorological Society, 79(1), 61-78, 1998. 
Torrence, C., and P. J. Webster, Interdecadal changes in the enso-monsoon system, jcl, 12, 2679-2690, 1999.

Vitorino, M. I., Análise das oscilações intrasazonais sobre a américa do sul e oceanos adjacentes utilizando a análise de ondeletas, Tese de doutorado, Instituto Nacional de Pesquisas Espacias - INPE, São José dos Campos, SP, 2002. 